\title{
O papel dos profissionais de saúde na qualidade da informação de óbitos perinatais e nascidos vivos no Município de São Paulo
}

\author{
Daniela Schoeps
}

Tese apresentada para ao programa de Pós-

Graduação em Saúde Pública da Universidade de São Paulo para obtenção do título de Doutor em Saúde Pública.

Área de concentração: Epidemiologia

Orientadora: Profa. Dra. Marcia Furquim de Almeida

São Paulo

2012 
É expressamente proibida a comercialização deste documento, tanto na sua forma impressa como eletrônica. Sua reprodução total ou parcial é permitida exclusivamente para fins acadêmicos e científicos, desde que na reprodução figure a identificação do autor, título, instituição e ano da tese/dissertação. 


\section{DEDICATÓRIA}

Aos meus pais, Hans e Marta, e irmãos, Rafael e Marina.

Aos meus avós Jaques e Bertinha.

Não existem palavras que possam expressar uma vida de dedicação, apoio, compreensão e amor. 


\section{AGRADECIMENTOS}

À professora Marcia Furquim de Almeida. Pela orientação e envolvimento com o projeto. Pela amizade, contribuição e orientação também na minha formação.

Ao Fernando Lefevre pela orientação na formulação das questões e emprego da técnica do Discurso do Sujeito Coletivo.

À Zilda Pereira da Silva pelo incentivo, apoio na elaboração de artigos, discussões que trouxeram muita reflexão e resultados importantes.

Ao Gizelton Pereira Alencar que ao longo de tantos anos contribuiu para minha formação e nesse trabalho mais uma vez acrescentou muito com sugestões e análise dos dados. Pela amizade.

À Marina Schoeps por todo apoio desde a etapa das entrevistas até a finalização da escrita da tese.

À Priscila Ribeiro Raspantini que participou e dividiu momentos importantes do trabalho de campo e finalização dos textos.

À Hillegonda Maria Dutilh Novaes, Airlane Pereira Alencar, Luis Patrício Ortiz, Elaine Garcia Minuci e Denise Schout integrantes do grupo de pesquisa do projeto "Avaliação da Qualidade da Informação sobre Mortalidade Perinatal no Município de São Paulo" que proporcionaram momentos de reflexão, conhecimento e apoio na concepção desse projeto.

À Ana Maria Cavalcante Lefevre que há alguns anos me apresentou a técnica de analise do Discurso do Sujeito Coletivo.

Ao Eduardo Luiz Andrade Mota, Fabiola Zione, Fernando Lefevre e Otaliba Libanio de Morais Neto pelas preciosas contribuições na fase da pré-banca.

Ao Marcelo Marchetti Coelho, que me incentivou para o início dessa etapa. Pela descontração em momentos de estresse e pelos momentos que me ensinaram a ter foco.

Algumas pessoas que deram apoio, suporte e ajudaram na reta final desse processo. À Celia Pecci, pela compreensão dos momentos de ausência no trabalho. Alba Cerdeira pela ajuda na finalização da estrutura do texto. Às amigas Ana Luiza Borges, Elaine Oliveira Teixeira e Heloisa Trenche Belusci.

À Fapesp pelo apoio e financiamento do projeto "Avaliação da Qualidade da Informação sobre Mortalidade Perinatal no Município de São Paulo" (convênio Fapesp-CNPq-SUS pelo apoio no projeto PPSUS - Processo no 2006/61304-3), ao qual esta tese esta vinculada. 


\title{
RESUMO
}

A tese será apresentada no formato de três artigos científicos

\section{Artigo 1 - COMPLETITUDE, RESPONSÁVEIS E FONTES DE DADOS UTILIZADAS PARA OBTENÇÃO DE INFORMAÇÕES PERINATAIS DO SIM E SINASC, NO MUNICÍPIO DE SÃO PAULO.}

\author{
Schoeps $\mathrm{D}^{1}$, Almeida $\mathrm{MF}^{1}$, Silva $\mathrm{ZP}^{1}$ \\ ${ }^{1}$ Departamento de Epidemiologia da Faculdade de Saúde Pública da Universidade de São Paulo.
}

\section{Resumo}

Introdução: Estudos têm mostrado completitudes insatisfatórias para variáveis do SIM e SINASC, importantes para a obtenção de indicadores específicos de saúde perinatal. Bases de dados secundários ou administrativos como estes possuem uma multiplicidade de fontes de obtenção da informação e sua documentação se mostra essencial para padronização e normatização da coleta. Este estudo tem o objetivo de identificar a completitude, os responsáveis e as principais fontes utilizadas no preenchimento das declarações de nascido vivo e de óbito fetal e neonatal.

Métodos: Foram calculados indicadores de completitude e realizadas entrevistas sobre o preenchimento da Declaração de Nascido Vivo (DN) e Declaração de Óbito (DO) em 14 hospitais, com e sem vínculo com o SUS, no Município de São Paulo.

Resultados: A completitude das informações das DNs foi excelente para a maioria das variáveis. Já para as DOs neonatal e fetal a completitude é insatisfatória. Verificou-se que as informações da DN são preenchidas por enfermeiras ou por pessoal administrativo. As DOs são preenchidas por pessoal administrativo e por médicos, sendo que nos hospitais SUS há o preenchimento também pelo $\mathrm{SVO} /$ necrotério e nos não-SUS por enfermeiras. Ressalte-se que o campo da causa de morte foi preenchido pelos médicos em todos os hospitais. Foram identificadas diversas fontes para o preenchimento da DN: os documentos hospitalares, observação e informação verbal. Para as DOs, além dessas fontes também foram identificadas a própria DN. Não foram encontradas diferenças entre hospitais SUS e não-SUS.

Conclusões: Os resultados obtidos sobre as fontes de dados mais frequentemente empregadas e dos responsáveis pelo preenchimento das declarações poderão contribuir para o desenvolvimento de estratégias de treinamento junto aos hospitais para o aprimoramento das informações perinatais disponíveis no SIM e SINASC.

Palavra-chave: Sistema de Informações em Saúde; Declaração de Nascido Vivo; Declaração de Óbito; Registros Hospitalares; Fonte de dados 


\title{
COMPLETENESS, RESPONSIBLE AND SOURCES OF DATA USED TO OBTAIN PERINATAL INFORMATION FOR SINASC AND SIM, IN CITY OF SAO PAULO
}

Schoeps $\mathrm{D}^{1}$, Almeida $\mathrm{MF}^{1}$, Silva $\mathrm{ZP}^{1}$

1 Department of Epidemiology, School of Public Health, University of Sao Paulo.

\begin{abstract}
Summary
Introduction: Studies have shown unsatisfactory completeness to birth and death certificates variables, important for the attainment of specific indicators of perinatal health. Secondary or administrative databases as these have multiple sources for obtaining information and documentation is essential for standardization of the collection. This study aims to identify the completeness, the leaders and the main sources used for the completion of the birth and fetal and neonatal death certificates.

Methods: It was calculated indicators of completeness and interviewed on the filling of DN (birth) and DO (death declaration) in 14 hospitals with and without public health system (SUS) paying, in the City of São Paulo.

Results: The completeness of the information of DN was excellent for most variables. The neonatal and fetal DO completeness is unsatisfactory. It was found that the information in the DN is filled by nurses or administrative staff. The death certificates are filled by administrative staff and physicians, and hospitals in the public system were also filling the SVO/morgue and non-SUS by nurses. It should be noted that the field of cause of death was filled out by doctors in all hospitals. We identified several sources to fill the DN: hospital documents, observation and verbal information. For DO it also includes the DN information. No differences were found between SUS and non-SUS hospitals.

Conclusions: The identification of the most often employed data sources and the responsible for completing the declaration may contribute to the development of training strategies from hospitals in order to improve perinatal information available on birth and death certificates.
\end{abstract}

Keywords: Health Information System; Statement of Live Birth, death certificates, hospital records, data source 


\title{
Artigo 2 - REPRESENTAÇÕES SOCIAIS DE MÉDICOS OBSTETRAS E NEONATOLOGISTAS QUE ATUAM EM HOSPITAIS SUS E NÃO-SUS NO MUNICÍPIO DE SÃO PAULO SOBRE DECLARAÇÃO DE ÓBITO FETAL E NENAOTAL PRECOCE.
}

\author{
Schoeps $\mathrm{D}^{1}$, Almeida $\mathrm{MF}^{1}$, Lefevre $\mathrm{F}^{2}$ \\ ${ }^{1}$ Departamento de Epidemiologia da Faculdade de Saúde Pública da Universidade de São Paulo. \\ ${ }^{2}$ Departamento de Prática de Saúde Pública da Faculdade de Saúde Pública da Universidade de São \\ Paulo.
}

\begin{abstract}
Resumo
Introdução: É crescente o uso das informações da Declaração de Óbito (DO) para estudos epidemiológicos;contudo, a completitude insatisfatória de algumas variáveis ainda é impedimento para determinadas análises. O preenchimento das DOs é de responsabilidade dos médicos que estão inseridos em instituições que apresentam diferenças na estrutura, organização e nos tipos de serviços de saúde o que acaba por influenciar na rotina do trabalho médico e consequentemente no registro de dados.

Objetivo: Avaliar a representação social dos médicos em relação à coleta das informações e preenchimento da DO.

Métodos: Foram realizadas 25 entrevistas com médicos obstetras e neonatologistas em 15 hospitais, com e sem vínculo com o SUS, no Município de São Paulo, em 2009. As análises foram realizadas utilizando a metodologia qualitativa com a técnica do Discurso do Sujeito Coletivo.

Resultados: As diferentes funções e cargos ocupados pelos médicos entrevistados implicam em diferenças de representação social que estes possuem a respeito das DOs. Em relação ao preenchimento, nem sempre o médico que atende o paciente é aquele que preenche o documento e a maioria recebe auxílio de outros profissionais para preenchimento dos campos relativos à identificação da mãe. Foram relatadas dificuldades em definir a causa e evolução do óbito e quando há necessidade de consultar outras fontes de informação. A maior parte dos entrevistados teve treinamento para preenchimento da DO apenas durante o curso médico.

Conclusões: Para que os dados preenchidos nas DOs tenham melhor qualidade é necessário que os registros e informações hospitalares, como cadastro do paciente e prontuário, sejam identificados de forma mais clara. Atribuir aos profissionais que preenchem esses documentos treinamento podem ser também estratégias dos hospitais para melhorar a qualidade destes dados.
\end{abstract}

Palavra-chave: Sistema de Informações em Saúde; Declaração de Óbito; Representação Social; Registro Médico 


\section{SOCIAL REPRESENTATION OF OBSTETRICIANS AND NEONATOLOGISTS WORKING IN SUS AND NON-SUS HOSPITALS IN THE CITY OF SAO PAULO ON FETAL AND EARLY NEONATAL DEATH DECLARATIONS. \\ Schoeps $\mathrm{D}^{1}$, Almeida $\mathrm{MF}^{1}$, Lefevre $\mathrm{F}^{2}$ \\ 1 Department of Epidemiology, School of Public Health, University of Sao Paulo. \\ 2 Department of Public Health Practice, School of Public Health, University of Sao Paulo.}

\section{Summary}

Introduction: It is increasing the use of information on death declaration (DO) for epidemiological studies; however, the unsatisfactory completeness of some variables still interferes in the results of its analysis. The completion of the DOs is the responsibility of doctors who are embedded in institutions that differ in structure, organization and types of health services, which influence the routine medical work and consequently the data record.

Objective: To assess the social representation of doctors in relation to data collection and completion of the DO.

Methods: We conducted 25 interviews with obstetricians and neonatologists in 15 hospitals (SUS and non-SUS), in São Paulo in 2009. Analyses were performed using qualitative methodology with the technique of Collective Subject Discourse.

Results: The different roles and positions held by the physicians interviewed may result in differences of social representation that they have about the DOs. Regarding the fulfillment, the doctor who assists the patient is not always the one who fills the document and most receive assistance from other professionals to fill the variables related to the identification of the mother. It has been reported difficulties in defining the cause and evolution of death and to consult other sources of information when needed. Most respondents had training to fill the DO only in medical school.

Conclusions: To improve the quality of the data filled in DO it is necessary that the records and hospital information, such as patient records and medical records, are more clearly identified. Assign the professionals who fill these documents and training them can provide hospitals strategies to improve data quality.

Keywords: Health Information System, Death Certificate, Social Representation, Medical Record 


\title{
Artigo 3 - SIM E SINASC: REPRESENTAÇÃO SOCIAL DE ENFERMEIROS E PROFISSIONAIS DE SETORES ADMINISTRATIVOS QUE ATUAM EM HOSPITAIS SUS E NÃO-SUS NO MUNICÍPIO DE SÃO PAULO.
}

\author{
Schoeps $\mathrm{D}^{1}$, Almeida $\mathrm{MF}^{1}$, Lefevre $\mathrm{F}^{2}$ \\ ${ }^{1}$ Departamento de Epidemiologia da Faculdade de Saúde Pública da Universidade de São Paulo. \\ ${ }^{2}$ Departamento de Prática de Saúde Pública da Faculdade de Saúde Pública da Universidade de São \\ Paulo.
}

\section{Resumo}

Introdução: A mortalidade perinatal é um importante indicador de saúde maternoinfantil, por esse motivo vem ocorrendo uma evolução nos estudos dessas informações. Muitos estudos avaliam a qualidade dos dados do Sistema de Informações de Nascidos Vivos (SINASC) e Sistemas de Informações de Mortalidade (SIM) com métodos quantitativos (validade/completitude), porém são escassas as investigações qualitativas.

Objetivo: Avaliar a representação social dos enfermeiros e profissionais de setores administrativos sobre o preenchimento das Declarações de Nascido Vivo (DNs) e se ou como auxiliam no preenchimento das Declarações de Óbito (DOs) fetais e neonatais.

Métodos: Foram realizadas 24 entrevistas com enfermeiros e profissionais de setores administrativos em 16 hospitais, com e sem vínculo com o SUS, no município de São Paulo, em 2009. As análises foram realizadas utilizando a metodologia qualitativa com a técnica do Discurso do Sujeito Coletivo.

Resultados: Os profissionais e enfermeiros se reconhecem como parte integrante do processo de produção da informação. Os discursos indicam que a atividade está incorporada na rotina do trabalho; há comprometimento na busca de soluções quando se deparam com dificuldades de preenchimento; há valorização de se sentirem acompanhados por uma instância superior do sistema; sentem que o treinamento é um espaço de encontro para retorno e compreensão das finalidades e usos das informações que produzem. Esta consciência aumenta o comprometimento e assegura informações mais fidedignas.

Conclusões: Tanto nos hospitais SUS como não-SUS não se verificou um padrão relativo ao profissional responsável pelo preenchimento das DNs, apesar da definição legal de que o médico é o responsável pelas informações da DO muitas vezes outros profissionais preenchem parte das informações. As entrevistas revelaram que os profissionais conhecem e reconhecem a utilidade das informações registradas nas DNs com base nos treinamentos fornecidos pela equipe do Sistema de Informação de Nascidos Vivos (SINASC). Os profissionais e enfermeiros se reconhecem como parte integrante do processo de produção da informação e sentem que o treinamento é um espaço de encontro para retorno e compreensão das finalidades e usos das informações que produzem. Essa consciência aumenta o comprometimento e assegura informações mais fidedignas.

Palavra-chave: Sistema de Informações em Saúde; Declaração de Nascido Vivo; Declaração de Óbito; Representação Social; Registros Hospitalares 


\title{
SIM AND SINASC: SOCIAL REPRESENTATION OF NURSES AND ADMINISTRATIVE PROFESSIONAL SECTORS THAT WORK IN HOSPITALS SUS AND NON-SUS IN THE CITY OF SAO PAULO.
}

Schoeps $\mathrm{D}^{1}$, Almeida $\mathrm{MF}^{1}$, Lefevre $\mathrm{F}^{2}$

${ }^{1}$ Departamento de Epidemiologia da Faculdade de Saúde Pública da Universidade de São Paulo.
2 Department of Public Health Practice, School of Public Health, University of Sao Paulo.

\begin{abstract}
Summary
Introduction: Considering that perinatal mortality is an important indicator of maternal and child health., there has been an evolution in the studies of such information. Many studies assess its quality with quantitative methods (validity / completeness), but there are few qualitative investigations. Objective: To assess the social representation of nurses and administrative sectors on how to complete the Declarations of Live Birth (DN) and whether or how to assist in completing fetal and neonatal death certificates (DO). Methods: We conducted 24 interviews with nurses and administrative staff in 16 hospitals (SUS and non- SUS), in the City of São Paulo in 2009. Analyses were performed using a qualitative methodology with the technique of Collective Subject Discourse.

Results: The speeches indicate that the activity is incorporated into the routine of work; there is involvement in finding solutions when they find difficulties in filling; there is a feeling that they should have a higher member of staff supervision. Conclusions: Both SUS and non-SUS hospitals have no specific professional responsible for the completion of $\mathrm{DN}$, despite the legal definition of what the doctor is responsible for the information of $\mathrm{DO}$, it is often common to find other professionals filling part of the information. The interviews showed that the professionals know and recognize the usefulness of the information recorded in DN based on training provided by staff of the Information System (SINASC). Professionals and nurses see themselves as part of the process of information production and feel that training is a meeting place for feedback and understanding of the purposes and uses of the information they produce. This awareness increases the commitment and ensures more reliable information.
\end{abstract}

Keywords: Health Information System; Statement of Live Birth, Social Representation, Hospital Records, Nurse 


\section{Índice}

1 INTRODUÇÃO

1.1 INFORMAÇÕES NECESSÁRIAS PARA O MONITORAMENTO DA

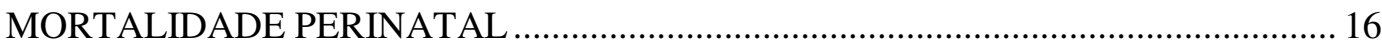

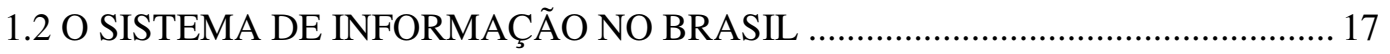

1.3 O SISTEMA DE INFORMAÇÕES SOBRE MORTALIDADE - SIM....................... 18

1.4 O SISTEMA DE INFORMAÇÃO DE NASCIDOS VIVOS - SINASC ..................... 21

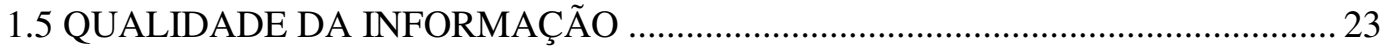

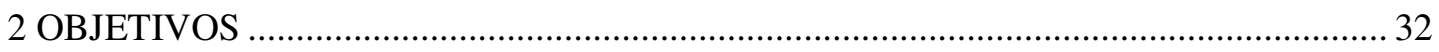

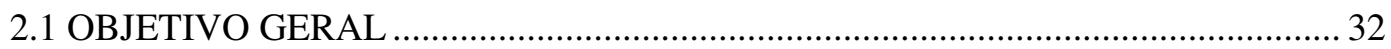

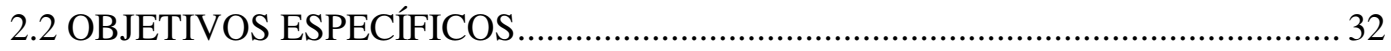

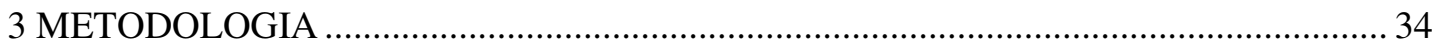

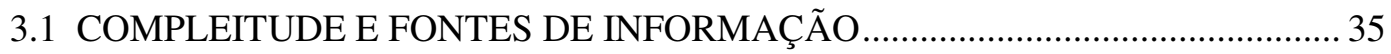

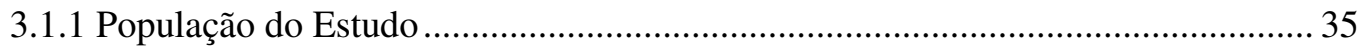

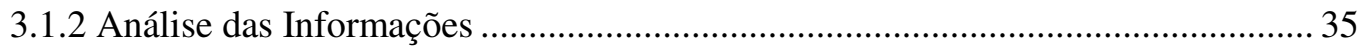

3.2 REPRESENTAÇÕES SOCIAIS DOS PROFISSIONAIS DE SAÚDE A RESPEITO DO PREENCHIMENTO DAS DECLARAÇÕES DE NASCIDOS VIVOS EDECALRAÇÕES DE ÓBITOS PERINATAIS …......................................................... 36

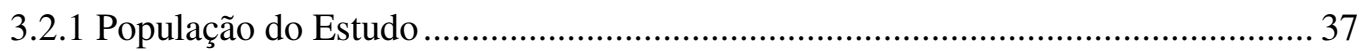

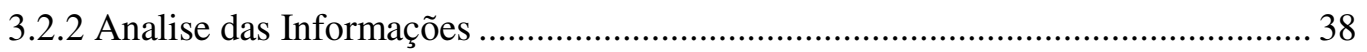

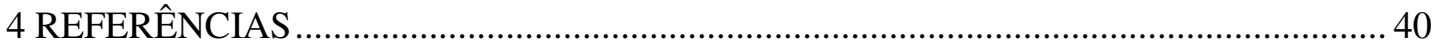

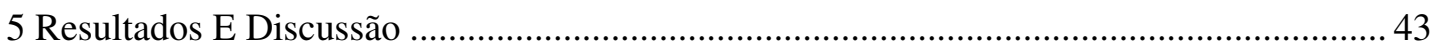

Artigo 1 - COMPLETITUDE, RESPONSÁVEIS E FONTES DE DADOS UTILIZADAS PARA OBTENÇÃO DE INFORMAÇÕES PERINATAIS DO SIM E SINASC, NO MUNICÍPIO

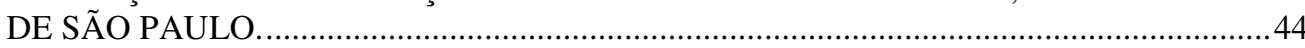

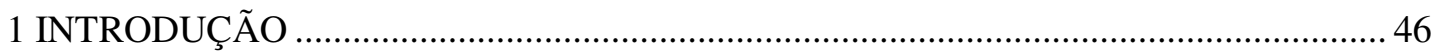

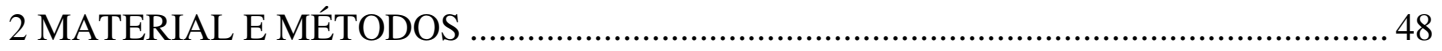

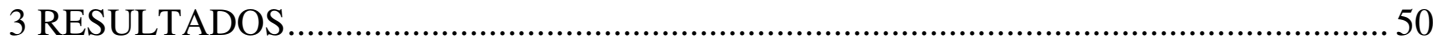

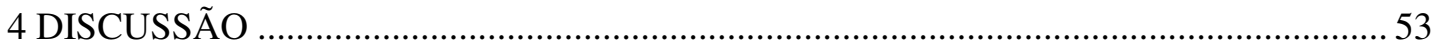

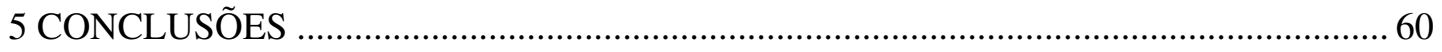

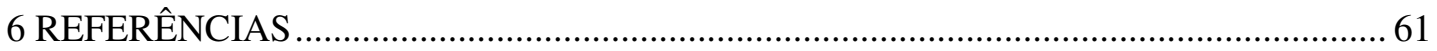

Artigo 2 - REPRESENTAÇÕES SOCIAIS DE MÉDICOS OBSTETRAS E NEONATOLOGISTAS QUE ATUAM EM HOSPITAIS SUS E NÃO-SUS NO MUNICÍPIO DE SÃO PAULO SOBRE DECLARAÇÃO DE ÓBITO FETAL E NEONATAL PRECOCE..............................68

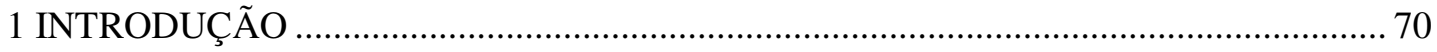

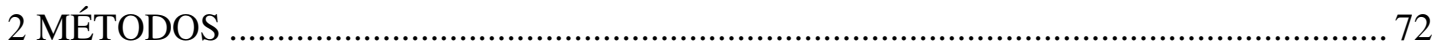


2.2 CARACTERÍSTICAS DA POPULAÇÃO DE ESTUDO E AS ENTREVISTAS .... 73

2.3 ANÁLISE DOS DADOS: DISCURSO DO SUJEITO COLETIVO............................ 74

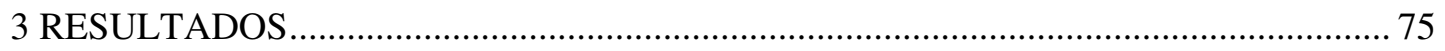

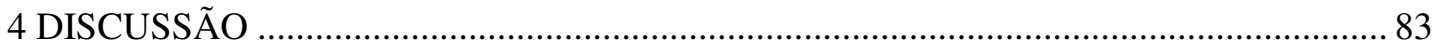

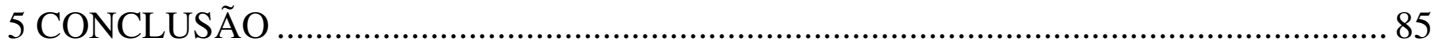

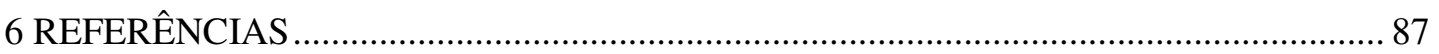

Artigo 3 - SIM E SINASC: REPRESENTAÇÃO SOCIAL DE ENFERMEIROS E PROFISSIONAIS DE SETORES ADMINISTRATIVOS QUE ATUAM EM HOSPITAIS SUS E NÃO-SUS NO MUNICÍPIO DE SÃO PAULO.................................................................................99

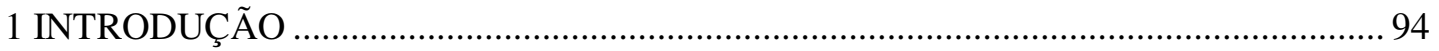

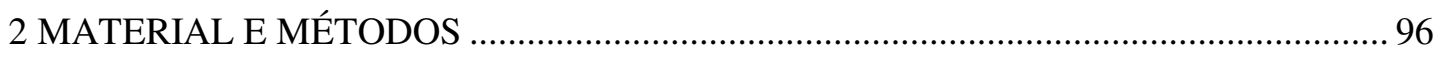

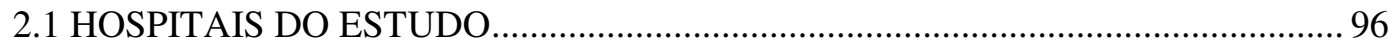

2.2 CARACTERÍSTICAS DA POPULAÇÃO DE ESTUDO E AS ENTREVISTAS .... 97

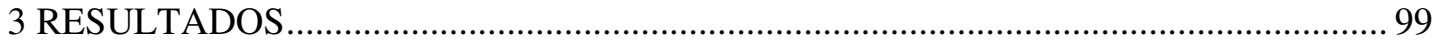

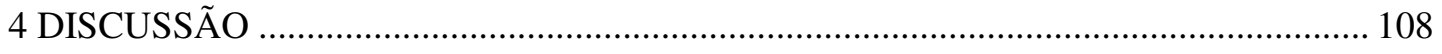

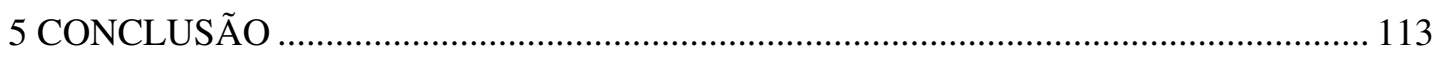

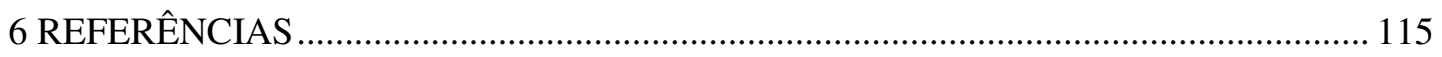

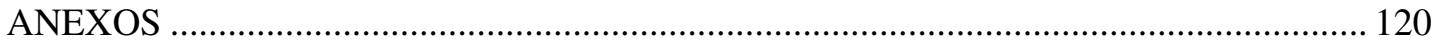

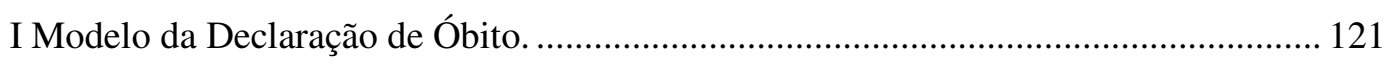

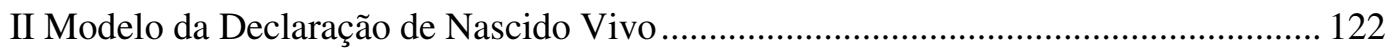

III Quadros de identificação para as fontes de preenchimento das DOs e DNs............... 123

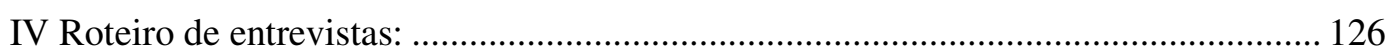

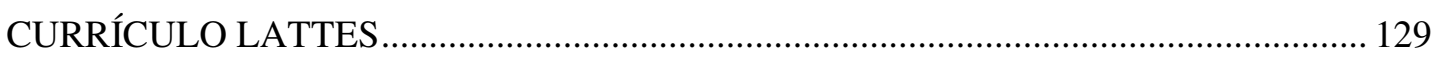




\section{LISTA DE TABELAS}

TABELAS - ARTIGO 1

Tabela 1 - Completitude (\%) das variáveis das Declarações de Nascido Vivo (DN), de Óbito Neonatal e de Óbito Fetal (DO) por tipo de hospital do parto, Município de São Paulo, $1^{\circ}$ semestre 2008.

Tabela 2 - Número de hospitais segundo responsáveis e fontes de dados para o preenchimento das Declarações de Nascidos Vivos, segundo variáveis, amostra de 14 hospitais do Município de São Paulo, 2009.

Tabela 3 - Número de hospitais segundo responsável, fonte de dados e variáveis para o preenchimento da DO-neonatal, amostra de 14 hospitais do Município de São Paulo, 2009.

Tabela 4 - Número de hospitais segundo responsáveis, fonte de dados e variáveis para o preenchimento da DO fetal amostra de 9 hospitais do Município de São Paulo, 2009. ... 67

TABELAS - ARTIGO 2

Tabela 1 - Atividades da rotina de trabalho segundo médicos entrevistados em hospitais SUS e não-SUS, Município de São Paulo, 2009

Tabela 2 - Descrição dos médicos a respeito do preenchimento de DOs na rotina de trabalho em hospitais SUS e não-SUS, Município de São Paulo, 2009.

Tabela 3- Dificuldades apontadas por médicono preenchimento de DOs em hospitais SUS e não-SUS, Município de São Paulo, 2009.

Tabela 4 - Aspectos sobre treinamento para preenchimento de DOs, apontados pelos médicos entrevistados em hospitais SUS e não-SUS, Município de São Paulo, 2009 .90

Tabela 5 - Posicionamento frente às dúvidas de preenchimento das DOsapontados pelos médicos entrevistados em hospitais SUS e não-SUS, Município de São Paulo, 2009 ..... 90

Tabela 6 - Uso das informações do SIM apontados pelos médicos entrevistados em hospitais SUS e não-SUS, Município de São Paulo, 2009

TABELAS - ARTIGO 3

Tabela 1 - Existência de colaboração aos médicos para o preenchimento das DOs, relatada por enfermeiros e profissionais administrativos, Município de São Paulo, 2009

Tabela 2 - Dificuldades apontadas por enfermeiros e profissionais administrativos no preenchimento de DNs e DOs, Município de São Paulo, 2009

Tabela 3 - Aspectos sobre treinamento para preenchimento de DNs e DOs, relatados por enfermeiros e profissionais administrativos, Município de São Paulo, 2009

Tabela 4-Uso das informações do SIM e SINASC apontados por enfermeiros e profissionais administrativos, Município de São Paulo, 2009 


\section{LISTA DE QUADROS}

Artigo 3:

Quadro 1 - Perfil dos profissionais entrevistados de acordo com tipologia do hospital, formação, cargo e setor de trabalho no hospital, Município de São Paulo, 2009. 


\title{
SIGLAS UTILIZADAS
}

\author{
AIH - Autorização de Internações Hospitalares \\ CENEPI - Centro Nacional de Epidemiologia \\ CFM - Conselho Federal de Medicina \\ CNES - Cadastro Nacional de Estabelecimentos de Saúde \\ $\mathrm{CO}$ - Centro Obstétrico \\ CRM - Conselho Regional de Medicina \\ DATASUS - Departamento de Informática do SUS \\ DN - Declaração de Nascido Vivo \\ DO - Declaração de Óbito \\ DSC - Discurso do Sujeito Coletivo \\ MFC - Malformação congênita \\ MSP - Município de São Paulo
}

PROAIM/SMS/SP - Programa de Aprimoramento das Informações de Mortalidade no Município de São Paulo

SAME - Serviço de Arquivo Médico e Estatística

SEADE - Fundação Estadual de Análise de Dados

SINASC - Sistema de Informações de Nascido Vivo

SIM - Sistema de Informações sobre Mortalidade

SIS -Sistema de Informação em Saúde

SMS/SP - Secretaria Municipal de Saúde - São Paulo

SUS - Sistema Único de Saúde

SVO - Serviço de Verificação de Óbitos 
SVS/MS - Secretaria de Vigilância em Saúde - Ministério da Saúde UTI - Unidade de Terapia Intensiva 


\section{INTRODUÇÃO}

\subsection{INFORMAÇÕES NECESSÁRIAS PARA O MONITORAMENTO DA MORTALIDADE PERINATAL}

A mortalidade perinatal é um importante indicador de saúde maternoinfantil. O interesse crescente por este indicador e a preocupação com a qualidade da informação é decorrente da concentração progressiva dos óbitos infantis nos primeiros dias de vida em países desenvolvidos e em alguns países em desenvolvimento, dentre os quais o Brasil (ZEITLIN et al., 2003; ALMEIDA et al., 2006b).

Nos últimos anos houve uma mobilização dos países da Comunidade Europeia com objetivo de selecionar e padronizar indicadores para o monitoramento dos cuidados perinatais - PERISTAT Project (GRAAFMANS et al., 2001; BUITENDIJK et al., 2003 e ZEITLIN et al., 2003). Ao mesmo tempo foram definidos indicadores específicos para o monitoramento da mortalidade perinatal (BUITENDIJK et al., 2003). Como resultado foi formulado o Projeto Estatísticas Perinatais com objetivo de estabelecer um conjunto mínimo de indicadores com base nos sistemas de informação existentes nos países da comunidade europeia que possam permitir a avaliação da atenção perinatal.

O conjunto de indicadores específicos selecionados para acompanhamento da mortalidade perinatal foram desagregados em indicadores da mortalidade fetal, neonatal e infantil. Com relação aos indicadores de mortalidade fetal e neonatal precoce foram propostos indicadores de mortalidade específicos segundo idade da mãe, paridade, peso ao nascer e idade gestacional (BUITENDIJK et al., 2003). Esses indicadores seriam facilmente obtidos em nosso país desde que as informações 
registradas no SIM (Sistema de Informação sobre Mortalidade) e SINASC (Sistema de Informação de Nascidos Vivos) apresentassem boa completitude.

No Brasil a informação sobre idade gestacional e peso ao nascer são indispensáveis para a notificação de eventos, pois segundo o Manual da Declaração de Óbito devem ser emitidas declarações de óbito para os nascimentos sem manifestação vital para fetos de $500 \mathrm{~g}$ ou mais ou com idade gestacional acima de 22 semanas ${ }^{1}$.

Outras variáveis também são importantes para traçar o perfil dos óbitos perinatais, porém sua utilização depende da qualidade dos dados dos sistemas de informação. Em países com dados de boa qualidade, estudos permitiram definir as características maternas e da gestação associadas à mortalidade fetal, bem como a sua evolução temporal, tendo sido observada mortalidade mais elevada nas gestações múltiplas, em mulheres de idade avançada (35 anos e mais), grandes multíparas, gestações de pré-termo e de pós-termo (AHLENIUS e THOMASSEN, 1999; CNATTINGIUS e STEPHANSSON, 2002).

\subsection{O SISTEMA DE INFORMAÇÃO NO BRASIL}

A descentralização dos sistemas de informação de base epidemiológica foi formalizada com a Programação Pactuada Integrada de Epidemiologia e Controle de Doenças (PPI-ECD), que formaliza as atribuições e mecanismos de financiamento dos três níveis de gestão nos sistemas de informação ${ }^{2}$.

\footnotetext{
${ }^{1}$ Ministério da Saúde - FUNASA. Manual de Procedimentos do Sistema de Informações sobre Nascidos Vivos. 2001.

2 Ministério da Saúde, ABRASCO. Uso e disseminação de informações em saúde: subsídios para elaboração de uma política de informações em saúde para o SUS. Brasília. 1994.
} 
Em 1993, o Centro Nacional de Epidemiologia (CENEPI), por intermédio da Coordenação Geral de Análise de Informações em Saúde (CGAIS), foi a instituição responsável pela implantação do SINASC. Em 2003 o CENEPI é reestruturado e pelo decreto n. 4.726, de 9 de junho de 2003, em seu artigo 29, foi criada a Secretaria de Vigilância em Saúde, que passou a ser responsável pela coordenação dos sistemas de informação epidemiológicos, execução das atividades relativas à disseminação do uso da metodologia epidemiológica em todos os níveis do Sistema Único de Saúde (SUS), por prestar assessoria técnica e estabelecer cooperação com Estados, Municípios e o Distrito Federal visando potencializar a capacidade gerencial e fomentar novas práticas de vigilância e controle de doenças (MELLO-JORGE et al., 1992).

\subsection{O SISTEMA DE INFORMAÇÕES SOBRE MORTALIDADE - SIM}

O Sistema de Informação sobre Mortalidade (SIM) foi criado em 1975 como fonte complementar do sistema de informações para a vigilância epidemiológica. A criação do SIM representou um avanço na concepção dos sistemas de informação ao implantar um instrumento individual, padronizado e, em parte, pré-codificado para a coleta de dados - a Declaração de Óbito (DO) - segundo normas propostas pela Organização Mundial de Saúde, esta nova concepção de sistema de informação trouxe resultados positivos para a produção de informações. A coleta de dados foi padronizada e evitou-se a presença de erros devido à transcrição de dados dos mapas mensais de coleta então existente nos dados do registro civil de responsabilidade do IBGE e tornou viável iniciar o processamento eletrônico de dados (BALDIJÃO, 1992; MELLO-JORGE et al., 2009).

$\mathrm{Na}$ implantação do SIM foi criado um fluxo padronizado para os dados e estabelecido que a gestão do sistema fosse centralizada no Ministério da Saúde, o que incluía impressão, distribuição da DO e o processamento de dados, devido às 
dificuldades operacionais na codificação das causas de morte e falta de equipamentos eletrônicos nos municípios.

No final década de 1980, com o processo de redemocratização do país, a implantação do SUS e a descentralização das ações de saúde colocaram um novo ator na cena da política de saúde: a esfera local/municipal de gestão. Nesse período houve o crescimento da informatização dos serviços de saúde e iniciou-se a introdução da microinformática, que potencializou tal processo. Esse novo cenário propiciou uma demanda crescente para a descentralização da produção, disseminação e análise das informações em saúde (ALMEIDA, 1998; MELLO-JORGE et al., 2009).

O Programa de Aprimoramento das Informações de Mortalidade no Município de São Paulo (PRO-AIM) nasceu em 1989 no contexto da implantação do SUS. Portanto, trouxe no bojo de sua constituição os mesmos princípios que nortearam a construção do SUS. Sua criação veio responder a uma demanda por informações ágeis para a tomada de decisões, que permitissem a realização de diagnósticos e planejamento de saúde de forma descentralizada na gestão da Secretaria Municipal de Saúde de São Paulo. O PRO-AIM introduziu também atividades de vigilância dos óbitos.

À exemplo do município de São Paulo outros municípios passaram a se responsabilizar pela coleta de dados do SIM que passou a ser visto não apenas como um sistema de coleta de dados de mortalidade, mas como um elemento do sistema de vigilância. Com o avanço da incorporação da tecnologia de informação nos serviços de saúde também cresceu a demanda para a descentralização do SIM.

Contudo, a cobertura de eventos do SIM ainda mostrava sérios problemas. Havia falta de alimentação de dados em diversas localidades. Com objetivo de aumentar a captação e aprimorar a regularidade da informação, foi editada em 1997, a Portaria $\mathrm{N}^{\mathrm{0}}$ 1.882/GM, que determinou no país o Piso da Atenção Básica, prevendo que "a transferência de recursos será suspensa se a Secretaria Municipal de Saúde deixar de alimentar, por dois meses consecutivos, os Sistemas de Informação em Saúde", entre os quais, o SIM. 
Com o avanço da tecnologia de informação incorporada ao sistema e com a criação do aplicativo Seletor de Causa Básica (SBC) que permitiu simplificar a codificação da causa de morte e sua padronização, foi possível transferir a gestão do SIM a níveis estaduais e municipais. Para isso foi editada a Portaria MS/SVS no 20, e 3 de outubro de 2003(MELLO-JORGE et al., 2009).

Desde sua criação, a DO tem passado por diversas modificações e hoje contém as seguintes informações numeração sequencial para o controle da emissão, distribuição, coleta e resgate; número da Declaração de Nascido Vivo (DO de menores de um ano, variáveis para identificar se as mulheres falecidas em idade fértil estavam grávidas no momento da morte, ou tinham estado grávidas até um ano antes do evento fatal, visando as possíveis causas maternas; característica raça/cor; descrição referente aos óbitos por causas externas e a fonte que permitiu tal descrição; Condições e Causas de Morte, segundo recomendações da $10^{\mathrm{a}}$ Revisão da CID10. (Anexo I)

A DO apresenta as variáveis organizadas em blocos (modelo última versão, 1999- anexo I). Bloco I: identificação do cartório de registro civil. Bloco II: variáveis que identificam o tipo de óbito (fetal ou não), data e hora de ocorrência, e variáveis descritivas das características da mãe. Bloco III: variáveis de endereço do RN. Bloco IV: informações sobre o local onde ocorreu o óbito. Bloco V: variáveis sobre óbito fetal ou menor que um ano (informações sobre a mãe, gestação, parto e o número da declaração de nascido vivo). Bloco VI: identificação das condições e causas que provocaram o óbito. Bloco VII: identificação básica sobre o médico que assina a DO. Bloco VIII: refere-se às causas externas de óbito. O Bloco IX é destinado a óbitos em localidades onde não exista médico. Neste caso deve ser preenchido pelo cartório de Registro Civil e deverá constar o declarante e testemunha. (Anexo I)

O SIM vem aumentando gradativamente sua cobertura populacional, porém ainda apresenta problemas de qualidade dos dados produzido sem relação à completitude e validade das informações. Quanto à acessibilidade não há grandes problemas, uma vez que os dados estão disponíveis em meio físico e eletrônico 
(MELLO JORGE et al., 2002). O Ministério da Saúde tem desenvolvido ações para melhora dos dados e qualidade do SIM, como por exemplo, o Plano Pluri-anual 2004-2008 o Programa "Redução do percentual de óbitos com causa mal definida"3 que teve como objetivo a redução do percentual desses óbitos para menos de $10 \%$ principalmente nas regiões norte e nordeste. Esse resultado foi alcançado, o que indica que o investimento e programas específicos podem ajudar a melhorar a qualidade das informações do SIM.

\subsection{O SISTEMA DE INFORMAÇÃO DE NASCIDOS VIVOS - SINASC}

Em 1980, após a realização de um projeto-piloto para testar a viabilidade de obtenção de dados sobre nascidos em maternidades no município de Mogi das Cruzes, região metropolitana de São Paulo, a Fundação Estadual de Análise de Dados (SEADE) concluiu que era possível introduzir um instrumento para coleta de dados nos hospitais para obter informações mais detalhadas sobre os nascidos vivos (FERREIRA E ORTIZ; 1995). A Secretaria de Estado da Saúde de São Paulo criou um grupo de trabalho com o objetivo de propor uma "Declaração de Nascimento", tendo em vista o sucesso da implantação da declaração de óbito, a existência de declarações de nascido vivo em outros países e a possibilidade de obter informações mais ágeis e detalhadas sobre o perfil dos nascidos vivos, em 1984. Um projetopiloto em cinco maternidades, com diferentes perfis de clientela do município de São Paulo, conclui pela viabilidade da implantação de um instrumento específico para a coleta de dados nos hospitais ${ }^{4}$.

O SINASC foi implantado em 1990. A Declaração de Nascido Vivo (DN) é um documento individual e padronizado que apresenta numeração prévia, definida

3 Brasil. Ministério da Saúde. Secretaria de Vigilância em Saúde. Departamento de Análise de Situação em Saúde. Manual para investigação do óbito com causa mal definida / Ministério da Saúde, 2009.48 p.

4 Secretaria de Estado da Saúde de São Paulo. Grupo de trabalho referente a implantação de declaração de nascimentos no estado de São Paulo. Relatório São Paulo. 1987. 
pelo gestor nacional do sistema como mecanismo de controle de sua distribuição. $\mathrm{O}$ documento é formado por blocos de variáveis e composto por três vias: a primeira via é retida pelo serviço de saúde onde foi realizado o parto e posteriormente será encaminhada à Secretária Municipal de Saúde (SMS); a segunda via é entregue para a família e deverá ser apresentada no Cartório de Registro Civil no momento do registro de nascimento; o cartório arquiva esta via. A terceira via é arquivada junto ao prontuário médico do recém-nascido no estabelecimento de saúde onde foi realizado o parto.

Com a experiência obtida na implementação e desenvolvimento do SIM, o Departamento de Informática do SUS (DATASUS) desenvolveu um aplicativo para operar em microcomputadores incorporando a tecnologia de processamento eletrônico dos dados. A tecnologia propiciou maior agilidade e acesso aos dados do sistema e os estados seriam responsáveis pela coleta de dados municipais (ALMEIDA et al., 2009).

O CENEPI elaborou um manual de procedimentos do SINASC formalizando as diferentes atribuições dos três níveis de gestão do sistema, normatizando o fluxo de documentos para nascimentos hospitalares e domiciliares, assim como a coleta de dados e os procedimentos para emissão de segunda via, no caso da família ter perdido o documento (MELLO-JORGE et al., 1992).

Como rotina para o controle de qualidade, o Manual de procedimentos do SINASC recomenda a revisão de todos os campos preenchidos previamente à entrada dos dados, no nível municipal de gestão. Há controle na entrada dos dados pelo sistema operacional, por exemplo, para idade da mãe e peso ao nascer. Estas variáveis constituem-se em alertas e as informações registradas devem ser checadas na fonte de obtenção de dados. Após a identificação de informações ausentes ou incorretas, o manual de procedimentos do sistema indica que as DNs deverão retornar à unidade notificadora para correção. Há também a indicação de revisão dos dados por meio de relatórios de crítica, com devolução do Relatório de Inconsistências aos órgãos de origem, para correção, tanto no nível municipal, 
quando este for responsável pela entrada de dados, como no nível estadual, no momento da tabulação preliminar de $\operatorname{dados}^{5}$ (ALMEIDA et al., 2009).

Tendo em vista o enorme volume de nascidos vivos do município de São Paulo, a secretaria municipal de saúde normatizou que a digitação dos dados da DN pode ser realizada nos estabelecimentos e repassada para as coordenadorias de saúde das subprefeituras de São Paulo (São Paulo. Secretaria Municipal de Saúde. Portaria $n^{\circ} 325$, de 15 de maio de 2004). Ao definir esta norma a produção de informações ganhou maior agilidade.

A DN apresenta as variáveis organizadas em blocos. Bloco I: identificação do cartório de registro civil. Bloco II: variáveis que identificam o local de ocorrência do nascimento. Bloco III: características da mãe e número de filhos anteriores vivos e mortos. Bloco IV: variáveis sobre a gestação, pré-natal e parto. Bloco V: variáveis sobre o recém-nascido. Bloco VI: identificação (polegar direito da mãe e pé direito da criança). Bloco VII: identificação do responsável pelo preenchimento. (Anexo II)

\subsection{QUALIDADE DA INFORMAÇÃO}

Os estudos sobre avaliação da qualidade dos dados registrados nos sistemas de informação podem ser realizados de diversas formas; dentre elas destacam-se: a) avaliação da completitude; b) comparação com outra base de dados estruturada ou outro sistema de informações; c) comparação com a fonte de dados que é utilizada na obtenção de dados do sistema de informação; d) realização de entrevistas para obtenção de informações diretamente dos indivíduos; e) análise da documentação dos sistemas.

\footnotetext{
${ }^{5}$ Ministério da Saúde - FUNASA. Manual de Procedimentos do Sistema de Informações sobre Nascidos Vivos. 2001.
} 
Vem ocorrendo uma evolução nos estudos sobre avaliação dos sistemas de informações perinatais. Inicialmente, esses estudos eram destinados apenas à avaliação da completitude dos dados, evoluindo para avaliação de sua acurácia, por meio da concordância dos registros com outras fontes de dados. Finalmente, nos Estados Unidos na década de 90, surgiram estudos epidemiológicos de validação dos dados existentes nos sistemas de informação de mortalidade e de nascidos vivos. Esses estudos têm se tornado cada vez mais importantes devido à crescente disponibilidade de informações advindas do uso de meios eletrônicos, de divulgação de dados e à maior incorporação do uso da informática, que possibilita a ampliação do uso dessas informações (KIRBY, 1997).

A primeira etapa de avaliação da qualidade dos dados de um sistema de informação é avaliar a completitude dos registros das variáveis que fazem parte do documento utilizado para a coleta de dados, pois somente será possível a obtenção de indicadores com base nas variáveis que apresentam boa completitude ou integridade de registro.

Entre os estudos nacionais, destaca-se o estudo de SILVA et al. (1997), onde se comparou o grau de preenchimento/completitude dos dados existentes no SIM e no SINASC para nascimentos que resultaram em óbitos neonatais no Rio de Janeiro. CARVALHO (1997) também comparou o preenchimento de variáveis comuns a diversos sistemas de informação. Esses estudos concluíram que, para algumas variáveis, o SINASC apresentava excelente completitude de dados como, por exemplo, peso ao nascer e idade da mãe. COSTA e FRIAS (2009) também encontraram resultados semelhantes em estudo realizado em Pernambuco.

ALMEIDA e ALENCAR (2000) indicaram existir escassez de mecanismos de controle de qualidade no SINASC, apesar de o Manual de procedimentos do SINASC indicar como rotina para o controle de qualidade a revisão de todos os campos preenchidos previamente à entrada dos dados, no nível municipal de gestão. Após a identificação de informações ausentes ou incorretas, o manual de procedimentos do sistema indica que as DNs deveriam ser retornadas à unidade notificadora para correção. Porém, esta atividade nem sempre é realizada. Há 
também a indicação de revisão dos dados por meio de relatórios de crítica, com devolução do Relatório de Inconsistências aos órgãos de origem para correção, tanto no nível municipal, quando este for responsável pela entrada de dados, como no nível estadual, no momento da tabulação preliminar de dados.

Estudos realizados nos Estados Unidos avançaram nessa abordagem, fornecendo medidas de concordância de registros entre as bases de dados, não se restringindo à completitude dos dados coletados (PIPER et al., 1993; MCDEMOTT et al., 1997; REICHMAN e HADE, 2001). Estes tipos de estudos permitem identificar se há diferença na qualidade do registro de dados nas declarações de nascidos vivos dos sobreviventes e das crianças que morreram, como foi identificado por PIPER et al (1993) e ALMEIDA et al. (2006a).

No Brasil destaca-se o estudo de MELLO JORGE et al. (1993) que comparara as informações das DNs com aquelas registradas em prontuários hospitalares em cinco municípios paulistas, mostrando que algumas variáveis apresentavam elevada concordância com os registros hospitalares, como o peso ao nascer, e outras apresentavam baixa completitude e concordância, como o número de filhos anteriores .

Estudo sobre a completitude e validade das informações do SINASC realizado na região sul do município de São Paulo mostrou que havia elevada completitude de dados para algumas variáveis, enquanto outras apresentavam problemas como a presença de malformação congênita e paridade da mãe. Verificouse também que o SINASC fornecia excelente informação para identificar recémnascidos de baixo peso ao nascer, porém as informações registradas subestimavam em $10 \%$ a prevalência de nascimentos de pré-termo. As informações sobre prevalência de mães de baixa escolaridade e sem companheiro encontravam-se superestimadas. Observou-se ainda que os nascimentos que tinham dado origem a óbitos neonatais apresentavam menor completitude, porém as informações registradas apresentavam maior sensibilidade e especificidade (ALMEIDA et al., 2006b). 
ALMEIDA et al. (2006b) mostraram que a ausência de registro de informações no SINASC é inferior a 5\%, para a maioria das variáveis. Entretanto, a situação é completamente diferente para os óbitos fetais. No SIM há elevada ausência de informação sobre peso ao nascer $(23,4 \%)$, idade da mãe $(18,5 \%)$, tipo de gravidez $(13,8 \%)$, idade gestacional $(9,1 \%)$ e anos de estudo da mãe $(40,6 \%)$.

Diversos estudos verificaram omissões no preenchimento dos dados da DO e ganho de informações pós-resgate em prontuários médicos. Estudo realizado em Blumenau sobre a qualidade das informações de óbitos de menores de um ano identificou que, de forma geral, a DO de óbito fetal é pior preenchida que a de óbito não-fetal, apresentando para este último maior proporção de "ignorado" para a variável instrução do pai (86\%) e filhos tidos nascidos vivos (66\%) e mortos (89\%). A variável peso ao nascer se mostrou ausente em $42 \%$ das declarações de óbito fetal e 13,5\% não fetal. (SANTA HELENA, 2003).

ROMERO e CUNHA (2006) observaram que permanecia ruim a qualidade dos dados socioeconômicos e demográficos das declarações de óbito de menores de um ano em todas as regiões brasileiras e verificaram a existência de alto grau de omissão de determinadas variáveis relacionadas às características maternas e da criança, em especial, parturição, idade materna e peso ao nascer. Entretanto, esses autores observaram acentuada melhora na captação de dados da raça do recémnascido e de escolaridade materna, no período 1996-2001. Constataram também a necessidade de diminuir a defasagem de tempo entre a ocorrência do óbito e a disponibilidade dos dados (oportunidade) e de resolver problemas encontrados nos manuais do sistema (clareza metodológica).

Outra dimensão importante na avaliação da qualidade da informação é análise da documentação dos sistemas de informação. SOLOMON et al. (1991)indicam a definição clara e precisa do evento a ser notificado como um dos requisitos indispensáveis para um sistema de registro contínuo, o que inclui as normas de inclusão e de exclusão de eventos, aspectos legais que deverão ser observados, fonte de obtenção e processamento de dados que será utilizado. Pode-se 
ainda acrescentar que a análise da documentação dos sistemas deve avaliar o fluxo de documentos e as responsabilidades institucionais.

Uma análise preliminar dessa documentação sugere que, pelo menos em parte, as diferenças encontradas entre o grau de completitude do SIM e SINASC pode ter entre suas causas as normatizações distintas sobre o preenchimento dos documentos. Segundo as normas contidas no Manual de Preenchimento da Declaração de Nascido Vivo, estas podem ser preenchidas pelos profissionais dos serviços de saúde. Já o Manual de Preenchimento da Declaração de óbito estipula que "o médico é o responsável por todas as informações e não deve assinar uma Declaração de Óbito em branco ou deixar declarações previamente assinadas; deve verificar se todos os itens de identificação estão devida e corretamente preenchidos e é o responsável por todas as informações contidas na DO". 6

Ainda, consta nos manuais de preenchimento e procedimentos do Conselho Federal de Medicina ${ }^{7}$ e do Ministério da $\operatorname{Saúde}^{8}$ que o médico responsável pelo atendimento deve preencher os dados de identificação do paciente com base em um documento da pessoa falecida, registrar os dados sempre com letra legível e registrar as causas de morte obedecendo às normas internacionais. Ainda segundo os manuais, o médico tem responsabilidade ética e jurídica pelo preenchimento e assinatura da DO e, portanto, para todas as informações registradas no documento que não deve ser assinada antes de ser feita uma revisão de todos os campos. A DO possui finalidade legal para emissão da certidão de óbito e seu crescente uso em estudos epidemiológicos.

Algumas das variáveis que poderiam ser utilizadas para a obtenção de indicadores sugeridos pelo projeto Peristat, entretanto, como indica estudo de ALMEIDA et al. (2006) há diferenças de qualidade dos registros do SIM e SINASC e é preciso atentar para o uso das informações. O estudo indica que a proporção de

\footnotetext{
${ }^{6}$ Ministério da Saúde e Conselho Federal de Medicina. A Declaração de Óbito: documento necessário e importante. Brasília - DF 2006.

${ }^{7}$ Resolução CFM n ${ }^{\circ} 1.779$, de 11 de novembro de 2005.

${ }^{8}$ Ministério da Saúde - FUNASA b. Manual de Preenchimento da Declaração de Óbito. Brasília - DF 2001.
} 
registros em branco ou anotado como ignorado no Município de São Paulo para a variável tipo de gravidez foi $0,0 \%$ no SINASC, enquanto no SIM essa proporção foi de 43,8\% para óbitos fetais e 31,9\% para óbitos neonatais. Para o tipo de parto a proporção de em branco ou ignorado foi de $0,2 \%$ no SINASC e no SIM 68,8\% para óbitos fetais e 32,4\% para óbitos neonatais em 2005

A ausência de registro de informações compromete a obtenção do perfil da mortalidade perinatal no país e seu monitoramento. No entanto, teoricamente estes dados poderiam ser facilmente obtidos, pois mais de $95 \%$ dos eventos ocorreram em estabelecimentos hospitalares. Os hospitais constituem a principal fonte de notificação do SIM para óbitos perinatais e do SINASC. Assim, não seriam esperadas diferenças marcantes de completitude de dados entre o SIM e SINASC. Os dados apresentados levantam questões importantes quanto à qualidade dos dados e ao preenchimento das declarações nas rotinas dos hospitais que estão sendo estudadas pela Avaliação da Qualidade da Informação sobre Mortalidade Perinatal no Município de São Paulo. ${ }^{9}$

Como os hospitais se constituem a principal fonte de notificação do SIM e SINASC para nascidos vivos e óbitos perinatais não seriam esperadas diferenças marcantes de completitude de dados entre o SIM e SINASC. Os dados apresentados levantam questões importantes quanto à qualidade dos dados e ao preenchimento das declarações nas rotinas dos hospitais que estão sendo estudadas pelo projeto Avaliação da Qualidade da Informação sobre Mortalidade Perinatal no Município de São Paulo.

Na etapa I do projeto foi realizada técnica de vinculação determinística. Foram unificadas as fontes de dados de nascimentos e óbitos da SES-SP e da Fundação SEADE. Foram vinculados 99,8\% dos eventos de nascidos vivos e óbitos neonatais precoces. Esta base de dados e as DOs fetais foram vinculadas à base do CNES (Cadastro Nacional de Estabelecimentos de Saúde). Foram excluídos os eventos de não residentes, os ocorridos fora do MSP ou ocorridos em domicílios,

${ }^{9}$ FAPESP/CNPq/PPSUS - Processo no ${ }^{\circ}$ 2006/61304-3 
pronto-socorros, casa de parto e hospitais com menos de 100 partos/ano. Os eventos estudados são: 96.759 nascidos vivos; 547 óbitos neonatais precoces e 748 óbitos fetais referentes a 80 hospitais do MSP que prestavam assistência ao parto (Pereira, 2008).

Segundo os dados obtidos no projeto as DNs apresentaram completitude acima de $90 \%$ para todas variáveis estudadas. A completitude das DOs neonatais precoces é menor: nos hospitais SUS, três variáveis mostram ter preenchimento abaixo de $90 \%$ (escolaridade da mãe, filhos nascidos vivos e mortos, porém todas apresentavam completitude acima de 80\%); nos hospitais não-SUS essas variáveis apresentaram completitude inferior a $80 \%$. As DOs fetais exibem preenchimento precário; apenas duas variáveis apresentaram preenchimento superior a 90\% (peso ao nascer e duração da gestação) tanto nos hospitais SUS como não-SUS.

$\mathrm{Na}$ etapa II desse projeto foi realizado um estudo de validade das informações por meio de comparação das variáveis registradas nas declarações de nascido vivo, óbito fetal e neonatal com os dados obtidos por meio de protocolo para registrar as informações dos registros hospitalares.

Para essa etapa do estudo os hospitais foram sorteados por amostragem estratificada segundo grupos, de modo proporcional ao número de óbitos perinatais em cada hospital e complexidade de atenção ao parto. Considerou-se no grupo SUS de hospitais também a esfera administrativa (estadual, Organizações Sociais de Saúde, municipal e privado sem fins lucrativos).

Considerando que um dos elementos críticos para o sucesso de um sistema de informações é o controle de qualidade dos procedimentos na fase de coleta dos dados (SOLOMON et al., 1991; ARTS et al., 2002) e que fatores institucionais tais como estrutura, organização e tipo dos serviços de saúde podem influenciar no registro de dados, bem como na presença de suporte administrativo. Além disso, outro fator importante são os profissionais designados para proceder a coleta de dados dos sistemas de informação e o treinamento existente para o desenvolvimento desta tarefa (ARTS et al. 2002). 
Podem também influenciar na qualidade da informação o grau de informatização dos dados, nível de descentralização da operação dos sistemas de informação e as atividades de gestão destes sistemas (NOVAES, 2006).

Tendo em vista esses aspectos e com objetivo de analisar a completitude dos dados sobre nascidos vivos e óbitos perinatais (neonatais precoces e fetais), foram realizadas entrevistas para identificar os responsáveis e as principais fontes de obtenção de dados utilizadas no preenchimento das declarações de nascido vivo e de óbito fetal e neonatal em amostra de hospitais SUS e não-SUS, no Município de São Paulo (MSP) no primeiro semestre de 2008.

Para complementar as informações e contextualizar como se dá o registro de dados nos hospitais foi realizada uma pesquisa qualitativa, com objetivo de compreender como se dá esse registro no grupo social que o realiza e a instituição produtora da informação obtendo-se uma representação contextualizada socialmente e não apenas buscando a generalização de resultados (SOUZA E ZIONE, 2003). Neste tipo de abordagem os entrevistados expressam suas ideias e se posicionam sobre um tema expressando significados, motivos, aspirações, crenças, valores e atitudes, o que corresponde a um espaço mais profundo das relações, dos processos e dos fenômenos (SPINK, 1993).

A abordagem qualitativa busca o significado e as especificidades da dimensão subjetiva do objeto de estudo. Entre as diversas abordagens de pesquisa qualitativa, a teoria da representação social tem como objetivo o conhecimento que é elaborado socialmente no cotidiano, faz parte do senso comum e que funciona no sentido de interpretar, pensar e agir sobre a realidade (ALEXANDRE, 2004).

As representações sociais manifestas verbalmente são um conjunto de conceitos, frases e explicações originadas na vida diária durante o curso das comunicações sociais. São modalidades de conhecimento prático, orientadas para a comunicação e para compreensão do contexto social, material e ideológico que vivemos. Socialmente elaboradas e compartilhadas, contribuem para a construção de uma realidade comum, possibilitando a comunicação entre os indivíduos. Portanto, 
são fenômenos sociais que devem ser compreendidos a partir de seu contexto de produção a que servem e das formas de comunicação onde circulam (JODELET, 2001).

Considerando os hospitais como unidades produtoras da informação foram entrevistados enfermeiros e profissionais de setores administrativos para identificar o discurso sobre o preenchimento das Declarações de Nascido Vivo (DNs) e se ou como auxiliam no preenchimento das Declarações de óbito (DOs) fetais e neonatais.

Na pesquisa de representação social é preciso atentar que o conhecimento pode ser visto diferentemente pelos atores sociais vinculados a diversas realidades sociais; portanto, conhecimento e realidade devem ser compreendidos dentro de contextos sociais específicos. Deve-se ter o cuidado de investigar as origens e a quantidade de informações veiculadas num grupo, sobre dado objeto social, bem como o conjunto de ideias dominantes utilizadas pelos integrantes para se referirem ao objeto. Os estudos baseados nas teorias das representações sociais fornecem subsídios para que o pesquisador possa desenvolver pesquisas com a finalidade de desvelar o pensar e agir de grupos sociais, tendo como referencial a teoria das representações sociais (ALEXANDRE, 2004).

Este trabalho contempla as entrevistas realizadas na II etapa do projeto Avaliação da Qualidade da Informação sobre Mortalidade Perinatal no Município de São Paulo ${ }^{10}$ e será apresentado no formato de três artigos científicos que contemplam diferentes objetivos do estudo.

${ }^{10}$ FAPESP/CNPq/PPSUS - Processo n ${ }^{\circ}: 2006 / 61304-3$ 


\section{OBJETIVOS}

\subsection{OBJETIVO GERAL}

Estudar a completitude, fontes de informação e a representação social dos profissionais de saúde em relação ao preenchimento das declarações de nascido vivo e de óbito neonatal e fetal.

\subsection{OBJETIVOS ESPECÍFICOS}

Artigo 1 - Completitude, responsáveis e fontes de dados utilizadas para obtenção de informações perinatais do SIM e SINASC no Município de São Paulo.

- analisar a completitude dos dados sobre nascidos vivos e óbitos perinatais (neonatais precoces e fetais);

- identificar os responsáveis pelo preenchimento das informações das DNs e DOs perinatais;

- identificar as principais fontes de obtenção de dados utilizadas no preenchimento das DNs e DOs perinatais. 
Artigo 2 - Representação Social de médicos obstetras e neonatologias que atuam em hospitais SUS e não-SUS no Município de São Paulo sobre Declaração de Óbito fetal e neonatal precoce.

- contextualizar a rotina de trabalho dos médicos e como o preenchimento das DOs se insere nesse cotidiano;

- identificar como age o médico quando tem alguma dúvida ou dificuldade para o preenchimento dos documentos;

- identificar a aspectos relatados por médicos a respeito de treinamento/capacitação sobre o preenchimento dos documentos;

- estudar a representação social de médicos obstetras e neonatologistas sobre as informações das DOs fetais e neonatais.

\section{Artigo 3 - SIM E SINASC: Representação Social de enfermeiros e profissionais de setores administrativos que atuam em hospitais SUS e não-SUS no Município de São Paulo.}

- contextualizar a rotina de trabalho dos enfermeiros e profissionais dos setores administrativos e como o preenchimento das DNs se insere neste cotidiano;

- identificar se os enfermeiros e profissionais dos setores administrativos dos hospitais auxiliam no preenchimento das DOs fetais e neonatais;

- identificar aspectos relatados por enfermeiros e profissionais dos setores administrativos a respeito de treinamento/capacitação sobre o preenchimento dos documentos;

- estudar a representação social de enfermeiros e profissionais dos setores administrativos dos hospitais sobreas finalidades/usos das informações do SIM e SINASC. 


\section{METODOLOGIA}

Os hospitais foram considerados unidades produtoras de informação e consequentemente como unidades amostrais. Estes foram sorteados por amostragem estratificada proporcional ao número de óbitos perinatais em cada estabelecimento. Esta decisão teve por base os resultados preliminares que mostraram que a informação sobre óbitos perinatais é mais precária que a de nascidos vivos (ALMEIDA et al., 2006b), além do fato de que estes eventos são mais raros que os de nascidos vivos. Considerando que podem existir diferenças nas rotinas de preenchimento e fluxo dos documentos na rede SUS e não-SUS, foi sorteada uma amostra de 22 hospitais, sendo 14 SUS e oito não-SUS. Os estratos foram constituídos pelo agrupamento de hospitais segundo níveis de complexidade (SILVA et al., 2010).

A elevada participação de hospitais SUS na amostra teve por objetivo obter representatividade da diversidade de prestadores de serviços SUS no MSP. O conjunto de hospitais SUS engloba estabelecimentos estaduais, municipais, organizações sociais de saúde e hospitais filantrópicos. Fazem parte da amostra três hospitais universitários, sendo que um deles representa também o segmento filantrópico SUS. Além desses estabelecimentos há mais dois hospitais públicos que desenvolvem atividades de ensino (um estadual e outro municipal).

Foram considerados como inelegíveis dois hospitais SUS que mudaram o perfil de atendimento ao parto e ao recém-nascido em 2008 (o levantamento de dados e as entrevistas foram realizados em 2009). Houve recusa de participação na pesquisa de três hospitais (um SUS e dois não-SUS). Assim, a pesquisa que levantou outras informações além das aqui apresentadas foi realizada em 17 hospitais. 
A pesquisa foi previamente aprovada pelos Comitês de Ética em Pesquisa da Faculdade de Saúde Pública - USP/SP, dos hospitais e da Secretaria Municipal de Saúde da prefeitura Municipal de São Paulo; antes das entrevistas foi lido e assinado Termo de Consentimento Livre Esclarecido, garantindo anonimato dos médicos e dos hospitais nos quais a pesquisa foi realizada.

\subsection{COMPLETITUDE E FONTES DE INFORMAÇÃO}

\subsubsection{População do Estudo}

Para identificar as fontes de dados utilizadas e os responsáveis pelo preenchimento das Declarações de Nascido Vivo (DN) e de Óbito Neonatal (DO neonatal) e Fetal (DO Fetal) foram realizadas entrevistas, em 2009, com responsáveis pelo SAME (Serviço de Arquivo Médico e Estatística), médicos obstetras, neonatologistas e enfermeiras responsáveis pela obstetrícia e unidade neonatal, apresentando um quadro nos quais os entrevistados indicavam as fontes de dados utilizadas (Anexo III). Essa atividade foi realizada antes de aplicar o questionário com questões abertas, como será apresentado a seguir. Dos 17 hospitais que participaram do estudo, foi possível completar as entrevistas com os profissionais de saúde em 14 deles. Seis entrevistas com responsáveis pelo SAME, quatro entrevistas com médicos obstetras, neonatologistas e quatro entrevistas com enfermeiras responsáveis pela obstetrícia e unidade neonatal indicados pela direção dos hospitais.

\subsubsection{Análise das Informações}


Foram selecionadas variáveis comuns à DN e DO relativas às características da mãe (idade, escolaridade, número de filhos anteriores vivos e mortos); da gestação e parto (duração da gestação, tipo de gravidez, consultas de pré-natal e tipo de parto); do feto ou recém-nascido (sexo, peso ao nascer e raça/cor), além da presença de Malformações Congênitas (MFC), o que é exclusivo da DN. Para DOs fetais e neonatais foram obtidas também informações para as variáveis referentes ao óbito (tipo, causa e relação com o parto).

O indicador de completitude foi calculado pela proporção de campos em branco ou ignorado com relação ao total de declarações para cada variável. Para avaliar a completitude de registro de dados nas declarações de nascido vivo e de óbito neonatal e fetal foi utilizado critério adaptado de MELLO JORGE et al. (1993) e COSTA e FRIAS (2009): excelente (>95\%); bom (90 a 95\%); regular (70 a 90\%); ruim $(50$ a $70 \%)$ e muito ruim $(<50 \%)$.

Para apresentação dos resultados foram consideradas apenas as categorias SUS e não-SUS. Quando não houve diferença essas categorias não foram consideradas.

\subsection{REPRESENTAÇÕES SOCIAIS DOS PROFISSIONAIS DE SAÚDE A RESPEITO DO PREENCHIMENTO DAS DECLARAÇÕES DE NASCIDOS VIVOS E DECLARAÇÕES DE ÓBITOS PERINATAIS}

Nas pesquisas por meio de questões fechadas são coletadas opiniões previamente disponíveis, ou seja, nelas a ação de opinar é entendida como o ato de escolher uma opinião dentre uma série de opções ou alternativas previamente elencadas oferecidas ao pesquisado.

A formulação de questões abertas é condizente com a teoria da representação social porque propicia que o entrevistado manifeste sua opinião e 
possibilita que se posicione sobre um tema, por meio de depoimento discursivo. $\mathrm{O}$ individuo entrevistado não é apenas um produto das determinações sociais e nem um produto individual, pois as representações são sempre construções contextualizadas (SPINK, 1993).

Já a entrevista qualitativa (questões abertas) com profissionais responsáveis pelo preenchimento das DNs e Dos possibilitou identificar as ideias que eles possuem sobre esses sistemas de informação e como esse objeto se insere no cotidiano do seu trabalho. O questionário foi semi-estruturado e as entrevistas foram realizadas nos hospitais, gravadas e transcritas para análise das informações.

\subsubsection{População do Estudo}

Definiu-se como critério entrevistar médicos diretamente envolvidos no preenchimento das DOs fetais e neonatais; assim, para atingir este objetivo, antes do início das entrevistas foi perguntado aos médicos obstetras e pediatras/neonatologistas se já haviam preenchido pelo uma vez os documentos. Em um hospital particular uma médica obstetra nunca havia preenchido o documento, por esse motivo a entrevista não foi realizada. No total, foram entrevistados seis médicos em hospitais não-SUS e 19 em hospitais do SUS.

O roteiro de entrevista (Anexo IV) foi definido por perguntas que buscaram identificar aspectos relatados por profissionais a respeito de treinamento/capacitação sobre o preenchimento dos documentos, identificar como age o profissional quando tem alguma dúvida ou dificuldade para o preenchimento dos documentos e conhecer a ideia que o profissional de saúde possui sobre as finalidade /usos das DOs.

Foram entrevistados profissionais envolvidos no preenchimento das DNs. Para tanto solicitou-se que a direção do hospital os indicasse. No total, foram entrevistados dois enfermeiros e cinco profissionais de setores administrativos em 
hospitais não-SUS e seis enfermeiros e 11 profissionais de setores administrativos em hospitais do SUS, totalizando 24 entrevistas.

O roteiro de entrevista foi definido por perguntas que buscaram contextualizar a rotina de trabalho e como o preenchimento das DNs e DOs se insere nesse cotidiano. Esse roteiro teve ainda como objetivo captar a existência de possíveis dificuldades, participação em treinamentos e representação social desses profissionais sobre o SIM e o SINASC. Antes das entrevistas foi lido e assinado Termo de Consentimento Livre Esclarecido, garantindo anonimato dos médicos e dos hospitais nos quais a pesquisa foi realizada.

\subsubsection{Análise das Informações}

Para o processamento dos depoimentos, empregou-se a técnica do Discurso do Sujeito Coletivo (DSC), que busca superar os impasses das pesquisas tradicionais de representação social, recuperando na escala coletiva a natureza discursiva e argumentativa do pensamento.

A opinião é obtida através de questões abertas propiciando ao entrevistado a geração de um depoimento discursivo e não somente a escolha entre alternativas prédefinidas pelo pesquisador. Cada questão gera um número variado posicionamentos, ou seja, de distintos DSCs que resultam de uma agregação de diferentes discursos ou extratos de discursos individuais que representam sentido semelhante (LEFEVRE e LEFEVRE, 2003).

Esses DSCs são distintos tanto do ponto de vista qualitativo, na medida em que veiculam opiniões e posicionamentos diferentes, produtos da coletividade, quanto do ponto de vista quantitativo, pois mesmo que composto de um só depoimento o DSC faz parte de uma coletividade. A dimensão quantitativa do DSC está ligada ao fato de que cada DSC é composto com extratos de depoimentos 
oriundos de uma parcela de indivíduos do total pesquisado. A soma dos resultados corresponde ao número de ideias em cada categoria e não ao número de entrevistados (LEFEVRE e LEFEVRE, 2003; LEFEVRE e LEFEVRE, 2006).

Cada DSC reúne sob uma mesma categoria conteúdos e agrupamentos que compõe uma opinião compartilhada por um conjunto de pessoas. A pesquisa realizada e analisada pela técnica do Discurso do Sujeito Coletivo - DSC e do software Qualiquantisoft ${ }^{11}$ possibilita, para cada questão, a construção de categorias de respostas nas quais observam-se as ideias ou representações compartilhadas entre os sujeitos que responderam à pesquisa (LEFEVRE e LEFEVRE, 2003).

O discurso de cada entrevistado pode conter uma ou mais ideias a respeito da questão estabelecida. Para o processo de análise são atribuídas expressões-chave a cada ideia para que, então, seja possível agrupar as expressões-chave de sentindo semelhante em categorias de respostas. Com as categorias de ideias compartilhadas e seus respectivos discursos estabelecidos torna-se possível a análise qualitativa dos depoimentos e também quantificar a porcentagem de ideias compartilhadas em cada uma das questões (LEFEVRE e LEFEVRE, 2003; LEFEVRE e LEFEVRE, 2006).

${ }^{11}$ SPi-Sales \& Paschoal informática. www.spi.com.br. Elaborado com base na teoria do DSC. 


\section{REFERÊNCIAS}

Ahlenius I, ThomassenP.The changing panorama of late fetal death in Sweden between 1984 and 1991.Acta ObstetGynecolScand.1999;78:408-414.

Alexandre M. Representação Social: uma genealogia do conceito. Comum. 2004; 10(23): 122-138.

Almeida MF, Alencar GP, França Jr I, Novaes HM, Siqueira AAF, Schoeps D, Campbell O, Rodrigues RC. Validade das informações das declarações de nascidos vivos com base em estudo de caso-controle. Cad. Saúde Pública. 2006;22(3):643652. (a)

Almeida MF, Alencar GP, Novaes HMD, Ortiz LP. Sistemas de informação e mortalidade perinatal: conceitos e condições de uso em estudos epidemiológicos. Rev. bras. Epidemiol.2006; 9(1):56-68. (b)

Almeida MF, Alencar GP. Informações em saúde: necessidade de introdução de mecanismos de gerenciamento dos sistemas. Informe Epidemiológico do SUS. 2000;9(4):241-249.

Almeida MF, Alencar GP, Schoeps D. Sistema de Informações sobre Nascidos Vivos - SINASC: uma avaliação de sua trajetória. In: Ministério da Saúde. (Org.). Sistemas de Informação em Saúde. Brasilia: Editora MS; 2009.

Arts DG, De Keizer NF, SchefferGJ.Defining and improving data quality in medical registries: a literature review, case study, and generic framework. J Am Med Inform Assoc. 2002;9(6):600-11.

Buitendijk S, Zeitlin J, Cuttini M, Langhoff-Roos J, Bottu J. Indicators of fetal infant health outcomes. European Journal of Obstetrics and Gynecology and Reproductive Biology.2003;111: S66-S77.

Carvalho DM. Grandes sistemas nacionais de informação em saúde: revisão e discussão da situação atual. InformeEpidemiológico SUS. 1997; VI: 35-41.

Cnattingius S, Stephansson O. The epidemiology of stillbirth.SeminPerinatol 2002; 26:25-30.

Costa JMBS, Frias PG. Avaliação da completitude das variáveis da Declaração de Nascido Vivo de residentes em Pernambuco, Brasil, 1996 a 2005. Cad. Saúde Pública. 2009;25(3):613-624. 
Graafmans WC, Richardus J-H, Macfarlane A, Rebagliato M, Blondel B, VerlooveVanhorick SP, Mackenbach JP. Comparability of published perinatal mortality rates in Western Europe: the quantitative impact of differences in gestational age and birthweight criteria. Br J ObstetGynaecol.2001;108:1237-1245.

Jodelet D, organizadora. As Representações Sociais. Rio de Janeiro: EdUERJ. 2001. $420 \mathrm{p}$.

Kirby RS.The quality of vital perinatal statistics data, with special reference to prenatal care.PaediatricandPerinatal Epidemiology1997; 11:122-128.

Lefevre, F; Lefevre, A.M.C. O discurso do sujeito coletivo: um novo enfoque em pesquisa (desdobramentos). Caxias do Sul: EDUCS, 2003.

Lefevre, F; Lefevre, A.M.C. O sujeito coletivo que fala. Interface São Paulo. 2006;10(20):517-520,

McDermott J, Drews C, Green D, Berg C. Evaluation of prenatal care information on birth certificates.Paediatricand Perinatal Epidemiology.1997; 11:105-21.

Mello-Jorge MHP, Gotlieb SLD, Soboll MLMS, Almeida MF, LatorreMRDO.Osistema de informação sobre nascidos vivos - SINASC. São Paulo: CBCD, série divulgação. 1992;7:45.

Mello-Jorge MHP, Gotlieb SLD, Soboll MLMS, Almeida MF, Latorre MRDO. Avaliação do sistema de informação sobre nascidos vivos e o uso de seus dados em epidemiologia e estatísticas de saúde. Rev.Saúde Pública. 1993; 27(6).

Mello Jorge MHP, Gotlieb SDL, Laurenti R. O Sistema de Informações sobre Mortalidade: problemas e propostas para o seu enfrentamento. I - Mortes por Causas Naturais. Rev. bras. epidemiol. 2002;5(2):197-211.

Mello Jorge MHP de, Laurenti R, Gotlieb SLD. O Sistema de informações sobre Mortalidade - SIM: Concepção, Implantação e Avaliação. In: Ministério da Saúde. (Org.). Sistemas de Informação em Saúde. Brasilia: Editora MS; 2009.

Novaes, MHD. Da produção à avaliação de tecnologias dos sistemas de saúde: desafios do século XXI. Rev. Saúde Pública. 2006;40:133-140.

Pereira MG. Epidemiologia Teoria e Prática. Rio de Janeiro: Guanabara-Koogan. 1999:366-373.

Piper JM, Mitchell Jr. EF, Snowden M, Hall C, Adams M, Taylor P. Validation of 1989 Tennessee Birth certificates using maternal and newborn hospital records. American Journal of Epidemiology 1993; 137:758-68. 
Reichman NE, Hade EM. Validation of birth certificate data: a study of women in New Jersey's Health Start Program. Annals of Epidemiology. 2001; 11: 186-93.

Romero DE, Cunha CB. Avaliação da qualidade das variáveis socioeconômicas e demográficas dos óbitos de crianças menores de um ano registrados no Sistema de Informações sobre Mortalidade do Brasil (1996/2001). Cad. Saúde Pública. 2006; 22: $673-684$.

Santa Helena ET, Rosa MB. Avaliação da qualidade das informações relativas aos óbitos em menores de um ano em Blumenau,1998. Rev. Brasileira Saúde Materna e Infantil. 2003;3(1):75-83.

Silva RI,Theme Filha MM, Noronha CP. Sistema de Informações sobre Nascidos Vivos na Cidade do Rio de Janeiro 1993/1996. Informe Epidemiológico SUS. 1997; VI:34-48.

Silva ZP, Almeida MF, Flores LPO, Alencar GP, Alencar AP, Schoeps D, Minuci EG, Novaes HM. Morte neonatal precoce segundo complexidade hospitalar e rede SUS e não-SUS na Região Metropolitana de São Paulo, Brasil. Cad. SaúdePública. 2010;26(1):123-134.

Solomon DJ, Henry RC, Hogan JG, Van Amburg GH, Taylor J. Evaluation and Implementation of Public Health Registries.Public Health Reports.1991; 106(2):142154.

Spink MJP. O conceito de representação social na abordagem psicossocial. Cad. Saúde Pública. 1993; 9(3): 300-3008.

Souza DV, Zioni F. Novas perspectivas de análise em investigações sobre meio ambiente: a teoria das Representações Sociais e a técnica qualitativa da triangulação de dados. Saudesoc. 2003; 12(2): 76-85.

ZEITLIN J, Wildman K, Bréart G, Alexander S et al. Selecting an indicator set for monitoring and evaluating perinatal health in Europe: criteria, methods and results from the PERISTAT project. European Journal Obstetrics\& Gynecology and Reproductive Biology. 2003;111: S5-S14. 


\section{RESULTADOS E DISCUSSÃO}

Os resultados e discussão obtidos no presente estudo estão apresentados sob a forma de três artigos científicos:

Artigo 1 - Completitude, responsáveis e fontes de dados utilizadas para obtenção de informações perinatais do SIM e SINASC, no Município de São Paulo.

Artigo 2 - Representação Social de médicos obstetras e neonatologias que atuam em hospitais SUS e não-SUS no Município de São Paulo sobre Declaração de Óbito fetal e neonatal precoce.

Artigo 3 - SIM E SINASC: Representação social de enfermeiros e profissionais de setores administrativos que atuam em hospitais SUS e não-SUS no Município de São Paulo. 


\title{
Artigo 1 - COMPLETITUDE, RESPONSÁVEIS E FONTES DE DADOS UTILIZADAS PARA OBTENÇÃO DE INFORMAÇÕES PERINATAIS DO SIM E SINASC, NO MUNICÍPIO DE SÃO PAULO.
}

\author{
Schoeps $\mathrm{D}^{1}$, Almeida $\mathrm{MF}^{1}$, Silva $\mathrm{ZP}^{1}$ \\ ${ }^{1}$ Departamento de Epidemiologia da Faculdade de Saúde Pública da Universidade de São Paulo.
}

\section{Resumo}

Introdução: Estudos têm mostrado completitudes insatisfatórias para variáveis do SIM e SINASC, importantes para a obtenção de indicadores específicos de saúde perinatal. Bases de dados secundários ou administrativos como estes possuem uma multiplicidade de fontes de obtenção da informação e sua documentação se mostra essencial para padronização e normatização da coleta. Este estudo tem o objetivo de identificar a completitude, os responsáveis e as principais fontes utilizadas no preenchimento das declarações de nascido vivo e de óbito fetal e neonatal.

Métodos: Foram calculados indicadores de completitude e realizadas entrevistas sobre o preenchimento da Declaração de Nascido Vivo (DN) e Declaração de Óbito (DO) em 14 hospitais, com e sem vínculo com o SUS, no Município de São Paulo.

Resultados: A completitude das informações das DNs foi excelente para a maioria das variáveis. Já para as DOs neonatal e fetal a completitude é insatisfatória. Verificou-se que as informações da DN são preenchidas por enfermeiras ou por pessoal administrativo. As DOs são preenchidas por pessoal administrativo e por médicos, sendo que nos hospitais SUS há o preenchimento também pelo SVO/necrotério e nos não-SUS por enfermeiras. Ressalte-se que o campo da causa de morte foi preenchido pelos médicos em todos os hospitais. Foram identificadas diversas fontes para o preenchimento da $\mathrm{DN}$ : os documentos hospitalares, observação e informação verbal. Para as DOs, além dessas fontes também foram identificadas a própria DN. Não foram encontradas diferenças entre hospitais SUS e não-SUS.

Conclusões: Os resultados obtidos sobre as fontes de dados mais frequentemente empregadas e dos responsáveis pelo preenchimento das declarações poderão contribuir para o desenvolvimento de estratégias de treinamento junto aos hospitais para o aprimoramento das informações perinatais disponíveis no SIM e SINASC.

Palavra-chave: Sistema de Informações em Saúde; Declaração de Nascido Vivo; Declaração de Óbito; Registros Hospitalares; Fonte de dados 


\section{COMPLETENESS, RESPONSIBLE AND SOURCES OF DATA USED TO OBTAIN PERINATAL INFORMATION FOR SINASC AND SIM, IN CITY OF SAO PAULO.}

Schoeps $\mathrm{D}^{1}$, Almeida $\mathrm{MF}^{1}$, Silva $\mathrm{ZP}^{1}$

1 Department of Epidemiology, School of Public Health, University of Sao Paulo.

\section{Summary}

Introduction: Studies have shown unsatisfactory completeness to birth and death certificates variables, important for the attainment of specific indicators of perinatal health. Secondary or administrative databases as these have multiple sources for obtaining information and documentation is essential for standardization of the collection. This study aims to identify the completeness, the leaders and the main sources used for the completion of the birth and fetal and neonatal death certificates.

Methods: It was calculated indicators of completeness and interviewed on the filling of DN (birth) and DO (death declaration) in 14 hospitals with and without public health system (SUS) paying, in the City of São Paulo.

Results: The completeness of the information of DN was excellent for most variables. The neonatal and fetal DO completeness is unsatisfactory. It was found that the information in the DN is filled by nurses or administrative staff. The death certificates are filled by administrative staff and physicians, and hospitals in the public system were also filling the SVO/morgue and non-SUS by nurses. It should be noted that the field of cause of death was filled out by doctors in all hospitals. We identified several sources to fill the DN: hospital documents, observation and verbal information. For DO it also includes the DN information. No differences were found between SUS and non-SUS hospitals.

Conclusions: The identification of the most often employed data sources and the responsible for completing the declaration may contribute to the development of training strategies from hospitals in order to improve perinatal information available on birth and death certificates

Keywords: Health Information System; Statement of Live Birth, death certificates, hospital records, data source 


\section{INTRODUÇÃO}

Os sistemas de informação sobre nascidos vivos e de mortalidade têm sido utilizados para avaliar a atenção ao parto e ao recém-nascido, tanto no Brasil (ALMEIDA et al., 2009)como no exterior (GOULD, 1999). Com o avanço do processo de informatização e o aumento de cobertura de eventos há hoje maior facilidade de acesso às bases de dados, o que teoricamente permitiria a obtenção de indicadores específicos, tais como a mortalidade perinatal segundo idade da mãe, tipo de gravidez, peso ao nascer e duração da gestação, que se constituem em ferramentas indispensáveis para o monitoramento da assistência ao parto e ao recémnascido, à semelhança do que é praticado de forma rotineira na União Europeia (ZEITLIN et al 2003). Entretanto, uma das dificuldades encontradas tem sido a completitude insatisfatória de algumas variáveis, impedindo o cálculo desses indicadores (SILVA et al., 2010, COSTA e FRIAS, 2009; ALMEIDA et al., 2006a).

A qualidade da informação depende sobretudo da adequada coleta de dados gerados no local onde ocorre o evento (ARTS et al., 2002; SOLOMON et al., 1991). Os serviços de saúde se constituem como a principal fonte de dados dos Sistemas de Informação sobre Mortalidade (SIM) e de Nascidos Vivos (SINASC) e a qualidade dessas informações depende do registro das informações hospitalares (TERRIS et al., 2009). O Cadastro Nacional de Estabelecimentos de Saúde (CNES) indica que no Brasil há uma extensa rede com cerca de 6.400 estabelecimentos que formam as unidades de coleta desses dados. No entanto, apesar de existir uma concentração dos eventos vitais nos hospitais, são poucos os estudos que avaliam como as informações são produzidas nesses ambientes (NOVAES, 2006). E são

praticamente inexistentes os estudos que buscam identificar quais as fontes empregadas para a obtenção dos dados e os responsáveis por sua coleta (ALMEIDA et al., 2004). Conhecer tais aspectos ajuda a compreender como ocorre a produção 
da informação nos serviços de saúde, que deve ser entendida como parte importante dos processos de gestão da qualidade da assistência (NOVAES, 2006).

Fatores institucionais como estrutura, organização e tipo dos serviços de saúde podem influenciar no registro de dados, bem como a presença de suporte administrativo. Outro fator importante são os profissionais designados para proceder a coleta de dados dos sistemas de informação e treinamento existente para o desenvolvimento dessa tarefa. Além desses fatores, também podem influenciar na qualidade; grau de informatização dos dados, nível de descentralização da operação dos sistemas de informação e atividades de gestão destes sistemas (NOVAES, 2006), tais como treinamento e atividades rotineiras de controle da qualidade das informações em todas as etapas de sua produção. Um dos elementos críticos para o sucesso de um sistema de informações é o controle de qualidade dos procedimentos nas fases de coleta e processamento dos dados (ARTS et al., 2002; SOLOMON et al., 1991).

Segundo ARTS et al. (2002), para assegurar a qualidade das informações é necessário garantir algumas atividades na etapa anterior à coleta de dados, como por exemplo, um protocolo de coleta com definições claras, treinamento e motivação do profissional responsável pelo preenchimento das informações. Este estudo tem por objetivos analisar a completitude dos dados sobre nascidos vivos e óbitos perinatais (neonatais precoces e fetais) do primeiro semestre de 2008 e identificar os responsáveis e principais fontes de obtenção de dados utilizadas no preenchimento das declarações de nascido vivo e de óbito fetal e neonatal por meio de entrevistas realizadas em 2009 em amostra de hospitais SUS e não-SUS, no Município de São Paulo (MSP). 


\section{MATERIAL E MÉTODOS}

Os hospitais foram considerados como unidades produtoras de informação e consequentemente como unidades amostrais. Assim, foram sorteados por amostragem estratificada proporcional ao número de óbitos perinatais em cada estabelecimento. Essa decisão teve por base os resultados preliminares que mostraram que a informação sobre óbitos perinatais é mais precária que a de nascidos vivos (ALMEIDA et al., 2006b), além do fato de que esses eventos são mais raros que os de nascidos vivos. Considerando que podem existir diferenças nas rotinas de preenchimento e fluxo dos documentos na rede SUS e não-SUS, foi sorteada uma amostra de 22 hospitais, sendo 14 SUS e oito não-SUS. Os estratos foram constituídos pelo agrupamento de hospitais segundo níveis de complexidade (SILVA et al., 2010). A elevada participação de hospitais SUS na amostra teve por objetivo obter representatividade da diversidade de prestadores de serviços SUS no MSP. O conjunto de hospitais SUS engloba estabelecimentos estaduais e municipais, organizações sociais de saúde e hospitais filantrópicos. Fazem parte da amostra três hospitais universitários, sendo que um deles representa também o segmento filantrópico SUS. Além destes estabelecimentos, há mais dois hospitais públicos que desenvolvem atividades de ensino, um estadual e outro municipal.

Foram considerados como inelegíveis dois hospitais SUS que mudaram o perfil de atendimento ao parto e ao recém-nascido em 2008. O levantamento de dados e as entrevistas foram realizados em 2009. Houve recusa de participação na pesquisa de três hospitais (um SUS e dois não-SUS). Assim, a pesquisa foi realizada em 17 hospitais e levantou outras informações, além das aqui apresentadas.

Para identificar as fontes de dados utilizadas e os responsáveis pelo preenchimento das Declarações de Nascido Vivo (DN) e de Óbito neonatal (DO neonatal) e fetal (DO Fetal) foram realizadas seis entrevistas com responsáveis pelo SAME (Serviço de Arquivo Médico e Estatística), quatro entrevistas com médicos 
obstetras, neonatologistas e quatro entrevistas com enfermeiras responsáveis pela obstetrícia e unidade neonatal indicados pela direção dos hospitais. Dos 17 hospitais que participaram do estudo, só foi possível completar as entrevistas com os profissionais de saúde em 14 deles.

A pesquisa foi previamente aprovada pelos Comitês de Ética em Pesquisa da Faculdade de Saúde Pública - USP/SP, dos hospitais e da Secretaria Municipal de Saúde da prefeitura Municipal de São Paulo. Antes das entrevistas foi lido e assinado o Termo de Consentimento Livre Esclarecido, garantindo anonimato dos médicos e dos hospitais nos quais a pesquisa foi realizada.

Foram selecionadas variáveis comuns à $\mathrm{DN}$ e $\mathrm{DO}$ relativas às características: da mãe (idade, escolaridade, número de filhos anteriores vivos e mortos); da gestação e parto (duração da gestação, tipo de gravidez, consultas de prénatal e tipo de parto); do feto ou recém-nascido (sexo, peso ao nascer e raça/cor), além da presença de Malformação Congênita (MFC), que é exclusiva da DN. Para DOs fetais e neonatais foram obtidas também informações para as variáveis referentes ao óbito (tipo, causa e relação com o parto).

O indicador de completitude foi calculado pela proporção de campos em branco ou ignorados do total com relação ao total de declarações para cada variável. Para avaliar a completitude de registro de dados nas declarações de nascido vivo e de óbito neonatal e fetal foi utilizado critério adaptado de MELLO JORGE et al. (1993) e COSTA E FRIAS (2009): excelente (>95\%); bom (90 a 95\%); regular (70 a 90\%); ruim $(50$ a $70 \%)$ e muito ruim $(<50 \%)$.

Para apresentação dos resultados serão consideradas apenas as categorias SUS e não-SUS. Quando não houver diferença essas categorias não serão consideradas. 


\section{RESULTADOS}

A Tabela 1 mostra que a completitude das variáveis da DN pode ser considerada excelente para: idade da mãe, tipo de gravidez, tipo de parto, peso ao nascer, Apgar $1^{\circ}$ e $5^{\circ}$ minuto e sexo para os hospitais SUS e não-SUS. O registro de presença de MFC é bom nos hospitais SUS e ruim nos hospitais não-SUS. A variável raça/cor apresentou preenchimento regular para os hospitais SUS e muito ruim para os não-SUS. As variáveis: escolaridade da mãe, número de consultas de pré-natal duração da gestação apresentaram preenchimento bom nos hospitais SUS e excelente para nos hospitais não-SUS.

As DOs neonatais apresentaram preenchimento muito ruim para as variáveis: idade da mãe, número de filhos anteriores vivos e mortos nos hospitais SUS e não-SUS. A variável escolaridade da mãe apresentou preenchimento muito ruim em hospitais SUS e ruim em hospitais não-SUS. Duração da gestação e tipo de gravidez apresentaram preenchimento ruim em hospitais SUS e regular em hospitais não-SUS. Presença de malformação congênita apresentou preenchimento muito ruim e regular enquanto peso ao nascer apresentou regular e ruim para hospitais SUS e não-SUS. Número de consultas de pré-natal e sexo apresentaram preenchimento excelente em hospitais SUS e bom em hospitais não-SUS. E por fim, preenchimento excelente nos hospitais SUS e não-SUS só foi observado para variável tipo de parto.

Com relação à completitude das variáveis as DO-Fetais apresentaram preenchimento excelente apenas para a variável duração da gestação nos hospitais não-SUS, enquanto que nos hospitais SUS o preenchimento para essa variável foi bom. Ao contrário, a variável sexo apresentou preenchimento excelente em hospitais SUS e bom em hospitais não-SUS. O tipo de gravidez apresentou preenchimento regular em hospitais SUS e bom em hospitais não-SUS. O peso ao nascer apresentou preenchimento bom nos dois grupos de hospitais. As demais variáveis apresentaram preenchimento ruim e muito ruim tanto nos hospitais SUS como não-SUS. 
Os dados sobre responsáveis pelo preenchimento das DNs nos 14 hospitais estudados se encontram na Tabela 2. Os resultados apresentados não consideram a tipologia SUS e não-SUS porque não houve diferença quanto às variáveis estudadas e mostram que as informações são preenchidas por enfermeiras ou pelo pessoal administrativo dos hospitais.

Com relação às fontes empregadas para obtenção de dados para o preenchimento da DN, também não há distinção entre hospitais SUS e não-SUS, sendo que para as variáveis relativas às características maternas a principal fonte utilizada na DN é verbal ou seja, são informações obtidas diretamente por meio de perguntas dirigidas às mães (Tabela 2). As variáveis relativas à gestação e ao parto são predominantemente obtidas por meio de consulta a documentos hospitalares (que incluem informações registradas nos prontuários, documentos não oficiais, como aviso de nascimento, e informações registradas nos sistemas de informação existentes em dois hospitais SUS).

$\mathrm{Na} \mathrm{DN}$, o tipo de parto foi mais frequentemente mencionado como informação obtida diretamente na observação em sala de parto. Com relação aos dados sobre consultas de pré-natal realizadas pelas mães, verificou-se que oito hospitais utilizavam informações registradas nos documentos hospitalares e seis obtinham estes dados por comunicação verbal das mães. As variáveis relativas às características do recém-nascido na DN são preferencialmente obtidas nos documentos hospitalares. A raça/cor do RN é obtida por meio de informação verbal da mãe e a presença de malformações congênitas é obtida tanto por meio de documentos como de observação.

Os responsáveis pelo preenchimento das DOs-neonatais são os médicos e o pessoal administrativo dos hospitais (Tabela 3). $\mathrm{Na}$ maior parte dos estabelecimentos, as variáveis relativas às características maternas são preenchidas pelo pessoal administrativo. Com relação às variáveis que descrevem as condições da gestação e do parto há uma ligeira predominância do pessoal administrativo (8/14) em relação aos médicos (6/14). Já para as variáveis relativas ao recém-nascido, não há um padrão para todas elas. A causa de morte é preenchida exclusivamente pelos 
médicos. O número da $\mathrm{DN}$ é praticamente preenchido só pelo pessoal administrativo (12/14), assim como a raça/cor (11/14). As demais variáveis apresentam perfil semelhante ao das informações relativas à gestação e parto (Tabela 3).

$\mathrm{Na}$ DO neonatal as fontes de dados mais frequentes no preenchimento das variáveis estudadas são os documentos hospitalares, seguidas da informação verbal obtida das mães. A observação direta e a DN são pouco referidas. Não se identificou um padrão diferencial de fontes nos hospitais SUS e não-SUS (Tabela3). Alguns hospitais utilizaram a comunicação verbal das mães para obter a idade materna (5/14) e a escolaridade (4/14). A DN foi utilizada para o preenchimento da variável escolaridade materna em um hospital, para a raça/cor em dois hospitais e para o preenchimento do número da DN existente para os óbitos infantis em quatro hospitais. Um dos hospitais SUS relatou não preencher essa variável.

Há diferença entre os responsáveis pelo preenchimento das variáveis das DO-fetais nos hospitais SUS e não-SUS (Tabela 4). Dos 11 hospitais SUS, cinco indicaram que o preenchimento de todas as variáveis das DOs fetais era realizado pelo Serviço de Verificação de Óbitos (SVO) ou por Necrotérios existentes nos hospitais (ALMEIDA et al., 2011). Do conjunto restante (seis hospitais SUS e três hospitais não-SUS), a causa de morte sempre foi preenchida pelos médicos. Nos seis hospitais SUS que não enviam os óbitos fetais para o SVO e necrotérios, as demais variáveis da DO são preenchidas por médicos e pessoal administrativo. Para as variáveis relativas à gestação/parto e feto há uma predominância de preenchimento pelos médicos, à exceção da variável raça/cor. Nos hospitais não-SUS, além dos profissionais já mencionados, as enfermeiras também preenchem algumas informações (idade e escolaridade da mãe, sexo, peso ao nascer, raça/cor do $\mathrm{RN}$ e tipo de óbito).

As fontes empregadas para o preenchimento da DO-fetal apresentam diversidade entre os hospitais SUS e não-SUS, pois os hospitais SUS incluem entre suas fontes o SVO e necrotérios (Tabela 5). Não fosse a presença do SVO/necrotério, observar-se-ia que a fonte de dados mais empregada para o preenchimento de todas 
as variáveis são os documentos hospitalares (prontuários, avisos de óbito e sistemas de informação hospitalares).

\section{DISCUSSÃO}

A atenção ao parto é formada por 85 hospitais no Município de São Paulo e se concentra em hospitais de alta complexidade $(87,4 \% \text { dos partos })^{1}$. Na rede SUS a proporção de partos realizados em hospitais de alta complexidade era de 96,9\% e na rede não-SUS era 72,8\% em 2006. Com relação à amostra estudada, as recusas ocorreram principalmente entre os hospitais não-SUS de média e baixa complexidade, à semelhança de estudo realizado no Município do Rio de Janeiro (GUERRA et al., 2008). Apesar das recusas, este estudo fornece uma visão da produção das informações na rede hospitalar do MSP, tendo em vista que assistência ao parto e ao recém-nascido se concentra nos hospitais de alta complexidade.

Segundo SOLOMON et al. (2001), para garantir a qualidade da informação é fundamental que existam métodos para coleta de dados, definição das variáveis que serão objeto de coleta e a rotina para obtenção de dados. Seminário realizado na década de 1990, para avaliação dos sistemas de informação, identificou a necessidade de documentação dos sistemas de informação como um mecanismo importante para garantir a qualidade dos dados. O SINASC foi implantado juntamente com introdução do seu respectivo Manual de Instruções e no inicio do processo de descentralização dos sistemas de informação.

As declarações de nascidos vivos apresentaram completitude elevada, à semelhança do que outros estudos já haviam mostrado (ALMEIDA et al., 2006;

\footnotetext{
${ }^{1}$ Fundação SEADE. Nascidos Vivos, Nascidos Mortos, Óbitos Neonatais Precoces e Perinatais e Taxas de Mortalidade. Disponível em: http://www.seade.gov.br/produtos/mortinf/tabelas/distritos.pdf
} 
ROMERO E CUNHA, 2006; MELLO JORGE et al., 2009; COSTA e FRIAS, 2009).

Os dados obtidos mostram que a DN é preenchida basicamente pelo pessoal administrativo dos hospitais e pelas enfermeiras. Os médicos não foram mencionados por nenhum hospital como responsáveis pelo preenchimento da DN. Resultado semelhante foi obtido em estudo realizado em duas maternidades do Rio de Janeiro (GUERRA et al., 2008).

Para obter informações sobre as variáveis da DN relativas às características maternas a fonte de dados mais frequentemente utilizada é a verbal. Após o parto são realizadas entrevistas pelo pessoal administrativo do hospital ou enfermeiras com as mães e os dados obtidos são registrados diretamente na DN. Alguns hospitais mencionaram que essa prática é utilizada para garantir uma informação mais segura, pois muitas mães chegam ao hospital já em trabalho de parto e como consequência as informações iniciais registradas nos prontuários são prestadas por acompanhantes.

A estratégia mostrou-se adequada para a obtenção da idade materna, mas insuficiente para conseguir um bom preenchimento da escolaridade e paridade, sendo que, estudos anteriores já haviam mostrado a fragilidade das informações sobre paridade na DN (ALMEIDA et al., 2006a; ROMERO E CUNHA, 2006; COSTA e FRIAS, 2009). Possivelmente, o formato da variável contida na DN, juntamente com a ausência de treinamento especifico, pode estar contribuindo para o preenchimento precário das variáveis número de filhos anteriores vivos e mortos. A ausência de registro de dados na $\mathrm{DN}$ em primíparas (sem filhos vivos e mortos anteriores) pode estar elevando artificialmente o não preenchimento dessas variáveis. Essa dificuldade poderá ser contornada com a implantação do novo modelo de DN que introduz a categoria "nenhum filho vivo ou morto anterior", a exemplo do modelo de DN existente nos EUA (OSTERMAN et al., 2009).

A fonte mais frequente para a variável raça/cor do recém-nascido também foi a informação verbal prestada pelas mães, mostrando que a maior parte dos hospitais segue a orientação existente de que essa variável deve ser auto referida e 
não obtida por meio de observações de terceiros. O melhor preenchimento da variável raça/cor nos hospitais SUS indica que tais serviços se comprometeram em seguir normatização de registro desses dados nos seus documentos, enquanto nos hospitais não-SUS esta prática ainda não é frequente.

As variáveis referentes às características da gestação/parto e do recémnascido são predominantemente obtidas nos documentos hospitalares. Porém, identificou-se uma grande diversidade de documentos consultados, além dos prontuários, tais como aviso de nascimento, registro de parto e outros, o que pode dificultar a normatização da coleta e avaliações futuras do grau de confiabilidade das informações registradas no SINASC.

$\mathrm{O}$ registro de dados sobre o índice de Apgar no $1^{\circ}$ e $5^{\circ}$ minutos mostrou-se precário, sendo que as fontes de dados mais frequentemente mencionadas para sua obtenção foram os documentos hospitalares e a observação direta na sala de parto, resultado semelhante ao encontrado em estudo realizado em Recife (COSTA e FRIAS, 2009). A ausência de registro dessa informação sugere duas hipóteses: a) a não realização desta medida na sala de parto, o que sugere baixa qualidade da atenção prestada ao parto e recém-nascido; b) a realização da medida, mas pouco cuidado com seu registro na DN. As duas hipóteses levam a restrição do uso desse indicador, que tem se mostrado importante em estudos populacionais sobre mortalidade neonatal, pois se constitui em uma das medidas de viabilidade dos recém-nascidos (ALMEIDA et al., 2002; RIBEIRO et al., 2009).

Identificou-se que a fonte de dados mais frequentemente utilizada para o preenchimento da variável presença de malformação congênita (MFC) é a observação. Dessa forma, as MFCs mais identificadas nas DNs serão as clinicamente perceptíveis. Existe dificuldade de preenchimento para malformações congênitas não aparentes, pois para estes casos o tempo de diagnóstico é maior e muitas vezes quando a malformação é identificada, a DN já foi emitida. Estudo realizado em 2006 no Município de São Paulo por GEREMIAS et al. (2009), observou esse mesmo resultado nas MFCs registradas nas DNs, porém após vinculação com dados das DOs essas informações foram recuperadas (pela causa básica de morte), o que pode 
ocorrer devido ao tempo de internação do RN no hospital e mais tempo para diagnóstico (GEREMIAS et al., 2009). Houve sensível melhora do preenchimento da variável presença de malformações congênitas na DN: em 2000/01, no MSP, essa informação estava ausente em quase $30 \%$ das DNs e, no primeiro semestre de 2008, estava ausente em menos de $10 \%$. A melhoria é resultado do esforço empreendido pela Secretaria de Vigilância em Saúde - Ministério da Saúde (SVS/MS) e Secretaria Municipal de Saúde - São Paulo (SMS/SP) por meio de treinamento frequente (SES, 2007).

A completitude das DOs neonatais e fetais foi ruim ou regular para a maior parte das variáveis à exceção do peso ao nascer e duração da gestação, tanto nos hospitais SUS como nos hospitais não-SUS. Os resultados obtidos são semelhantes aos encontrados em estudo realizado em Blumenau (TIRAJU e BITTENCOURT, 1998).

As variáveis estudadas em sua maioria são comuns à DN e DO. A ausência de registro de dados nas DOs neonatais inicialmente apresenta-se como incoerente, uma vez que os mesmos dados foram preenchidos nas respectivas DNs, considerando a pequena proporção de transferência de recém-nascidos para outros hospitais. Porém, a diferença de completitude pode ser resultante de diferenças do fluxo desses documentos nos hospitais e do momento em que as declarações são preenchidas.

Os dados obtidos mostraram que em todos os hospitais a causa de morte é preenchida exclusivamente pelos médicos. Entretanto, no preenchimento das demais variáveis relativas aos óbitos neonatais e fetais há participação dos profissionais que trabalham na área administrativa dos hospitais. Cabe lembrar que a Resolução no 1.779 do Conselho Federal de Medicina prevê em seu artigo $1^{\circ}$ que "O preenchimento dos dados constantes na Declaração de Óbito é da responsabilidade do médico que atestou a morte".

Estudo realizado no Rio de Janeiro em 1990 já mostrava que os médicos preenchiam a causa de morte, enquanto as demais informações eram frequentemente preenchidas por outros profissionais (NIOBEY et al., 1990). A semelhança de 
resultados indica que não houve grandes mudanças na rotina de preenchimento das declarações de óbito desde os anos 1990. Como os médicos têm obrigatoriedade legal para o preenchimento desse documento, são eles que recebem treinamento. $\mathrm{O}$ preenchimento das DOs por profissionais que não foram treinados pode gerar dúvidas e, consequentemente, interferir na completitude e fidedignidade dos dados.

Para emissão das DOs neonatais e fetais é necessário recuperar as informações cadastrais maternas, tarefa realizada pelo pessoal administrativo dos hospitais. Não se observou distinção dos responsáveis pelo preenchimento das DOs neonatais entre os hospitais SUS e não-SUS, o que indica que essa é uma prática frequente nos estabelecimentos hospitalares no MSP. O preenchimento das variáveis relativas às características maternas foi mais frequentemente realizado pelos funcionários do setor administrativo, do que para as informações relativas à gestação/parto e recém-nascido.

Nos hospitais SUS há elevada proporção de encaminhamento dos fetos para o SVO para a emissão da DO, enquanto que nos hospitais não-SUS esta proporção é bem menor. Tal diferença pode ser creditada à rotina de trabalho nos hospitais, pois enquanto na rede privada de hospitais boa parte dos partos é realizada pelos obstetras que acompanharam a gestação, na rede SUS os médicos que realizam o parto não acompanharam o pré-natal da gestante e como a maior parte dos óbitos fetais são anteparto, muitos médicos indicam o SVO para a emissão da DO (ALMEIDA et al., 2011).

Com relação às fontes de dados utilizadas para o preenchimento da DO, observou-se que os documentos hospitalares constituem-se como a principal fonte de informação para as variáveis relativas à gestação/parto e RN. Alguns hospitais utilizaram a DN como fonte de dados para algumas variáveis, sugerindo que seu emprego poderia resultar no aprimoramento do preenchimento da DO neonatal.

Verificou-se que há o emprego de outras fontes além do prontuário para obtenção de dados (verbal ou observação), tanto para nascimentos quanto para os óbitos neonatais e fetais nos hospitais. O uso dessas fontes resultou em estratégia 
mais efetiva para a obtenção de dados no SINASC que no SIM. Do ponto de vista da operacionalidade de um sistema de informação, a padronização da fonte de obtenção de dados e dos profissionais responsáveis é o caminho mais adequado para se assegurar a qualidade da informação (SOLOMON, 1991). A ausência de padronização das fontes dificulta a recuperação e a validação dos dados registrados nos sistemas de informação (SOLOMON et al., 1991; PIPER et al., 1993).

A elevada completitude observada no SINASC também pode ser creditada à descentralização da produção das informações nos hospitais. No Município de São Paulo as DNs são digitadas nos hospitais, existindo assim um comprometimento direto da unidade produtora de dados com a operação do sistema. Além disto, a Secretaria Municipal de Saúde, por meio das suas instâncias regionais, desenvolve importante papel de apoio junto aos hospitais na operação do sistema.

Outro fator importante para qualidade do registro de dados nos sistemas de informação é o treinamento frequente visando à correção de possíveis dúvidas existentes. A SMS/SP tem promovido treinamentos frequentes e estabeleceu em 2010 o selo SINASC ${ }^{2}$ como forma de incentivar os hospitais nas boas práticas do sistema.

Por um lado, a responsabilidade dos serviços de saúde pela operação do sistema estabelece outro vínculo com a produção de dados, pois é possível gerar relatórios trazendo uma retroalimentação para as fontes produtoras da informação. Por outro lado, para viabilizar a operação do sistema no nível local foi necessário realizar treinamentos frequentes, conforme relatado nas entrevistas, o que pode ter contribuído para a maior completitude da DN.

A menor completitude das variáveis das DOs fetais e neonatais pode também ser atribuída a diferenças no plano simbólico. Enquanto a DN será utilizada para o registro de um novo indivíduo, as DOs neonatais e fetais representam uma perda para a sociedade e para o sistema de saúde. Alguns autores (ALMEIDA et al.,

2 Prefeitura do Município de São Paulo. Secretária Municipal de Saúde. Coordenação de Epidemiologia e Informação - CEInfo. Manual do Selo SINASC 2010. 
2011; FROEN et al., 2009; NIOBEY et al, 1990) indicam existir relutância dos profissionais de saúde em relatar desfechos desfavoráveis, o que também pode explicar a ausência de registro de dados nas DOs.

O SIM é operado pela SMS-MSP, que recebe as informações provenientes do Serviço Funerário Municipal e cobre os eventos ocorridos no MSP. O Programa de Aprimoramento do Sistema de Informação de Mortalidade (PRO-AIM) da SMSSP trouxe enormes benefícios para a redução dos registros das causas de morte mal definidas no MSP, porém há um distanciamento maior da produção da informação e operação do sistema do que o observado no SINASC. Tal fato pode levar a uma retroalimentação menos eficiente para os hospitais, resultando na menor aderência dos profissionais de saúde envolvidos na produção destes dados, que aqueles envolvidos na operação do SINASC. As entrevistas também relataram que os treinamentos para o preenchimento da DO são pouco frequentes. Cabe comentar também que este é dirigido apenas aos médicos, sendo que na prática, uma parcela das variáveis é preenchida pelo pessoal administrativo dos hospitais. Os fatos associados ao maior distanciamento da operação do sistema podem esclarecer a menor completitude das DOs perinatais.

O pequeno retorno das informações perinatais já trabalhadas para as unidades produtoras de dados (hospitais), pode também contribuir para o pior preenchimento das DOs porque muitos profissionais não visualizam o potencial de análise dos dados registrados nesses documentos. GOULD (1999) aponta que na medida em que houver um maior envolvimento dos clínicos na produção dessas informações, seguindo as definições dos eventos e gerando informações mais completas e acuradas, irão contribuir para o seu aprimoramento e ampliar o potencial uso destas informações.

Outro problema que está presente na produção dessas informações é a duplicidade de registros de dados existente nos hospitais SUS. Grande parte das variáveis que compõem os formulários das Dos neonatais e fetais e DNs também faz parte dos formulários das AIH (Autorização de Internações Hospitalares), contudo, ainda não há um aplicativo para recuperar essas informações que são transcritas 
manualmente para a DN ou DO fetal e neonatal, posteriormente são redigitadas gerando uma duplicidade de registro de dados desnecessária. Fato semelhante ocorre nos hospitais não-SUS de alta complexidade que possuem sistemas próprios de informações hospitalares. O emprego de um aplicativo poderia recuperar essas informações, reduzindo o custo e dando maior agilidade para a sua produção.

A baixa completitude de variáveis como idade materna, paridade e escolaridade impede o cálculo de indicadores específicos de mortalidade, sendo necessário recorrer ao uso de técnicas de linkage (RIBEIRO et al., 2009; ALMEIDA e MELLO JORGE, 1996) para obtê-los, o que dificulta seu emprego no nível local e implica em custos adicionais para sua obtenção.

\section{CONCLUSÕES}

Verificou-se que há o emprego de outras fontes, além do prontuário, para obtenção de dados (verbal ou observação), tanto para nascimentos quanto para os óbitos neonatais e fetais nos hospitais. O uso dessas fontes para a obtenção de dados resultou em estratégia mais efetiva no SINASC do que no SIM.

Os resultados obtidos sobre as fontes de dados mais frequentemente empregadas e dos responsáveis pelo preenchimento das DNs e das DOs neonatais e fetais poderá contribuir para o desenvolvimento de estratégias de treinamento junto aos hospitais para o aprimoramento das informações perinatais disponíveis no SIM e SINASC e a geração de indicadores específicos.

Esses achados poderão também contribuir para que os gestores hospitalares desenvolvam atividades para rever e/ou aprimorar os processos de preenchimento destes documentos, garantindo maior segurança e confiabilidade das informações. 


\section{REFERÊNCIAS}

Almeida MF, Mello-Jorge MHP. O uso da técnica de "linkage" de sistemas de informação em estudos de coorte sobre mortalidade neonatal. Rev Saúde Pública. 1996; 30:141-7.

Almeida MF, Alencar GP, Novaes MDH, Rodrigues LC. Mortalidade neonatal no Município de São Paulo: influência de peso ao nascer e de fatores sóciodemográficos e assistenciais. Rev. bras. epidemiol. 2002;5(1):62-76.

Almeida MF. Debate sobre o artigo de Hillegonda Maria Dutilh Novaes. Cad. Saúde Pública. 2004;20(2):S167-S168.

Almeida MF, Alencar GP, França Jr I, Novaes HM, Siqueira AAF, Schoeps D, Campbell O, Rodrigues RC. Validade das informações das declarações de nascidos vivos com base em estudo de caso-controle. Cad. Saúde Pública. 2006;22(3):643652.

Almeida MF, Alencar GP, Novaes HMD, Ortiz LP. Sistemas de informação e mortalidade perinatal: conceitos e condições de uso em estudos epidemiológicos. Rev. bras. epidemiol. 2006; 9(1):56-68.

Almeida MF, Alencar GP, Schoeps D. Sistema de Informações sobre Nascidos Vivos - SINASC: uma avaliação de sua trajetória. In: Ministério da Saúde. (Org.). Sistemas de Informação em Saúde. Brasilia: Editora MS; 2009.

Almeida MF, Alencar GP, Schoeps D, Minuci EG, Silva ZP, Ortiz LP, Novaes $\mathrm{MDH}$, Alencar AP, Raspantini PR, Santos PC. Qualidade das informações registradas nas declarações de óbito fetal em São Paulo, SP. Rev. SaúdePública. 2011;4(5):845-853.

Arts DG, De Keizer NF, Scheffer GJ. Defining and improving data quality in medical registries: a literature review, case study, and generic framework. J AmMedInform Assoc. 2002;9(6):600-11.

Costa JMBS, Frias PG. Avaliação da completitude das variáveis da Declaração de Nascido Vivo de residentes em Pernambuco, Brasil, 1996 a 2005. Cad.SaúdePública. 2009;25(3):613-624.

Froen JF, Gordijn SJ, Abdel-Aleem H, Bergsjo P, Betran A, Duke CW, et al. Makingstillbirths count, making numbers talk: issues in data collection for stillbirths. BMC PregnancyChildbirth.2009;9:58. 
GeremiasALAlmeida MF, Flores LPO. Avaliação das declarações de nascido vivo como fonte de informação sobre defeitos congênitos. Rev. bras. epidemiol. 2009; 12(1):60-68.

Gould JB. Vital records for quality improvement. Pediatrics. 1999;103;278-290.

Guerra FAR, Lerena JC, Gama SGN, Cunha CB, Theme MMF. Confiabilidade das informações das declarações de nascido vivo com registro de defeitos congênitos no Município do Rio de Janeiro,Brasil, 2004. Cad. Saúde Pública. 2008; 24(2):438-446.

Mello Jorge MHP, Gotlieb SLD, Soboll MLMS, Almeida MF, Latorre MRDO. Avaliação do sistema de informação sobre nascidos vivos e o uso de seus dados em epidemiologia e estatísticas de Saúde. Rev. Saúde Pública. 1993;27;1-46.

Mello Jorge MHP de, Laurenti R, Gotlieb SLD. O Sistema de informações sobre Mortalidade - SIM: Concepção, Implantação e Avaliação. In: Ministério da Saúde. (Org.). Sistemas de Informação em Saúde. Brasilia: Editora MS; 2009.

Niobey FML, Cascão AM, Duchiade MP, Sabroza PC. Qualidade do preenchimento de atestados de óbitos de menores de um ano na região metropolitana do Rio de Janeiro. Rev. Saúde públ. 1990;24(4):311-8.

Novaes, MHD. Da produção à avaliação de tecnologias dos sistemas de saúde: desafios do século XXI. Rev. SaúdePública. 2006;40:133-140.

Osterman MJK, Joyce AM, Menacker F. Expanded Health Data From the New Birth Certificate, 2006. National Vital Statistics Rep. 2009;58(5):1-21.

Piper JM, Mitchell JE, Snowden M, Hall C, Adams M, Taylor P. Validation of 1989 Tenessee birth certificates using maternal and newborn hospital records. Am. J. Epidemiol. 1993;137:758-68.

Ribeiro AM, Guimarães MJ, Lima MC, Sarinho SW, Coutinho SB. Fatores de risco para mortalidade neonatal em crianças com baixo peso ao nascer. Rev. Saúde Pública. 2009;43(2):246-255.

Romero DE, Cunha CB. Avaliação da qualidade das variáveis sócio-econômicas e demográficas dos óbitos de crianças menores de um ano registrados no Sistema de Informações sobre Mortalidade do Brasil (1996/2001). Cad. Saúde Pública. 2006; 22(3):673-684.

Silva ZP, Almeida MF, Flores LPO, Alencar GP, Alencar AP, Schoeps D, Minuci EG, Novaes HM. Morte neonatal precoce segundo complexidade hospitalar e rede SUS e não-SUS na Região Metropolitana de São Paulo, Brasil. Cad. SaúdePública. 2010;26(1):123-134. 
Solomon DJ, Henry RC, Hogan JG, Van Amburg GH, Taylor J. Evaluation and implementation of public health registries. Public Health Rep.1991;106:141-150.

Terris DD, Litaker DG, Koroukian SM. Health state information derived from secondary databases is affected by multiple sources of bias. JournalofClinicalEpidemiology. 2007;60:734-741.

Tiaraju SHE, Bittencourt RM. Avaliação da qualidade das informações relativas aos óbitos em menores de um ano em Blumenau,1998. Rev. Bras. Saúde Mater. Infant.2003;3(1):75-83.

Zeitlin J, Wildman K, Bréart G, Alexander S. Selecting an indicator set for monitoring and evaluating perinatal health in Europe: criteria, methods and results from the PERISTAT project. Eur J ObstetGynecolReprod Biol. 2003;111:S5-S14. 
TABELAS

Tabela 1 - Completitude (\%) das variáveis das Declarações de Nascido Vivo (DN), de Óbito Neonatal e de Óbito Fetal (DO) por tipo de hospital do parto, Município de São Paulo, $1^{\circ}$ semestre 2008.

\begin{tabular}{|c|c|c|c|c|c|c|}
\hline \multirow{2}{*}{ Variáveis } & \multicolumn{2}{|c|}{$\mathrm{DN}(\mathrm{N}=19994)$} & \multicolumn{2}{|c|}{$\begin{array}{c}\text { DO neonatal } \\
19994)\end{array} \quad(\mathrm{N}=$} & \multicolumn{2}{|c|}{ DO fetal $(\mathrm{N}=271)$} \\
\hline & $\begin{array}{c}\text { SUS } \\
(\mathrm{n}=14787)\end{array}$ & $\begin{array}{l}\text { Não-SUS } \\
(\mathrm{n}=5207)\end{array}$ & $\begin{array}{c}\text { SUS } \\
(\mathrm{n}=14787)\end{array}$ & $\begin{array}{l}\text { Não-SUS } \\
(\mathrm{n}=5207)\end{array}$ & $\begin{array}{c}\text { SUS } \\
(\mathrm{n}=240)\end{array}$ & $\begin{array}{c}\text { Não-SUS } \\
(\mathrm{n}=31)\end{array}$ \\
\hline \multicolumn{7}{|l|}{ Mãe } \\
\hline Idade da Mãe & 95,2 & 97,7 & 49,7 & 48,8 & 62,5 & 35,5 \\
\hline $\begin{array}{l}\text { Escolaridade da } \\
\text { Mãe }\end{array}$ & 94,6 & 97,5 & 41,4 & 58,7 & 30,4 & 25,8 \\
\hline $\begin{array}{l}\text { Número de } \\
\text { Consultas }\end{array}$ & 94,5 & 97,7 & 100,0 & 91,5 & NSA & NSA \\
\hline $\begin{array}{l}\text { Filhos Nascidos } \\
\text { Vivos }\end{array}$ & 54,0 & 39,5 & 34,3 & 23,5 & 53,3 & 45,2 \\
\hline $\begin{array}{l}\text { Filhos Nascidos } \\
\text { Mortos }\end{array}$ & 5,0 & 2,6 & 31,4 & 5,9 & 37,1 & 38,7 \\
\hline $\begin{array}{l}\text { Gestação/Parto } \\
\text { Duração da } \\
\text { Gestação }\end{array}$ & 94,8 & 97,7 & 59,8 & 71,6 & 91,3 & 96,8 \\
\hline Tipo de Gravidez & 95,2 & 97,8 & 59,8 & 64,3 & 83,3 & 93,5 \\
\hline $\begin{array}{l}\text { Tipo de Parto } \\
\text { Recém } \\
\text { Nascido/Feto }\end{array}$ & 95,2 & 97,8 & 100,0 & 95,9 & 38,8 & 58,1 \\
\hline Peso ao nascer & 95,2 & 97,8 & 70,6 & 60,4 & 89,6 & 87,1 \\
\hline Raça/cor & 89,6 & 34,8 & 23,5 & 94,7 & 0,0 & 0,0 \\
\hline Apgar1 & 95,0 & 97,7 & NSA & NSA & NSA & NSA \\
\hline Apgar5 & 95,1 & 97,7 & NSA & NSA & NSA & NSA \\
\hline $\begin{array}{l}\text { Malformação } \\
\text { Congênita }\end{array}$ & 92,9 & 58,6 & 47,1 & 89,9 & NSA & NSA \\
\hline Sexo & 100,0 & 100,0 & 100,0 & 94,1 & 99,6 & 90,3 \\
\hline
\end{tabular}

NSA - Não se aplica 
Tabela 2 - Número de hospitais segundo responsáveis e fontes de dados para o preenchimento das Declarações de Nascidos Vivos, segundo variáveis, amostra de 14 hospitais do Município de São Paulo, 2009.

\begin{tabular}{|c|c|c|c|c|c|c|}
\hline \multirow[b]{2}{*}{ Variáveis } & \multicolumn{2}{|c|}{ Responsável } & \multicolumn{3}{|c|}{ Fontes } & \multirow[t]{2}{*}{ Total } \\
\hline & Administrativo & Enfermeira & $\begin{array}{c}\text { Documentos } \\
\text { Hosp/SIH }\end{array}$ & Observação & Verbal & \\
\hline Mãe & & & & & & \\
\hline Idade & 7 & 7 & 4 & 0 & 10 & 14 \\
\hline Escolaridade & 7 & 7 & 2 & 0 & 12 & 14 \\
\hline $\begin{array}{l}\mathrm{N}^{\circ} \text { filhos gestações } \\
\text { anteriores }\end{array}$ & 7 & 7 & 4 & 0 & 10 & 14 \\
\hline Gestação e parto & & & & & & \\
\hline $\begin{array}{l}\text { Duração da } \\
\text { gestação }\end{array}$ & 7 & 7 & 12 & 0 & 2 & 14 \\
\hline Tipo da gravidez & 7 & 7 & 10 & 2 & 2 & 14 \\
\hline Tipo de parto & 7 & 7 & 9 & 5 & 0 & 14 \\
\hline $\begin{array}{l}\mathrm{N}^{\circ} \text { consultas de } \\
\text { pré-natal }\end{array}$ & 7 & 7 & 8 & 0 & 6 & 14 \\
\hline Recém-nascido & & & & & & \\
\hline Sexo & 7 & 7 & 10 & 4 & 0 & 14 \\
\hline Peso ao nascer & 7 & 7 & 10 & 4 & 0 & 14 \\
\hline Raça/cor & 7 & 7 & 1 & 3 & 10 & 14 \\
\hline Apgar & 7 & 7 & 9 & 5 & 0 & 14 \\
\hline Presença MFC & 7 & 7 & 7 & 7 & 0 & 14 \\
\hline
\end{tabular}


Tabela 3- Número de hospitais segundo responsável, fonte de dados e variáveis para o preenchimento da DO-neonatal, amostra de 14 hospitais do Município de São Paulo, 2009.

\begin{tabular}{|c|c|c|c|c|c|c|c|}
\hline \multirow[b]{2}{*}{ Variáveis } & \multicolumn{2}{|c|}{ Responsável } & \multicolumn{3}{|c|}{ Fontes } & \multirow[b]{2}{*}{$\mathrm{DN}$} & \multirow[t]{2}{*}{ Total } \\
\hline & Administrativo & Médico & $\begin{array}{c}\text { Documentos } \\
\text { Hosp/SIH }\end{array}$ & Observação & Verbal & & \\
\hline Mãe & & & & & & & \\
\hline Idade & 12 & 2 & 9 & 0 & 5 & 0 & 14 \\
\hline Escolaridade & 12 & 2 & 9 & 0 & 4 & 1 & 14 \\
\hline $\mathrm{N}^{\mathrm{o}}$ filhos & & & & & & & \\
\hline $\begin{array}{l}\text { gestações } \\
\text { anteriores }\end{array}$ & 9 & 5 & 12 & 0 & 2 & 0 & 14 \\
\hline $\begin{array}{l}\text { Gestação e } \\
\text { parto }\end{array}$ & & & & & & & \\
\hline $\begin{array}{l}\text { Duração da } \\
\text { gestação }\end{array}$ & 8 & 6 & 12 & 0 & 2 & 0 & 14 \\
\hline Tipo da gravidez & 8 & 6 & 13 & 0 & 0 & 0 & 14 \\
\hline Tipo de parto & 8 & 6 & 13 & 1 & 0 & 0 & 14 \\
\hline Recém-nascido & & & & & & & \\
\hline Sexo & 8 & 6 & 13 & 1 & 0 & 0 & 14 \\
\hline Peso ao nascer & 8 & 6 & 13 & 1 & 0 & 0 & 14 \\
\hline Raça/cor & 11 & 3 & 10 & 1 & 1 & 2 & 14 \\
\hline Tipo de óbito & 9 & 5 & 14 & 0 & 0 & 0 & 14 \\
\hline $\begin{array}{l}\text { Morte em } \\
\text { relação ao parto }\end{array}$ & 8 & 6 & 13 & 1 & 0 & 0 & 14 \\
\hline $\mathrm{N}^{\mathrm{o}} \mathrm{DN}$ & 12 & 2 & 9 & 0 & 0 & 4 & 14 \\
\hline Causa de morte & 0 & 14 & NSA & 4 & NSA & NSA & 14 \\
\hline
\end{tabular}

NSA - Não se aplica 
Tabela 4 - Número de hospitais segundo responsáveis, fonte de dados e variáveis para o preenchimento da DO fetal amostra de 9* hospitais do Município de São Paulo, 2009.

\begin{tabular}{|c|c|c|c|c|c|c|c|}
\hline \multirow[b]{2}{*}{ Variáveis } & \multicolumn{3}{|c|}{ Responsável } & \multicolumn{3}{|c|}{ Fonte } & \multirow[b]{2}{*}{ Total } \\
\hline & Administrativo & Médico & Enfermeira & $\begin{array}{c}\text { Doc. } \\
\text { Hosp/SIH }\end{array}$ & Observação & Verbal & \\
\hline \multicolumn{8}{|l|}{ Mãe } \\
\hline Idade mãe & 5 & 3 & 1 & 6 & 0 & 3 & 9 \\
\hline Escolaridade & 5 & 3 & 1 & 6 & 0 & 3 & 9 \\
\hline $\begin{array}{l}\mathrm{N}^{\text {o }} \text { filhos gestações } \\
\text { anteriores } \\
\text { Gestação/parto }\end{array}$ & 3 & 6 & 0 & 6 & 0 & 3 & 9 \\
\hline $\begin{array}{l}\text { Duração da } \\
\text { gestação }\end{array}$ & 3 & 6 & 0 & 7 & 0 & 2 & 9 \\
\hline Tipo da gravidez & 3 & 6 & 0 & 8 & 1 & 0 & 8 \\
\hline Tipo de parto & 3 & 6 & 0 & 8 & 1 & 0 & 9 \\
\hline \multicolumn{8}{|l|}{ Feto } \\
\hline Sexo & 5 & 3 & 1 & 8 & 1 & 0 & 9 \\
\hline Peso ao nascer & 3 & 6 & 0 & 8 & 1 & 0 & 9 \\
\hline Raça/cor & 6 & 2 & 1 & 8 & 1 & 0 & 9 \\
\hline Tipo de óbito & 5 & 3 & 1 & 9 & 0 & 0 & 9 \\
\hline $\begin{array}{l}\text { Morte em relação } \\
\text { ao parto }\end{array}$ & 3 & 6 & 0 & 8 & 1 & 0 & 9 \\
\hline Causa de morte & 0 & 9 & 0 & - & - & - & \\
\hline
\end{tabular}

*Foram excluídos 5 hospitais que relataram que encaminham os óbitos fetais para o SVO. 
Artigo 2 - REPRESENTAÇÕES SOCIAIS DE MÉDICOS OBSTETRAS E NEONATOLOGISTAS QUE ATUAM EM HOSPITAIS SUS E NÃO-SUS NO MUNICÍPIO DE SÃO PAULO SOBRE DECLARAÇÃO DE ÓBITO FETAL E NEONATAL PRECOCE.

Schoeps $\mathrm{D}^{1}$, Almeida $\mathrm{MF}^{1}$, Lefevre $\mathrm{F}^{2}$

${ }^{1}$ Departamento de Epidemiologia da Faculdade de Saúde Pública da Universidade de São Paulo.

${ }^{2}$ Departamento de Prática de Saúde Pública da Faculdade de Saúde Pública da Universidade de São Paulo.

\section{Resumo}

Introdução: É crescente o uso das informações da Declaração de Óbito (DO) para estudos epidemiológicos; contudo, a completitude insatisfatória de algumas variáveis ainda é impedimento para determinadas análises. O preenchimento das DOs é de responsabilidade dos médicos que estão inseridos em instituições que apresentam diferenças na estrutura, organização e nos tipos de serviços de saúde o que acaba por influenciar na rotina do trabalho médico e consequentemente no registro de dados.

Objetivo: Avaliar a representação social dos médicos em relação à coleta das informações e preenchimento da DO.

Métodos: Foram realizadas 25 entrevistas com médicos obstetras e neonatologistas em 15 hospitais, com e sem vínculo com o SUS, no Município de São Paulo, em 2009. As análises foram realizadas utilizando a metodologia qualitativa com a técnica do Discurso do Sujeito Coletivo.

Resultados: As diferentes funções e cargos ocupados pelos médicos entrevistados implicam em diferenças de representação social que estes possuem a respeito das DOs. Em relação ao preenchimento, nem sempre o médico que atende o paciente é aquele que preenche o documento e a maioria recebe auxílio de outros profissionais para preenchimento dos campos relativos à identificação da mãe. Foram relatadas dificuldades em definir a causa e evolução do óbito e quando há necessidade de consultar outras fontes de informação. A maior parte dos entrevistados teve treinamento para preenchimento da DO apenas durante o curso médico.

Conclusões: Para que os dados preenchidos nas DOs tenham melhor qualidade é necessário que os registros e informações hospitalares, como cadastro do paciente e prontuário, sejam identificados de forma mais clara. Atribuir aos profissionais que preenchem esses documentos treinamento podem ser também estratégias dos hospitais para melhorar a qualidade destes dados.

Palavra-chave: Sistema de Informações em Saúde; Declaração de Óbito; Representação Social; Registro Médico 


\section{SOCIAL REPRESENTATION OF OBSTETRICIANS AND NEONATOLOGISTS WORKING IN SUS AND NON-SUS HOSPITALS IN THE CITY OF SAO PAULO ON FETAL AND EARLY NEONATAL DEATH DECLARATIONS.}

Schoeps $\mathrm{D}^{1}$, Almeida $\mathrm{MF}^{1}$, Lefevre $\mathrm{F}^{2}$

1 Department of Epidemiology, School of Public Health, University of Sao Paulo.

2 Department of Public Health Practice, School of Public Health, University of Sao Paulo.

\section{Summary}

Introduction: It is increasing the use of information on death declaration (DO) for epidemiological studies; however, the unsatisfactory completeness of some variables still interferes in the results of its analysis. The completion of the DOs is the responsibility of doctors who are embedded in institutions that differ in structure, organization and types of health services, which influence the routine medical work and consequently the data record.

Objective: To assess the social representation of doctors in relation to data collection and completion of the DO.

Methods: We conducted 25 interviews with obstetricians and neonatologists in 15 hospitals (SUS and non-SUS), in São Paulo in 2009. Analyses were performed using qualitative methodology with the technique of Collective Subject Discourse.

Results: The different roles and positions held by the physicians interviewed may result in differences of social representation that they have about the DOs. Regarding the fulfillment, the doctor who assists the patient is not always the one who fills the document and most receive assistance from other professionals to fill the variables related to the identification of the mother. It has been reported difficulties in defining the cause and evolution of death and to consult other sources of information when needed. Most respondents had training to fill the DO only in medical school.

Conclusions: To improve the quality of the data filled in DO it is necessary that the records and hospital information, such as patient records and medical records, are more clearly identified. Assign the professionals who fill these documents and training them can provide hospitals strategies to improve data quality.

Keywords: Health Information System, DeathCertificate, Social Representation, Medical Record 


\section{INTRODUÇÃO}

O Sistema de Informação sobre Mortalidade (SIM) foi criado em 1975 e representou um avanço na concepção dos sistemas de informação ao implantar um instrumento individual padronizado e, em parte, pré-codificado para a coleta de dados com a introdução da Declaração de Óbito (DO) - segundo normas propostas pela Organização Mundial de Saúde (BALDIJÃO, 1992). A DO apresenta as variáveis organizadas em blocos (Anexo I). Bloco I: identificação do cartório de registro civil. Bloco II: variáveis que identificam o tipo de óbito (fetal ou não), data e hora de ocorrência, e variáveis descritivas das características da mãe. Bloco III: variáveis de endereço do RN. Bloco IV: informações sobre o local onde ocorreu o óbito. Bloco V: variáveis sobre óbito fetal ou menor que um ano. Bloco VI: identificação das condições e causas que provocaram o óbito. Bloco VII: identificação básica sobre o médico que assina a DO. Bloco VIII: se refere às causas externas de óbito. O Bloco IX: é destinado a óbitos em localidades onde não exista médico, nesse caso, deve ser preenchido pelo cartório de Registro Civil e deverá constar o declarante e testemunhas.

Como consta nos manuais de preenchimento e procedimentos do Conselho Federal de Medicina ${ }^{1}$ e do Ministério da $S$ aúde $^{2}$, o médico responsável pelo atendimento deve preencher os dados de identificação do paciente com base em um documento da pessoa falecida, registrar os dados sempre com letra legível e registrar as causas de morte obedecendo as normas internacionais. Ainda, segundo os manuais, o médico tem responsabilidade ética e jurídica pelo preenchimento e assinatura da DO e, portanto, para todas as informações registradas no documento que não deve ser assinada antes de ser feita uma revisão de todos os campos.

\footnotetext{
${ }^{1}$ Brasil. Ministério da Saúde. Declaração de óbito: documento necessário e importante. Conselho Federal de Medicina. Brasília: MS: 2006.

2 Brasil. Ministério da Saúde. Secretaria de Vigilância em Saúde. Departamento de Análise de Situação de Saúde. Manual de Instruções para o preenchimento da Declaração de Óbito. Brasília: MS: 2009.
} 
A DO possui finalidade legal para emissão da certidão de óbito e é crescente o uso das informações para estudos epidemiológicos. Com o aumento de cobertura e informatização crescente, há mais facilidade de acesso às bases de dados, o que teoricamente permitiria a obtenção de indicadores específicos, tais como a mortalidade perinatal segundo idade da mãe, tipo de gravidez, peso ao nascer e duração da gestação, que se constituem em ferramentas indispensáveis para seu monitoramento, da assistência ao parto e ao recém-nascido, à semelhança do que é praticado de forma rotineira na União Europeia (ZEITLIN et al., 2003). Entretanto, uma das dificuldades encontradas tem sido a completitude insatisfatória de algumas variáveis, impedindo o cálculo desses indicadores (ALMEIDA et al.,2006).

Estudo de revisão de qualidade dos dados e métodos aplicados para avaliação dos sistemas de informação em saúde realizado por LIMA et al. (2009), apontou que $48 \%$ das publicações a respeito dos sistemas de informação em saúde se referem ao SIM, e ainda que $90 \%$ avaliaram a qualidade dos dados considerando quatro dimensões: confiabilidade, completitude, cobertura e validade.

Um dos elementos críticos para o sucesso de um sistema de informações é o controle de qualidade dos procedimentos nas fases de coleta e processamento dos dados (ARTS et al., 2002; SOLOMON et al., 1991). A qualidade da informação vai depender, sobretudo, da adequada coleta de dados gerados no local onde ocorre o evento. Os serviços de saúde se constituem como a principal fonte de dados do SIM e a qualidade da informação depende do registro das informações hospitalares (TERRIS et al., 2007). Fatores institucionais, tais como o tipo de serviço de saúde, a estrutura e a organização dos serviços de saúde podem influenciar o registro de dados, bem como o suporte administrativo entre outros fatores. Além desses fatores, também podem ser importantes para qualidade o grau de informatização dos dados, o nível de descentralização da operação dos sistemas de informação e as atividades de gestão destes sistemas (NOVAES, 2006), tais como o treinamento e as atividades rotineiras de controle da qualidade das informações em todas as etapas de sua produção. 
A coleta de dados de óbitos ocorre predominantemente nos hospitais, que no Brasil formam uma rede de cerca de 6.400 estabelecimentos inscritos no Cadastro Nacional de Estabelecimentos de Saúde, ou seja, uma extensa rede de unidades de coleta desses dados. No entanto, apesar de existir uma concentração dos eventos vitais nos hospitais, são poucos os estudos que avaliam como as informações são produzidas nesses ambientes (COCHRAN, 1972).

Segundo ARTS et al. (2002), para assegurar a qualidade das informações é necessário garantir algumas atividades na etapa anterior à coleta de dados, como por exemplo, um protocolo de coleta com definições claras, treinamento e motivação do profissional responsável pelo preenchimento das informações. Tendo em vista esse aspecto e os diversos aspectos envolvidos para compreensão do registro das informações foi realizado estudo com abordagem qualitativa objetivando compreender como se dá o registro no grupo social que o realiza e a instituição produtora da informação obtendo-se uma representação contextualizada socialmente e não apenas buscando a generalização de resultados (SOUZA E ZIONE, 2003).

Os médicos são os responsáveis pelo preenchimento das DOs e como já foi mencionado, diferenças institucionais, estrutura e organização do tipo de serviços de saúde podem interferir na rotina do trabalho médico e consequentemente no registro de dados nas DOs; por essa razão foram realizadas entrevistas com médicos para avaliar sua representação social das informações existentes sobre óbitos fetais e neonatais em uma amostra de hospitais SUS e não-SUS no Município de São Paulo (MSP).

\section{MÉTODOS}

\subsection{HOSPITAIS DO ESTUDO}


O estudo foi realizado no âmbito da pesquisa ${ }^{3}$ "Avaliação da Qualidade da Informação sobre Mortalidade Perinatal no Município de São Paulo" que considerou os hospitais como unidades amostrais, sendo sorteados por amostragem estratificada proporcional ao número de óbitos perinatais em cada estabelecimento (SILVA et al., 2010).

Os hospitais sorteados são representativos das diferentes entidades mantenedoras que prestam serviço ao SUS, contemplando hospitais filantrópicos, estaduais, municipais e organizações sociais e de saúde.

\subsection{CARACTERÍSTICAS DA POPULAÇÃO DE ESTUdO E AS ENTREVISTAS}

Entre os 17 hospitais que participaram do estudo, foram realizadas entrevistas com médicos em 15 deles em 2009. As entrevistas semi estruturadas com roteiro pré-definido composto por questões abertas tiveram como objetivo captar a representação social que possuem sobre o SIM e como o preenchimento desses documentos está inserido no trabalho cotidiano.

Definiu-se como critério entrevistar médicos diretamente envolvidos na rotina de preenchimento das DOs fetais e neonatais indicados pela coordenação dos hospitais. Para atingir esse objetivo, antes do inicio das entrevistas, foi perguntado aos médicos obstetras e pediatras/neonatologistas se já haviam preenchido pelo menos uma vez os documentos. Em um hospital particular uma médica obstetra nunca havia preenchido o documento e por este motivo a entrevista não fora realizada.

\footnotetext{
${ }^{3}$ FAPESP/PPSUS - Processo no: 2006/61304-3
} 
No total foram entrevistados 24 médicos, sendo seis médicos em hospitais não-SUS e 19 em hospitais do SUS. A pesquisa foi previamente aprovada pelos Comitês de Ética em Pesquisa da Faculdade de Saúde Pública - USP/SP, dos hospitais e da Secretária Municipal de Saúde da prefeitura Municipal de São Paulo. Antes das entrevistas foi lido e assinado Termo de Consentimento Livre Esclarecido, garantindo anonimato dos médicos e dos hospitais nos quais a pesquisa foi realizada.

O roteiro de entrevista foi definido por perguntas que buscaram identificar aspectos relatados por esses profissionais a respeito de treinamento/capacitação sobre o preenchimento dos documentos, e também como age o profissional quando tem alguma dúvida ou dificuldade para o preenchimento dos documentos, bem como conhecer a ideia que o profissional de saúde possui sobre as finalidades/usos das DOs. As entrevistas foram realizadas nos hospitais, gravadas e transcritas para análise das informações.

\subsection{ANÁLISE DOS DADOS: DISCURSO DO SUJEITO COLETIVO}

Foi utilizada a técnica do Discurso do Sujeito Coletivo (DSC), procedimento metodológico de natureza qualiquantitativa que busca superar os impasses das pesquisas tradicionais de representação social, recuperando na escala coletiva a natureza discursiva e argumentativa do pensamento. A opinião é obtida por meio de questões abertas propiciando ao entrevistado a geração de um depoimento discursivo. Cada questão gera um número de diferentes posicionamentos, ou seja, de distintos DSCs que resultam de uma agregação de diferentes discursos ou extratos de discursos individuais que representam sentido semelhante (LEFEVRE e LEFEVRE, 2003).

O discurso de cada entrevistado pode conter uma ou mais ideias a respeito da questão estabelecida. Para o processo de análise são atribuídas expressões chaves a 
cada ideia para que, então, seja possível agrupar as expressões chave de sentido semelhante e criar categorias de respostas. Com as categorias de ideias compartilhadas e seus respectivos discursos estabelecidos torna-se possível a análise qualitativa dos depoimentos de ideias compartilhadas em cada uma das questões. As somas dos resultados correspondem ao número de ideias em cada categoria e não ao número de indivíduos entrevistados.

A pesquisa foi analisada empregando o método do Discurso do Sujeito Coletivo - DSC e do software Qualiquantisoft ${ }^{4}$ que possibilita, para cada questão, a construção de categorias de respostas nas quais observam-se as ideias ou representações compartilhadas entre os sujeitos que responderam à pesquisa (LEFEVRE e LEFEVRE, 2003; LEFEVRE e LEFEVRE, 2006).

Por meio da abordagem qualitativa os entrevistados expressam suas ideias e se posicionam sobre um tema expressando significados, motivos, aspirações, crenças, valores e atitudes, o que corresponde a um espaço mais profundo das relações, dos processos e dos fenômenos. Busca-se entender os fenômenos em termos de significados conferidos pelos entrevistados, entretanto a realidade objetiva não pode ser captada, busca-se então conhecer os significados por meio de representações. $\mathrm{O}$ indivíduo entrevistado não é apenas um produto das determinações sociais e nem um produto individual, pois as representações são sempre construções contextualizadas (SPINK, 1993).

\section{RESULTADOS}

As entrevistas foram realizadas com dez médicos ginecologistas/obstetras e 14 neonatalogistas com o objetivo de abranger as especificidades de preenchimento das declarações de óbitos fetais e neonatais. Em um hospital que possui serviço de

\footnotetext{
${ }^{4}$ SPi-Sales \& Paschoal informática. www.spi.com.br. Elaborado com base na teoria do DSC.
} 
setor de verificação de óbitos foi indicado o médico patologista responsável pelas necropsias. O número de entrevistas realizadas para cada especialidade variou de acordo com indicação dos hospitais. A maior parte dos médicos entrevistados (20) trabalhava também em outro hospital e cinco trabalhavam somente no hospital onde foi realizada a entrevista.

O trabalho dos médicos em outros hospitais pode implicar em uma rotina de preenchimento das DOs diferente daquelas abordadas durante as entrevistas, pois essa pode variar de acordo com cada serviço de saúde. E pode ainda gerar atitudes diferentes devido a diferentes contextos e situações de trabalho nos quais são preenchidas as DOs. Além disso, o trabalho em mais de um hospital indica que o profissional não tem exclusividade em um único serviço, podendo atender pacientes em diferentes horários e turnos, o que pode influenciar no preenchimento dos documentos dependendo do tempo disponível de acompanhamento para cada paciente.

Em relação à rotina de trabalho, 14 médicos atuavam exclusivamente na assistência aos pacientes e dez relataram exercer cargos de diretoria, coordenação ou pesquisa. $\mathrm{O}$ dia a dia de trabalho desses profissionais envolve além da prestação de assistência, a orientação de residentes. Participação em comitês foi relatada apenas por médicos de hospitais do SUS (Tabela 1).

As diferentes funções e cargos ocupados pelos médicos entrevistados podem implicar em diferenças nas representações sociais, que estes possuem a respeito das DOs. O médico plantonista tem com principal atribuição no seu dia a dia de trabalho a prestação de assistência, e o preenchimento dos documentos relativos ao paciente fazem parte desta rotina, mas não é seu foco principal. Enquanto o trabalho de coordenação ou diretoria clínica envolve além da assistência, a participação em comitês de mortalidade e pesquisas, onde parte das informações constantes da DO podem ser utilizadas, tendo assim uma representação social distinta desse documento. 
Ainda, com objetivo de identificar como o preenchimento dos documentos está inserido nas atribuições cotidianas, foi perguntado como o preenchimento das declarações de óbito fazia parte da rotina de trabalho (Tabela 2). Oito médicos de hospitais SUS e um não-SUS mencionaram encaminhamento de óbitos perinatais para o Serviço de Verificação de Óbitos ${ }^{5}$ (SVO). Para os médicos que preenchem os documentos, foram relatadas duas situações. A primeira, em um hospital não-SUS, o médico relatou que não recebe auxílio para o preenchimento e cada médico preenche os documentos relativos aos seus pacientes, pois não há uma equipe do hospital para esta atividade. Em contrapartida, foram relatadas situações nas quais os médicos recebem ajuda de outros profissionais dos hospitais para preenchimento dos documentos, por exemplo, descrevem que a "ficha" (DO) vem preenchida com a parte considerada como burocrática, ou seja, dados de identificação do paciente já preenchidos e que completam apenas a parte médica, que para esses profissionais são as causas do óbito. Assim, informações epidemiológicas como idade e paridade maternas são muitas vezes consideradas burocráticas.

Diferentes representações sociais foram extraídas dos discursos desses médicos. Os resultados serão apresentados por questões e destacados alguns discursos. Os comentários se referem a todos os discursos encontrados.

$\mathrm{Na}$ Tabela 3 encontram-se as ideais centrais relativas a pergunta: Você considera que existe dificuldade para preencher alguma informação? Qual (is)?

Em relação à categoria $\mathrm{A}$, em que seis médicos relataram não sentirem dificuldades, esta situação foi agrupada em subcategorias de respostas: A.1 - não tem dificuldades porque já possui experiência com o preenchimento e faz isso com naturalidade; A.2 - não possui dificuldade quando a causa do óbito é aparente; A.3 existe uma rotina no hospital de registro de informações que esboçam a evolução do paciente, o que torna mais fácil definir a causa de morte; A.4 - um médico relatou não ter dificuldade porque encaminha o óbito para o SVO.

\footnotetext{
${ }^{5}$ Serviço que disponibiliza exames necroscópicos para definição da causa do óbito quando o médico não consegue diagnosticar a causa com base no quadro clínico do paciente ou em informações registradas nos prontuários ou fichas médicas, nessas situações o SVO é responsável pela emissão da DO.
} 
Em contrapartida, segundo relato dos entrevistados, a necessidade de consultar outras fontes de informação (categoria D) é um dos fatores que mais dificulta o preenchimento dos documentos, conforme DSC dos médicos:

\footnotetext{
"Olha, você está falando da declaração de óbito como um todo né? Não é só o que corresponde ao médico, os itens do atestado de óbito, da parte burocrática, vamos dizer, observações que o médico consegue fazer, tipo, um paciente que você não acompanhou, a gente sente um pouco de dificuldade para alguns dados relacionados a mãe, escolaridade da mãe, se a mãe é casada, se não é casada, são esses pequenos itens que às vezes o obstetra não informa isso lá na ficha, ou o pediatra que atende a criança na sala de parto. A gente tem dificuldade de preencher esses dados, a respeito principalmente de escolaridade da mãe, idade, se tem pré-natal ou não, e tem o número de consultas para preencher. Se o paciente não trouxe nenhum cartão de pré-natal você precisa adivinhar, às vezes o paciente fez e não trouxe, às vezes o paciente realmente não fez e diz que não trouxe então aí torna-se de certa forma gestação de risco, se me chegar um paciente, por exemplo, com trinta semanas de gestação e ela falar que é nove meses aí você imagina que pode ser um retardo de crescimento, mas podia ser prematuro, tem que olhar com cuidado, repetir os exames de novo no pronto socorro, ultrassom, pra avaliar se não é um retardo então dá um pouco mais de trabalho nesse sentido. São alguns campos que tem na declaração de óbito e às vezes os colegas são bem econômicos nos prontuários e muitas vezes a gente tem dificuldade em elaborar o diagnóstico".
}

Esse discurso indica que a rotina de registro de informação desempenha um papel importante para que os dados tenham maior fidedignidade. Desde a parte de registro/identificação da paciente, que muitas vezes é realizada no momento de urgência de internação e essas informações são fornecidas por parentes ou acompanhantes, até as informações médicas registradas nos prontuários.

A dificuldade de preencher a evolução do óbito (categoria C) envolve desde dúvidas em relação às causas básicas de morte até informações que contemplem a evolução do paciente. A dificuldade de definição da causa do óbito (categoria B), relatada principalmente por médicos de hospitais SUS, transpassa vários aspectos, 
que vão desde a qualidade da informação registrada nos prontuários até a situação inerente aos óbitos fetais e neonatais precoces, sendo que, na maior parte dos casos, o médico que atende a mãe ou o recém-nascido não é o médico que acompanhou a gestação e, portanto, não possui informações claras a respeito do seu histórico gestacional e da presença de possíveis fatores de risco.

Após abordar as dificuldades foi feita a pergunta: "Você recebeu treinamento/capacitação sobre o preenchimento dos documentos (DN e DO)? Se sim, o que achou desse treinamento?" com objetivo de identificar se os médicos recebem instruções para o preenchimento das declarações. Como mostra a Tabela 4, alguns entrevistados relataram que apenas receberam treinamento durante a faculdade ou residência:

\footnotetext{
"Eu vou te dizer, na faculdade a gente tem essa aula, se você me perguntar em que ano, eu não sou capaz de lembrar, mas eu me lembro que na faculdade a gente tinha esta aula, talvez. no quarto ano. Não lembro muito bem, mas assim, o que eu lembro é que ele foi indo item por item falando ressaltando importância daquela causa de óbito quando é óbito mulher jovem, idade fértil, alguma coisa assim que é importante preencher e preencher o máximo de coisas que a gente conseguir preencher. A gente recebeu também aquele livrinho da faculdade, acho que é da faculdade de saúde pública. Aqui no hospital nunca vi esse tipo de treinamento. Depois disso acaba, pega uma informação aqui outra ali né, pela vivência a gente vai percebendo como que é a situação, na verdade é em cima dos casos que surgem, não tem nem, assim, olha, uma aula específica como preencher um atestado de óbito, tem aula durante a faculdade e que a gente acaba fazendo adaptação para o natimorto, acontece. Então vem um pouco desse pout-pourri aí de informações que a gente teve durante a faculdade e durante vivência dos casos, durante a residência e depois na vida profissional da gente mesmo. Agora aula específica de como preencher uma declaração de óbito para natimorto, isso acho que na minha formação nunca teve”.
}

O discurso referente ao treinamento para preenchimento das DOs recebido em disciplinas específicas durante o curso de graduação de medicina mostra uma 
realidade distante do cotidiano de trabalho nos hospitais e a necessidade de que houvessem atualizações e palestras constantes.

Alguns hospitais, a maior parte SUS, oferecem algumas palestras (categorias A e B), para treinamento de preenchimento e conscientização da DO como direito do paciente. Segundo os entrevistados esses eventos são importantes e deveriam acontecer com mais frequência. Um médico de hospital não-SUS relatou ter participado de treinamento em hospital que aconteceu a alguns anos em outro hospital durante uma reunião clínica, a qual era obrigatória em um hospital escola referência. Conforme relata o entrevistado, é muito difícil promover esse tipo de palestra, pois os médicos não tem interesse no assunto:

\footnotetext{
"Agora, se eu marcar uma reunião aqui pra eu vir dar essas informações não aparece um. Só se eu obrigar os plantonistas a vir e se não vierem eu mandar embora, porque se só convidar não aparece uma alma, porque isso não faz sucesso no meio dos médicos, não vem ninguém, então se eu pedir pra conselho regional de medicina vir e fazer uma reunião grande, oferecer um jantar, não vem ninguém. O médico não tem nenhum interesse nisso."
}

Outro fato importante foi relatado por profissionais que aprenderam a preencher as DOs no dia a dia de trabalho (sem treinamento específico) e para reforçar ou tirar dúvidas utilizam o Manual de Preenchimento da DO e folhetos enviados pelo CRM (Conselho Regional de Medicina) ou Programa de Aprimoramento das Informações de Mortalidade no Município de São Paulo (Proaim/SMS/SP) (categoria D). Nesses discursos destaca-se que o manual nem sempre estava disponível; um dos médicos o encontrou por acaso, junto a outros documentos e passou a usá-lo. Dois médicos de hospitais SUS relataram não terem recebido treinamento; aprenderam a preencher na prática, com auxílio de outros colegas ou das enfermeiras (categoria F).

Os entrevistados que referiram terem assistido palestras ou participado de treinamentos fornecidos pelo CRM ou pelo Programa de Aprimoramento das 
Informações de Mortalidade no Município de São Paulo (PROAIM) (categoria E) demonstraram acharem importante para o aprimoramento e conhecimento dos documentos:

\begin{abstract}
"Os treinamentos são importantes, porque dá conhecimento para o médico, ajuda a melhorar o preenchimento, e o atestado, o SVO, o DNV, acho que é vital para a gente ter uma estatística bem feita neste país, que eu imagino, porque assim, em São Paulo é assim, imagine por aí afora como deve ser. Outra coisa que acontece aqui que assim, agora acontece menos, mas às vezes um laudo ou uma declaração de óbito que não está de acordo, o serviço de verificação de óbitos do município eles mandam pra gente depois de alguns meses uma carta endereçada comentando que deveria ter sido preenchido assim assado, e não do jeito que foi preenchido".
\end{abstract}

Para dar sequência à questão do treinamento, foi perguntado: Você recebe ajuda para o preenchimento das DOs? Em caso positivo, para quais informações? Essa pergunta teve como objetivo identificar como age o médico quando tem alguma dúvida ou dificuldade para o preenchimento dos documentos e se preenche a DO sozinho.

Como mostra a Tabela 5, a ideia central mais frequente (categoria A) foi que o médico costuma dialogar com outros médicos, principalmente em relação à causa do óbito:

\footnotetext{
"As vezes, se a gente está com alguma dúvida com relação ao diagnóstico é com outro colega aqui a gente sempre confirma, olha, então vamos atestar o óbito como sendo: 'prematuridade, levou uma imaturidade múltipla de órgãos, falência múltipla de órgãos'. Em relação a causas do óbito, nós estamos assim entre colegas, a gente até troca uma idéia, e é um paciente conhecido que já estava aqui e que a gente quer definir melhor a causa principal a causa secundária para você colocar tudo de acordo, porque você tem que também, qualquer coisa que você coloque hoje em dia pode ser usado contra você e principalmente em relação a processos, acho que é mais um apoio moral do que outra coisa.
} 
Mas não com uma entidade superior no hospital diretoria, não. Então geralmente é aquilo que eu te falei, a maior parte do atestado vem preenchido, a gente preenche mesmo a parte médica."

Esse DSC mostra que o médico se considera responsável apenas pelo campo da DO referente à causa do óbito. As outras ideias centrais $\mathrm{B}$ e $\mathrm{C}$ indicam que os demais campos são preenchidos por outros profissionais do hospital que internamente têm essa responsabilidade:

"Não tenho dificuldade porque a recepção que é o pessoal que faz a identificação e a internação do paciente, muitas vezes eles que preenchem o local do óbito o endereço do paciente, esses dados são eles que preenchem. A gente faz a parte médica, o restante o pessoal da burocracia (administração) faz o resto."

Nesses discursos foram relatadas questões referentes à causa do óbito e aos campos de identificação dos pacientes, dados preenchidos pelo setor administrativo do hospital como idade gestacional, paridade e número de filhos vivos e mortos. Esse fato indica que as variáveis não ganham destaque no cotidiano do preenchimento dos documentos; entretanto, quando perguntado aos médicos a respeito da utilidade das informações das DOs (Tabela 4), a grande maioria mostrou conhecimento da importância desses dados para uso epidemiológico e de saúde pública. Além da importância epidemiológica foram relatados usos da informação para o hospital para fins legais e para família (Tabela 6). 


\section{DISCUSSÃO}

As entrevistas com os médicos possibilitaram identificar a representação social que estes possuem sobre o preenchimento das DOs e como tal atribuição está inserida no dia a dia de trabalho.

O relato de encaminhamento de óbitos fetais para SVO foi associada a dificuldades de diagnosticar causas de morte dos óbitos anteparto e reflete uma rotina dentro do Município de São Paulo, dada a sua existência e proximidade, fato que resulta na elevada emissão de DOs fetais pelo SVO (75\%).Entretanto, a premissa de que o encaminhamento para o SVO auxiliaria no diagnóstico da causa de morte nem sempre é verdadeira, pois a autópsia não resultou em aprimoramento da indicação das causas de morte fetais (ALMEIDA et al., (2011). Ainda a diferença observada entre médicos dos hospitais SUS e não-SUS pode ter, entre outras causas, o não acompanhamento das gestantes no pré-natal pelos médicos dos hospitais SUS(ALMEIDA et al. 2007). Os óbitos que foram identificados como originados na gravidez, principalmente os fetais anteparto são considerados como tendo causa indeterminada e encaminhados ao SVO. Ao lado da dificuldade de diagnosticar a causa de morte em casos de óbitos intrauterinos, há também a relutância dos profissionais de saúde em relatar desfechos desfavoráveis (FROEN et al., 2009).

No modelo atual de serviço hospitalar, principalmente em hospitais SUS, a organização social da produção dos serviços médicos ocorre de maneira estratificada em termos de equipe institucional, ou seja, no lugar de um agente de trabalho surgem equipes que se revezam em esquemas de plantão, mas que se relacionam com o mesmo caso (paciente) (SCHRAIBER, 1995). Essa forma de articulação na relação entre o médico e paciente se reflete na dificuldade relatada pelos médicos entrevistados em determinar a causa de óbito de pacientes que não acompanharam durante a gestação. 
Entre as dificuldades de preenchimento descritas pelos médicos dos hospitais SUS está o histórico materno, com informações que constam no cartão de pré-natal, mas as mães nem sempre levavam o cartão para o hospital onde foi realizado o parto. Nos hospitais não-SUS esta dificuldade não foi mencionada, pois o médico que realizou o parto, em geral, foi o mesmo que acompanhou a mãe durante a gestação. Tal dificuldade poderia ser minimizada por meio da integração entre assistência pré-natal e ao parto, com informatização, disponibilidade e compartilhamento dos prontuários e históricos maternos para o médico que atendeu a parturiente e o recém-nascido. Cabe comentar que a qualidade dos registros também pode influenciar a disponibilidade dessa informação.

Outra dificuldade mencionada é a necessidade de consulta em diferentes fontes (prontuário ou consulta às mães), o que indica que a informação, segundo os entrevistados, é visualizada de forma fragmentada em informação burocrática (dados de identificação dos pacientes), informação clínica (processo de doença que levou ao óbito) e a dificuldade de compreensão sobre as variáveis epidemiológicas (idade e paridade materna, peso ao nascer) que estão no caminho causal dos óbitos perinatais.

Ao perguntar para os médicos se sentiam dificuldade para o preenchimento da DO, ficou evidente em seus discursos que estes se sentem responsáveis apenas pelo campo da causa de morte, enquanto as outras informações geralmente ficam a cargo dos setores administrativos do hospital. Esse resultado confirma os achados de NIOBEY et al. (1990).

Segundo a portaria MS 20/03 da Secretaria de Vigilância em Saúde, art. 8 (LOPES, 2011), a declaração de óbito deve ser usada em todo país para coleta de dados sobre óbitos e é "indispensável para a lavratura, pelos Cartórios de Registro Civil, da Certidão de Óbito", ou seja, é ao mesmo tempo documento base para o SIM e para produzir a certidão de óbito. Tendo em foco essa dupla finalidade, fica claro pelas entrevistas que o olhar do médico está voltado para os fins legais da DO e para atestar o óbito, assim como discutido por LOPES (2011). Apesar da postura dos médicos contemplar mais seus aspectos legais, vários profissionais mencionaram a importância de seus dados para estudos epidemiológicos. 
A ênfase no aspecto legal dirigida para o preenchimento da causa de morte e a rotina de trabalho implica em consequências para qualidade do preenchimento das declarações, pois apenas os médicos recebem treinamento e mesmo assim, muitos deles só receberam orientação durante a residência ou em aulas na faculdade de medicina. Os outros profissionais que na prática preenchem campos das DOs acabam não recebendo treinamento específico para cumprir tais atribuições.

Esse fato pode interferir na qualidade da informação. Segundo ARTS et al. 2002), os principais erros de preenchimento incluem definição não clara das variáveis e violação do protocolo de preenchimento. Portanto, a qualidade poderia ser melhorada com treinamento específico para os profissionais que, na prática, são responsáveis por parte de preenchimento da DO.

Nos Estados Unidos existe uma declaração específica para óbitos fetais e um responsável pelo preenchimento, o "funeral director", deve coletar as informações em fontes pré-definidas; a causa do óbito deve ser obtida pelo médico que atendeu ou assumiu o plantão enquanto os dados pessoais devem ser perguntados aos familiares (existe uma ordem de parentesco de preferência) ${ }^{6}$.

\section{CONCLUSÃO}

Os óbitos perinatais se constituem em desfecho negativo da gestação gerando um desconforto dos profissionais no preenchimento da DO e paralelamente há dificuldades no diagnóstico da causa de morte, que muitas vezes podem estar associadas ao histórico reprodutivo materno nem sempre acessíveis. Ainda, a dinâmica do modelo atual de serviço hospitalar, no qual, principalmente na rede SUS, existe um esquema de plantão e algumas vezes o médico que atendeu o

\footnotetext{
${ }^{6}$ National Center for Health Statistic. Specifications for Collecting and Editing the United States standard Certificates of Birth and Death- revision general guidelines. 2003.
} 
paciente que foi a óbito não é o mesmo que preenche as DOs. Estes são fatores que podem interferir na qualidade de preenchimento dos documentos.

A qualidade dos registros das DOs também pode ser afetada pelo conhecimento e compreensão dos campos relativos às variáveis de identificação, características maternas, do recém-nascido e da gestação. Muitas vezes o médico se sente responsável pelo preenchimento das causas de óbito, enquanto que o registro das outras variáveis fica a cargo de outros profissionais dos hospitais (profissionais da enfermagem e setores administrativos). Entretanto, como legalmente os médicos são os responsáveis pela DO, apenas eles recebem treinamento específico; os outros profissionais aprendem e compreendem os campos da DO por meio da rotina de trabalho ou auxílio de colegas. O treinamento dirigido aos profissionais que na prática preenchem grande parte do documento é uma questão estratégica a ser pensada e fundamental para melhoria da qualidade dos registros. 


\section{REFERÊNCIAS}

Almeida MF; Alencar GP; França Junior I, Novaes HMD, Siqueira AAF, Schoeps D, Rodrigues LC, Campbell O. Validade das informações das declarações de nascidos vivos com base em estudo de caso-controle. Cad. Saúde Pública. 2006, 22(3): 643652.

Almeida MF, Alencar GP, Novaes MHD, França I, Siqueira AAF, Campbell O, Schoeps D, Rodrigues LC. Risk factors for antepartum fetal deaths in the City of São Paulo, Brazil.Rev.SaúdePública.2007;(41):35-43.

Almeida MF, Alencar GP, Schoeps D, Minuci EG, Silva ZP, Ortiz LP, Novaes $\mathrm{MDH}$, Alencar AP, Raspantini PR, Santos PC. Qualidade das informações registradas nas declarações de óbito fetal em São Paulo, SP. Rev. SaúdePública. 2011;4(5):845-853.

Arts DG, De Keizer NF, Scheffer GJ. Defining and improving data quality in medical registries: a literature review, case study, and generic framework. J AmMedInform Assoc. 2002;9(6):600-11.

Baldijão MFA. Sistemas de informação em saúde. São Paulo em Perspectiva.1992; 6(4): 21-28.Cochran W. SamplingTechniques. New York: John Wiley \& Sons; 1977.

Froen JF, Gordijn SJ, Abdel-Aleem H, Bergsjo P, Betran A, Duke CW, et al. Makingstillbirths count, making numbers talk: issues in data collection for stillbirths. BMC Pregnancy Childbirth. 2009;9:58.

Lefevre, F; Lefevre, A.M.C. O discurso do sujeito coletivo: um novo enfoque em pesquisa (desdobramentos). Caxias do Sul: EDUCS; 2003.

Lefevre F, Lefevre AMC. O sujeito coletivo que fala. São Paulo: Interface; 2006. p. 517-520.

Lima CRA, Schhramm JMA, Coeli CM, Silva MEM. Revisão das dimensões de qualidade dos dados e métodos aplicados na avaliação dos sistemas de informação em saúde. Cad. Saúde Pública. 2009;25(10):2095-2109.

Lopes JCN. Aspectos éticos e jurídicos da declaração de óbito. Rev. Bioét. 2011;19(2):367-82. 
Niobey FML, Cascão AM, Duchiade MP, Sabroza PC. Qualidade do preenchimento de atestados de óbitos de menores de um ano na região metropolitana do Rio de Janeiro. Rev. Saúde públ. 1990;24(4):311-8.

Novaes, MHD. Da produção à avaliação de tecnologias dos sistemas de saúde: desafios do século XXI. Rev. Saúde Pública. 2006; 40:133-140.

Schraiber LB. O Trabalho Médico: Questões acerca da autonomia profissional. Cad. Saúde Pública. 1995;11(1):57-64.

Silva ZP, Almeida MF, Flores LPO, Alencar GP, Alencar AP, Schoeps D, Minuci EG, Novaes HM. Morte neonatal precoce segundo complexidade hospitalar e rede SUS e não-SUS na Região Metropolitana de São Paulo, Brasil. Cad. SaúdePública. 2010;26(1):123-134.

Solomon DJ, Henry RC, Hogan JG, Van Amburg GH, Taylor J. Evaluation and implementation of public health registries. Public Health Rep.1991; 106:141-150.

Spink MJP. O conceito de representação social na abordagem psicossocial. Cad.SaúdePública. 1993;9(3):300-3008.

Terris DD, Litaker DG, KoroukianSM.Health state information derived from secondary databases is affected by multiple sources of bias. JournalofClinicalEpidemiology. 2007; 60: 734 -741.

Souza DV, Zioni F. Novas perspectivas de análise em investigações sobre meio ambiente: a teoria das Representações Sociais e a técnica qualitativa da triangulação de dados. Saudesoc. 2003; 12(2): 76-85.

Zeitlin J, Wildman K, Bréart G, Alexander S. Selecting an indicator set for monitoring and evaluating perinatal health in Europe: criteria, methods and results from the PERISTAT project. Eur J ObstetGynecolReprod Biol. 2003;111:S5-S14. 


\section{TABELAS}

Tabela 1 - Atividades da rotina de trabalho segundo médicos entrevistados em hospitais SUS e não-SUS, Município de São Paulo, 2009

\begin{tabular}{llcc}
\hline Categorias & SUS & Não-SUS \\
\hline A & Rotina como Plantonista & 6 & 1 \\
B & Rotina como Diarista & 2 & 1 \\
& $\begin{array}{l}\text { Faz parte da rotina: assistência, orientação de } \\
\text { C }\end{array}$ & 5 & - \\
D & Rotina de diretoria, coordenação, pesquisa & 7 & 3 \\
\hline & Total & 20 & 5 \\
\hline
\end{tabular}

Tabela 2 - Descrição dos médicos a respeito do preenchimento de DOs na rotina de trabalho em hospitais SUS e não-SUS, Município de São Paulo, 2009

\begin{tabular}{llcc}
\hline Categorias & SUS & Não-SUS \\
\hline $\mathrm{A}$ & $\begin{array}{l}\text { Médico menciona situações que encaminha o óbito } \\
\text { para o SVO ou necrópsia }\end{array}$ & 8 & 1 \\
$\mathrm{~B}$ & $\begin{array}{l}\text { Nem sempre o médico que acompanhou o paciente } \\
\text { é o mesmo que preenche a DO }\end{array}$ & 7 & 1 \\
$\mathrm{C}$ & $\begin{array}{l}\text { Médico recebe ajuda de outros profissionais } \\
\text { doshospitais para preencher a DO }\end{array}$ & 6 & 1 \\
$\mathrm{D}$ & $\begin{array}{l}\text { O médico explica a rotina do preenchimento } \\
\text { mencionando o campo referente à causa do óbito }\end{array}$ & 3 & 1 \\
$\mathrm{E}$ & O médico que atendeu o paciente preenche & - & 1 \\
\hline Total & & 24 & 5 \\
\hline
\end{tabular}


Tabela 3- Dificuldades apontadas por médico no preenchimento de DOs em hospitais SUS e não-SUS, Município de São Paulo, 2009

\begin{tabular}{lcc}
\hline Categoria & SUS & Não-SUS \\
\hline A Não tem dificuldade & 5 & 1 \\
B Dificuldades em definir a causa do óbito & 5 & 1 \\
C Dificuldade em preencher a "evolução do óbito" & 3 & 1 \\
D Dificuldade quando precisa consultar outras fontes de & 5 & 2 \\
$\quad$ informação & 2 & 1 \\
E Dificuldade em relação a "ficha" da DO & 1 & - \\
G O preenchimento da DO é uma situação de estresse para o & 21 & 6 \\
\hline Total & 21 . & \\
\hline
\end{tabular}

Tabela 4 - Aspectos sobre treinamento para preenchimento de DOs, apontados pelos médicos entrevistados em hospitais SUS e não-SUS, Município de São Paulo, 2009

\begin{tabular}{llcc}
\hline Categoria & SUS & Não-SUS \\
\hline A & Hospital fornece treinamento e palestras constantes & 3 & - \\
$\mathrm{B}$ & $\begin{array}{l}\text { Hospital fornece treinamento e palestras esporádicos } \\
\text { Recebeu treinamento somente na faculdade ou } \\
\text { durante a residência }\end{array}$ & 2 & 1 \\
& $\begin{array}{l}\text { Aprendeu a preencher pelo Manual de } \\
\text { preenchimento da DO ou folhetos }\end{array}$ & 3 & 2 \\
D & 4 & 2 \\
E & $\begin{array}{l}\text { Recebeu treinamento da prefeitura ou CRM } \\
\text { Nunca recebeu treinamento }\end{array}$ & 2 & - \\
\hline Total & & 20 & 5 \\
\hline
\end{tabular}

Tabela 5 - Posicionamento frente às dúvidas de preenchimento das DOs apontados pelos médicos entrevistados em hospitais SUS e não-SUS, Município de São Paulo, 2009

\begin{tabular}{llcc}
\hline \multicolumn{2}{l}{ Categoria } & SUS & Não-SUS \\
\hline A & Tira dúvidas e discute as causas de óbito com outros & 9 & 1 \\
& médicos & 2 & 1 \\
B & Busca informações com as enfermeiras & 2 & 2 \\
C & Não tem dúvidas porque o administrativo preenche & 2 & - \\
& parte da DO & 2 & 4 \\
D & Tenta preencher da maneira mais correta possível & 15 & 4 \\
\hline Total & &
\end{tabular}


Tabela 6 - Uso das informações do SIM apontados pelos médicos entrevistados em hospitais SUS e não-SUS, Município de São Paulo, 2009

\begin{tabular}{llcc}
\hline \multicolumn{2}{l}{ Categoria } & SUS & Não-SUS \\
\hline A & As informações servem para uso epidemiológico e & 14 & 4 \\
& de saúde pública & 3 & - \\
B & São informações importantes para o hospital & 2 & - \\
C & São informações para fins legais & 2 & - \\
D & São informações importantes para família & 21 & 4 \\
\hline Total & & 21 \\
\hline
\end{tabular}




\title{
Artigo 3 - SIM E SINASC: REPRESENTAÇÃO SOCIAL DE ENFERMEIROS E PROFISSIONAIS DE SETORES ADMINISTRATIVOS QUE ATUAM EM HOSPITAIS SUS E NÃO-SUS NO MUNICÍPIO DE SÃO PAULO.
}

\author{
Schoeps $\mathrm{D}^{1}$, Almeida $\mathrm{MF}^{1}$, Lefevre $\mathrm{F}^{2}$ \\ ${ }^{1}$ Departamento de Epidemiologia da Faculdade de Saúde Pública da Universidade de São Paulo. \\ ${ }^{2}$ Departamento de Prática de Saúde Pública da Faculdade de Saúde Pública da Universidade de São \\ Paulo.
}

\begin{abstract}
Resumo
Introdução: A mortalidade perinatal é um importante indicador de saúde maternoinfantil, por esse motivo vem ocorrendo uma evolução nos estudos dessas informações. Muitos estudos avaliam a qualidade dos dados do Sistema de Informações de Nascidos Vivos (SINASC) e Sistemas de Informações de Mortalidade (SINASC) com métodos quantitativos (validade/completitude), porém são escassas as investigações qualitativas.
\end{abstract}

Objetivo: Avaliar a representação social dos enfermeiros e profissionais de setores administrativos sobre o preenchimento das Declarações de Nascido Vivo (DNs) e se ou como auxiliam no preenchimento das Declarações de Óbito (DOs) fetais e neonatais.

Métodos: Foram realizadas 24 entrevistas com enfermeiros e profissionais de setores administrativos em 16 hospitais, com e sem vínculo com o SUS, no município de São Paulo, em 2009. As análises foram realizadas utilizando a metodologia qualitativa com a técnica do Discurso do Sujeito Coletivo.

Resultados: Os profissionais e enfermeiros se reconhecem como parte integrante do processo de produção da informação. Os discursos indicam que a atividade está incorporada na rotina do trabalho; há comprometimento na busca de soluções quando se deparam com dificuldades de preenchimento; há valorização de se sentirem acompanhados por uma instância superior do sistema; sentem que o treinamento é um espaço de encontro para retorno e compreensão das finalidades e usos das informações que produzem. Esta consciência aumenta o comprometimento e assegura informações mais fidedignas.

Conclusões: Tanto nos hospitais SUS como não-SUS não se verificou um padrão relativo ao profissional responsável pelo preenchimento das DNs, apesar da definição legal de que o médico é o responsável pelas informações da DO muitas vezes outros profissionais preenchem parte das informações. As entrevistas revelaram que os profissionais conhecem e reconhecem a utilidade das informações registradas nas DNs com base nos treinamentos fornecidos pela equipe do Sistema de Informação de Nascidos Vivos (SINASC). Os profissionais e enfermeiros se reconhecem como parte integrante do processo de produção da informação e sentem que o treinamento é um espaço de encontro para retorno e compreensão das finalidades e usos das informações que produzem. Essa consciência aumenta o comprometimento e assegura informações mais fidedignas.

Palavra-chave: Sistema de Informações em Saúde; Declaração de Nascido Vivo; Declaração de Óbito; Representação Social; Registros Hospitalares 


\section{SIM AND SINASC: SOCIAL REPRESENTATION OF NURSES AND ADMINISTRATIVE PROFESSIONAL SECTORS THAT WORK IN HOSPITALS SUS AND NON-SUS IN THE CITY OF SAO PAULO.}

Schoeps $\mathrm{D}^{1}$, Almeida $\mathrm{MF}^{1}$, Lefevre $\mathrm{F}^{2}$

\footnotetext{
${ }^{1}$ Departamento de Epidemiologia da Faculdade de Saúde Pública da Universidade de São Paulo.

${ }^{2}$ Departamento de Prática de Saúde Pública da Faculdade de Saúde Pública da Universidade de São Paulo.
}

\section{Summary}

Introduction: Considering that perinatal mortality is an important indicator of maternal and child health., there has been an evolution in the studies of such information. Many studies assess its quality with quantitative methods (validity / completeness), but there are few qualitative investigations.

Objective: To assess the social representation of nurses and administrative sectors on how to complete the Declarations of Live Birth (DN) and whether or how to assist in completing fetal and neonatal death certificates (DO).

Methods: We conducted 24 interviews with nurses and administrative staff in 16 hospitals (SUS and non- SUS), in the City of São Paulo in 2009. Analyses were performed using a qualitative methodology with the technique of Collective Subject Discourse.

Results: The speeches indicate that the activity is incorporated into the routine of work; there is involvement in finding solutions when they find difficulties in filling; there is a feeling that they should have a higher member of staff supervision.

Conclusions: Both SUS and non-SUS hospitals have no specific professional responsible for the completion of $\mathrm{DN}$, despite the legal definition of what the doctor is responsible for the information of $\mathrm{DO}$, it is often common to find other professionals filling part of the information. The interviews showed that the professionals know and recognize the usefulness of the information recorded in DN based on training provided by staff of the Information System (SINASC). Professionals and nurses see themselves as part of the process of information production and feel that training is a meeting place for feedback and understanding of the purposes and uses of the information they produce. This awareness increases the commitment and ensures more reliable information.

Keywords: Health Information System; Statement of Live Birth, Social Representation, Hospital Records, Nurse 


\section{INTRODUÇÃO}

O Brasil dispõe de um conjunto de Sistemas de Informação em Saúde (SIS), sendo que um dos principais objetivos é fornecer as informações necessárias para subsidiar ações e políticas de saúde. A informação de qualidade é a primeira condição para que esta seja utilizada nos programas de saúde. No Brasil não existe um plano regular para monitoramento do SIS, resultando em iniciativas não sistemáticas e isoladas (LIMA et al., 2009). Embora o aplicativo operacional de entrada de dados do Sistema de Informações sobre Mortalidade (SIM) e do Sistema de Informações de Nascido Vivo (SINASC) incluam rotina de conferência, consistência dos dados e retorno para as fontes produtores de informação para possível correção das informações.

A mortalidade perinatal é um importante indicador de saúde materno-infantil. O interesse crescente por este indicador e a preocupação com a qualidade da informação é decorrente da concentração progressiva dos óbitos infantis nos primeiros dias de vida em países desenvolvidos e em alguns países em desenvolvimento, entre os quais o Brasil (ZEITLIN et al., 2003; ALMEIDA., 2006a).

Iniciativa da União Europeia formalizada no projeto PERISTAT propõe um conjunto de indicadores específicos selecionados para acompanhamento da mortalidade perinatal. Foram propostos indicadores de mortalidade fetal e neonatal precoce e indicadores de mortalidade específicos segundo: idade da mãe, paridade, peso ao nascer e idade gestacional (BUITENDIJK et al., 2003). Vem ocorrendo uma evolução nos estudos de avaliação dos sistemas informações perinatais. Inicialmente, esses estudos destinavam-se apenas à avaliação da completitude dos dados, evoluindo para avaliação de sua acurácia, por meio da concordância dos registros com outras fontes de dados e, finalmente, nos Estados Unidos na década de 90, surgiram estudos epidemiológicos de validação dos dados existentes nos sistemas de informação de nascidos vivos. Tais estudos têm se tornado cada vez mais 
importantes devido à crescente disponibilidade de informações advindas do uso de meios eletrônicos, de divulgação de dados e à maior incorporação do uso da informática, que possibilita a ampliação do uso dessas informações (KIRBY, 1997).

Fatores institucionais, tais como a estrutura, organização e tipo dos serviços de saúde podem influenciar a qualidade do registro de dados, bem como a presença de suporte administrativo. Outro fator importante são os profissionais designados para proceder a coleta de dados dos sistemas de informação e o treinamento existente para o desenvolvimento desta tarefa (SOLOMON et al., 1991).

Além desses fatores, alguns estudos indicam que a definição clara do evento, juntamente com a definição das variáveis utilizadas para sua descrição, também desempenha importante papel na qualidade dos dados (SOLOMON et al., 1991). Segundo ARTS et al. (2002), para assegurar a qualidade das informações é necessário garantir algumas atividades na etapa anterior a coleta de dados, como por exemplo um protocolo de coleta com definições claras, treinamento e motivação do profissional responsável pelo preenchimento das informações.

Segundo as normas contidas no Manual de Preenchimento da Declaração de Nascido vivo, estas podem ser preenchidas pelos profissionais dos serviços de saúde $^{1}$. Embora raros, alguns estudos buscam identificar a relação entre a qualidade das informações e a rotina de preenchimento dos dados. MISHIMA et al. (1999) também identificam que o preenchimento da DN é heterogêneo nos hospitais. Em estudo específico sobre malformações congênitas das DNs, GUERRA et al. (2008), encontrou que diferentes profissionais preenchem as DNs e nem sempre estes tem familiaridade com termos médicos do prontuário, o que pode interferir na qualidade dos dados. Alguns estudos (NIOBEY et al., 1990; ALMEIDA et al., 2011), mostram que além de preencher informações das DNs, muitos profissionais não médicos

\footnotetext{
${ }^{1}$ Brasil. Ministério da Saúde. Secretaria de Vigilância em Saúde. Manual de Instruções para o preenchimento da Declaração de Nascido Vivo. Brasília: MS/SVS: 2009.
} 
auxiliam no preenchimento das Declarações de Óbito (DO) que na prática é responsabilidade legal dos médicos ${ }^{2}$.

Tendo em vista esses aspectos e os diferentes aspectos mencionados que envolvem o registro de dados, foi realizado um estudo empregando técnica de pesquisa qualitativa, na qual os entrevistados expressam suas ideias e se posicionam sobre o tema (SPINK, 1993), com enfermeiros e profissionais dos setores administrativos dos hospitais para avaliar sua representação social sobre o preenchimento das Declarações de Nascido Vivo (DNs) e se ou como auxiliam no preenchimento das Declarações de Óbito (DOs) fetais e neonatais. Tendo em vista que podem existir diferenças nas rotinas de preenchimento dos documentos foi considerada tipologia SUS e não-SUS (SILVA et al., 2010).

\section{MATERIAL E MÉTODOS}

\subsection{HOSPITAIS DO ESTUDO}

Este estudo foi realizado no âmbito da pesquisa 3 “Avaliação da Qualidade da Informação sobre Mortalidade Perinatal no Município de São Paulo” que considerou os hospitais como unidades amostrais, sendo sorteados por amostragem estratificada proporcional ao número de óbitos perinatais em cada estabelecimento. (SILVA et al., 2010).

Os hospitais sorteados são representativos das diferentes entidades mantenedoras que prestam serviço ao SUS, contemplando hospitais filantrópicos, estaduais, municipais e organizações sociais e de saúde.

\footnotetext{
${ }^{2}$ Resolução CFM no $1.601 / 00$, de 9 de agosto de 2000.

${ }^{3}$ FAPESP/PPSUS - Processo n ${ }^{\circ}: 2006 / 61304-3$
} 


\subsection{CARACTERÍSTICAS DA POPULAÇÃO DE ESTUDO E AS ENTREVISTAS}

Entre os 17 hospitais que participaram do estudo, em 16 (quatro não-SUS e 12 SUS) em 2009, foram realizadas entrevistas qualitativas com profissionais que preenchem as DNs com objetivo de conhecer sua representação social sobre o SINASC e SIM e de que modo o preenchimento desses documentos esta inserido no trabalho cotidiano.

Para escolha dos entrevistados, definiu-se que os profissionais tivessem em sua rotina de trabalho o preenchimento das DNs ou auxílio nas DOs. Para atingir esse objetivo, foi solicitado à coordenação dos hospitais que indicassem os profissionais. Foram entrevistados dois enfermeiros e cinco profissionais de setores administrativos em hospitais não-SUS e seis enfermeiros e 11 profissionais de setores administrativos em hospitais do SUS totalizando 24 entrevistas.

A pesquisa foi previamente aprovada pelos Comitês de Ética em Pesquisa da Faculdade de Saúde Pública - USP/SP, dos hospitais e da Secretaria Municipal de Saúde da prefeitura de São Paulo. Antes das entrevistas, foi lido e assinado o Termo de Consentimento Livre Esclarecido garantindo anonimato dos entrevistados e dos hospitais que participaram do estudo. O roteiro de entrevista foi definido por perguntas que buscaram contextualizar a rotina de trabalho e como o preenchimento das DNs e DOs se insere no cotidiano. Esse roteiro teve ainda como objetivo captar a existência de possíveis dificuldades, a participação em treinamentos e sua representação social sobre o SIM e o SINASC.

Foi utilizada a técnica do Discurso do Sujeito Coletivo (DSC), procedimento metodológico de natureza qualiquantitativa, que busca superar os impasses das pesquisas tradicionais de representação social, recuperando na escala coletiva a natureza discursiva e argumentativa do pensamento. A opinião é obtida por meio de questões abertas propiciando ao entrevistado a geração de um depoimento discursivo. Cada questão gera um número variado de diferentes posicionamentos, ou seja, de distintos DSCs que resultam de uma agregação de diferentes discursos ou 
extratos de discursos individuais que representam sentido semelhante (LEFEVRE e LEFEVRE, 2003).

O discurso de cada entrevistado pode conter uma ou mais ideias a respeito da questão estabelecida e para o processo de análise são atribuídas expressões chaves a cada ideia para que, então, seja possível agrupar as expressões chave de sentido semelhante em categorias de respostas. Com as categorias de ideias compartilhadas e seus respectivos discursos estabelecidos torna-se possível a análise qualitativa dos depoimentos de ideias compartilhadas em cada uma das questões. As somas dos resultados correspondem ao número de ideias em cada categoria e não ao número de entrevistados (LEFEVRE e LEFEVRE, 2003).

A pesquisa foi analisada empregando o método do Discurso do Sujeito Coletivo - DSC e do software Qualiquantisoft ${ }^{4}$ que possibilita, para cada questão, a construção de categorias de respostas nas quais se observam as ideias ou representações compartilhadas entre os sujeitos que responderam à pesquisa (LEFEVRE e LEFEVRE, 2003; LEFEVRE e LEFEVRE, 2006).

As representações sociais manifestas verbalmente são um conjunto de conceitos, frases e explicações originadas na vida diária durante o curso das comunicações sociais. São modalidades de conhecimento prático, orientadas para a comunicação e para compreensão do contexto social, material e ideológico que vivemos. Socialmente elaboradas e compartilhadas, contribuem para a construção de uma realidade comum possibilitando a comunicação entre os indivíduos. Portanto, são fenômenos sociais que devem ser compreendidos a partir de seu contexto de produção a que servem, e das formas de comunicação onde circulam (JODELET, 2001).

${ }^{4}$ SPi-Sales \& Paschoal informática. www.spi.com.br. Elaborado com base na teoria do DSC. 


\section{RESULTADOS}

O Quadro1 mostra o perfil dos profissionais entrevistados. Entre os oito enfermeiros indicados pela coordenação dos hospitais, metade trabalhava na obstetrícia e metade na pediatria ou UTI neonatal. Foi relatado pelos entrevistados que em alguns hospitais os dados eram preenchidos na sala de parto e em outros na maternidade/alojamento conjunto.

Foi solicitado que os entrevistados descrevessem suas rotinas de trabalho. Quatro enfermeiros relataram exercer atividade assistencial e os outros quatro, atividade administrativa. Entre os profissionais que trabalhavam com preenchimento das DNs, oito relataram exercer atividade administrativa e outros, oito relataram que também faziam parte do seu trabalho o registro de informações clínicas. Não foram observadas diferenças, nos hospitais SUS e não-SUS, quanto às atividades dos enfermeiros e profissionais administrativos.

Na questão sobre: "O preenchimento das declarações de nascido vivo e de óbito faz parte desta rotina? Fale um pouco sobre isso.", três enfermeiros de hospitais SUS descreveram que preenchem apenas parte da DN, porque os dados cadastrais (informações individuais) são preenchidos pelo setor administrativo.

Entretanto, outros enfermeiros que trabalhavam em UTI neonatal/berçário informaram que recebiam, da sala de parto, as DNs já preenchidas com os dados de identificação da mãe. Esta rotina visava facilitar o preenchimento das demais variáveis, pois no momento do parto a sala fica muito cheia e "tumultuada".

Em hospitais não-SUS duas enfermeiras preenchiam toda DN. Uma delas que trabalhava na UTI neonatal relatou que fica sob sua responsabilidade o preenchimento das DNs de recém-nascidos que precisavam de cuidados imediatos. Outra enfermeira relatou que no hospital se estabeleceu que a atribuição de preenchimento do documento deveria ficar a cargo de um mínimo de pessoas, de 
forma que as informações ficassem mais claras e precisas. Como as enfermeiras participam de todo processo de atenção ao recém-nascido, tal responsabilidade foi atribuída a elas.

Em relação ao preenchimento da DO fetal e neonatal foi perguntado se os médicos recebiam auxilio para o preenchimento das DOs (Tabela 1). Foram observadas três situações pelo relato das enfermeiras: 1. uma não sabia responder 2. duas afirmaram que o médico não recebia auxílio (hospitais SUS); 3. outra indicou que os dados de identificação eram preenchidos pelo Serviço de Arquivo Médico e Estatística(SAME) (hospital não-SUS).

Quatro enfermeiras (três de hospitais SUS e uma não-SUS) relataram que auxiliam os médicos com informações dos prontuários, observadas na sala de parto ou baseadas em informações das DNs.

A maior parte dos outros profissionais que participaram das entrevistas (12 entre 16) indicaram que as informações das DOs relativas à identificação das mães não são preenchidas pelos médicos e sim por profissionais da admissão, internação ou SAME e essas informações são consideradas como dados cadastrais. Essa rotina é justificada pela necessidade de apresentação de documentos por parte dos pacientes para que os nomes sejam preenchidos corretamente, assim como a confirmação de endereço e CEP. Tais dados seriam dificilmente obtidos pelos médicos, devido à sua rotina de trabalho.

Na Tabela 2 encontram-se as ideias centrais relativas à pergunta: "Você considera que existe dificuldade para preencher alguma informação? Qual (is)?”.

Foram observados alguns relatos de dificuldades diferentes entre os profissionais administrativos e enfermeiros, principalmente quando referentes a campos específicos da DN. Em dois hospitais SUS e um não-SUS foram descritas dificuldades distintas em relação ao preenchimento do nome da mãe, relatado em duas situações: 
“A dificuldade que a gente tem é o nome da mãe que muitas vezes quando ela entra no hospital ela mostra o $R G$ de solteira, e não fala que é casada e não traz certidão de casamento e quem tá fazendo a matrícula, a internação dela também não pergunta, então toda a ficha dela é feita sobre aquele nome, e eu preencho a declaração de nascido vivo conforme está no sistema, então o que acontece, quando essa declaração chega pra ela, ela verifica o nome e ela fala que é casada, aí ela tem, o marido traz a certidão de casamento. Primeiro vai na sala de matrícula, porque lá que eles arrumam os nomes, qualquer erro referente a nome. Eles arrumam lá primeiro e me trazem a via amarela pra eu retificar. Eu arrumo na frente e atrás da declaração eu tenho que retificar que fui eu que arrumei aquilo, colocar o meu carimbo, colocar o carimbo do hospital porque se não o cartório não aceita"

“As vezes o nome delas também, às vezes elas falam o nome e às vezes não é aquele nome, tem que estar também pegando o RG delas, tem muito caso social de moradora de rua, pacientes que vivem, como que eu posso falar pra você, dá o nome e é outro”.

Em um hospital não-SUS foi relatada dificuldade no preenchimento da escolaridade materna, pois na maior parte das vezes essa informação não é dada em anos de estudo e pode ser ainda fornecida por parentes da paciente:

\footnotetext{
"No caso da mãe vai falar: 'não sei, eu acho que ela estudou até o ensino médio, ah não sei, eu acho que ela tem a faculdade tal', e você tem que ter uma noção do tempo, dos anos que ela estudou para poder tá fazendo o preenchimento. Seria mais fácil no caso da declaração se nós pudéssemos escrever de próprio punho a escolaridade do paciente, do cliente."
}

Foram relatadas dificuldades no preenchimento do endereço, tanto por enfermeiras como pelo pessoal administrativo. No hospital não-SUS a dificuldade se refere à informação do CEP da residência, mas a busca no prontuário resolve, pois essa informação está sempre presente. Nos hospitais SUS houve o relato de que as mães ou parentes tem dificuldade em fornecer o endereço correto. Em um hospital foi relatado o caso de mães bolivianas que tem medo de fornecer o endereço. 
"Muitas vezes elas vem com o endereço que é diferente daquele que ela reside e aí a gente tem que confirmar esse endereço. Às vezes elas chegam aqui elas dão o endereço ou então quem vem acompanhando elas dá endereço e quando você vai confirmar no leito é outro endereço, eu não moro mais aí, esse é o endereço da minha mãe, é o endereço da minha tia, e onde estou morando eu moro há pouco tempo então eu não sei, então é melhor recolher das próprias pacientes. Não sei se pelo grau de escolaridade das pessoas, é pouco, assim, é difícil você conseguir a informação correta da própria paciente ou pelo fato do filho estar com ela ali, não sei se elas ficam meio desorientadas, meio com receio de preencher alguma coisa, de responder, porque a gente sempre acaba perguntando: mãezinha, esse papel aqui a gente sempre acaba falando - mãezinha, esse papel é DNV, é para você registrar o seu bebê mais tarde no cartório se não elas parece que não entendem, ou ficam com medo"

A informação sobre o estado civil também foi mencionada como problemática na rede SUS e não-SUS. Os relatos indicam a mesma dificuldade em explicar para a mãe a diferença entre união estável e casamento civil. Muitas vezes a mãe que tem um companheiro, mas não é casada legalmente, não quer que seja preenchido como solteira.

O campo referente à ocupação foi mencionado por uma enfermeira de hospital SUS. Segundo a entrevistada, a mãe adolescente que só estuda não pode ser classificada como desempregada, mas ao mesmo tempo não possui ocupação.

Foram descritas dificuldades em relação à raça/cor dos recém-nascidos, principalmente quando os pais são de etnias diferentes (orientais, negros etc.), entretanto as enfermeiras e profissionais relatam que essa dificuldade tem diminuído após orientação da equipe do SINASC que esse campo deve ser auto referido.

Apenas enfermeiros e profissionais de hospitais SUS relataram dificuldades de preenchimentos em relação ao histórico materno e malformações. Uma enfermeira relatou que precisa ajudar no preenchimento, porque as escriturárias que são responsáveis pela DN não têm o conhecimento específico necessário para esses campos: 
"Como é rotina do nosso serviço esse preenchimento é com a secretária, a escriturária, a gente acaba tendo dificuldade sim, porque elas não tem o mesmo entendimento que o enfermeiro para perguntar, para saber, às vezes na maternidade, às vezes a gente tem que auxiliar a escrituraria nos dados, algumas perguntas que são mais complexas que elas não sabem preencher elas sempre solicitam a ajuda da enfermeira no plantão.

Elas sentem mais dificuldade, às vezes é quando a idade gestacional que elas nunca sabem se é prematuro, também é a paridade da mãe na gestação, se ela tem filho vivo ou morto, se esse morto é natimorto ou se é considerado como abortamento, elas sempre fazem confusão as pacientes e as escriturarias, então a gente sempre tem que estar lá confirmando e direcionando elas no preenchimento. Elas não são fixas, por causa que elas tem o problema delas das folgas delas no setor, acaba às vezes vindo outras escriturarias que não tem habilidade nenhuma com DNV, então aí a gente tem que ficar mais em cima dessas declarações na maternidade pra gente não correr o risco de estar cancelando, mas a gente também tem bastante erros".

Um profissional do setor administrativo de hospital SUS descreveu que geralmente os médicos se esquecem de preencher o item malformação congênita, então é necessário devolver os documentos para que este campo seja preenchido corretamente.

“Digamos, tem o campo 34 se tem má formação ou não. É o pediatra que tem que estar preenchendo no centro obstétrico, geralmente eles esquecem e nós temos que estar indo atrás dele tem que estar perguntando"

As dificuldades mencionadas pelas enfermeiras foram relativas à definição da malformação:

"A gente escreve o que os pediatras conseguem definir na hora, alguma coisa muito evidente, um pé torto congênito ou um dedo extranumerário, só que às vezes, uma coisa que 
eles não decidiram na hora, eles vão pesquisar que muitas vezes são os residentes que pegam os bebês, eles não sabem definir, eles vão definir depois, e aí, só que eu não posso esperar essa definição para colocar na DNV, ai eu coloco o que eles colocaram na ficha. Isso que gera mais dúvidas das anomalias, mas o hospital nos deu o curso, foi lá na secretaria, mais em cima disso, porque tem coisa que você não considera, se você tiver dúvida eles deixaram telefone tudo, aqui no caso até o neo mesmo, de repente a gente tem uma dúvida daquela anomalia a gente pode até fotografar e mandar pra lá, eles, a UNIFESP também faz um trabalho em cima disso. Mas, se por exemplo, eles não sabem se o bebê tem uma síndrome de down, que eles vão ainda pesquisar, se não colocaram eu não vou por também”.

Nos hospitais SUS houve também o relato de dificuldades do preenchimento de informações sobre características maternas e da gestação, como por exemplo, sobre a assistência pré-natal, pois as mães não levam ou esquecem o cartão de pré-natal onde seria possível obter as informações necessárias:

\footnotetext{
"Os campos sobre paridade, número de filhos, consultas. Consultas, essa história que elas esquecem a carteirinha de pré-natal ou às vezes elas não trazem porque é um lugar fora da região, então elas tem medo que a gente transfira ou que não aceite, então elas nem trazem "ah, esqueci, ah perdi". E aí? Como é que você vai escrever o número de consultas? Eu escrevo o que? O que ela refere, põe ignorado? Não sei também. Eu acabo anotando o que os obstetras anotam, eles perguntam para ela, então acaba sendo assim”.
}

Após abordar as dificuldades foi feita a pergunta: "Você recebeu treinamento/capacitação sobre o preenchimento dos documentos (DN e DO)? Se sim, o que achou desse treinamento?" com objetivo de identificar se os profissionais receberam instruções e se estas auxiliaram para o preenchimento das declarações (Tabela 3).

Uma enfermeira do hospital SUS referiu que trabalha com recém-nascidos há mais de 20 anos e aprendeu o preenchimento da DN na prática, conforme foi 
sendo incorporada no dia a dia de trabalho. Cinco enfermeiras relataram que receberam orientações do supervisor ou colegas de trabalho que já haviam participado de treinamentos ou tinham a rotina de preenchimento.

Enfermeiras:

"Eu só fui orientada, como preencher, mas não um curso formal ou uma orientação formal. A orientação foi dada pela minha chefe. Porque ela que vai nessas reuniões e passa pra gente, mas eu acho que como é tudo muito específico acho que precisa ter um curso mesmo, de algumas horas para a gente ter essas instruções e discutir cada ponto, porque é muito complicado isso. E às vezes, eu acho assim, que por falta de informação cada uma acaba preenchendo o que acha melhor, o que acha correto”.

Outros profissionais:

"Eu aprendi no dia a dia. com ajuda do pessoal que já sabia, passou ó, preenche assim,então foi assim sem curso sem nada. O treinamento a gente recebe com os colegas quando passa pro setor, entendeu, um passa para o outro. Ninguém cai no setor de balão. Então se você vai para determinado setor alguém te treina para assumir aquilo ali. Agora capacitação, propriamente dita, não."

A participação em treinamento e capacitação promovida pela Secretaria Municipal de Saúde - São Paulo (SMS/SP) foi relatada com maior frequência pelos profissionais do administrativo do que pelas enfermeiras. Todas as respostas indicam a importância dos treinamentos para esclarecimento de dúvidas e que, após a capacitação os profissionais, se sentem mais seguros para preencher os documentos.

\footnotetext{
"A declaração de nascido vivo eu tive, fui no SINASC teve uma reunião onde eles estavam explicando novamente como preencher. Um dos campos que eu recebi muito treinamento e o pessoal aqui também foi sobre endereço, ter o CEP certinho, tem que ter o número, o distrito
} 
corretamente, porque tudo isso vai via web, vai pela internet, tem que estar certinho. E o outro ponto do nascido vivo era raça e cor que não era preenchido, que eles pedem para a gente preencher, no caso assim é a auto declaração mãe, a gente pergunta para a mãe, a mãe que declara.O último que teve foi sobre anomalias congênitas que teve agora tem um mês mais ou menos que teve, e foi bom porque tinham algumas dúvidas sobre as anomalias mesmo, porque às vezes a gente colocava uma - o espaço era só para uma, e tinha mais de uma, entendeu, então isso foi esclarecido.

Lá no SINASC foi muito bom, eles esclarecem bastante as dúvidas. Depois de lá que foi, que assim que eu vim primeiro pro setor, depois que eu fui lá, então a gente se sente mais segura na hora de preencher".

Os profissionais do administrativo que auxiliam no preenchimento da DO relataram que receberam instruções de outros profissionais do setor, enquanto que para DN participaram de treinamentos fornecidos pela equipe do SINASC.

"Logo que fui admitida aqui no setor a minha chefia anterior que passou, que me orientou quanto ao preenchimento das DOs. Aqui, tinha uma pessoa que ela já fazia isso, porque quando eu vim pro setor internação lá é preenchida a declaração de óbitos, não são todos os casos, mas alguns casos você tem que preencher, aí você pega o documento na prática né, tem que preencher a data, o horário do óbito, o nome, então assim uma coisa, a gente procura preencher todos os campos necessários porque depois eles também tem uma certa dificuldade, às vezes eu deixo de preencher alguma coisa, já aconteceu né, mas nos casos, não preencher o sexo, não por a cútis da pessoa, aí o rapaz da funerária liga, qual é a cor? Sexo, principalmente estrangeiro, japonês, né, porque pra mim, Mitsú é nome feminino, só que na realidade é masculino, às vezes a pessoa esquece de preencher, é tão pequenininho que esquece, então tem que procurar preencher todos os dados possiveis, o grau de escolaridade, o estado civil. Agora das DNVs eu participo frequentemente das reuniões porque sempre há mudança de sistemas, nova versão de sistema, antes era por disquete a gente mandava a relação mensal por esse disquete, dava a maior confusão, eles vinham instalar, né, programas novos agora tudo é através da internet, está ótimo. Então são essas mudanças que está participando sempre". 
Com objetivo de identificar a representação social que os enfermeiros e profissionais administrativos do hospital tinham a respeito do uso das informações registradas nas DNs e DOs foi realizada a pergunta: "Para que servem as informações das declarações de nascido vivo e de óbito que você preenche? Como assim?". Entre as enfermeiras, quatro indicaram que o uso das informações das DNs e DOs possuem finalidade estatística e epidemiológica e quatro disseram que além deste uso, as informações também servem para registros de nascimentos e de óbitos no cartório (Tabela 4).

\footnotetext{
"Essa declaração de nascidos vivos ela serve para que essa pessoa seja registrada no cartório, registro de nascimento de que ela nasceu e a localidade, onde ela nasceu, a data é importante para que a pessoa seja registrada e reconhecida no País. A importância dela não só para a criança ter um registro, ser um cidadão”.

“...e também eu acho que é um Censo do Ministério da Saúde para saber o que está acontecendo, como essas crianças estão nascendo, e se essas mulheres estão fazendo prénatal, não estão, as informações pessoais, acho que é pra tudo isso, então são importantes, são informações importantes e que precisa ter uma uniformidade no preenchimento disso".
}

Cinco profissionais do administrativo relataram que a finalidade das informações e as declarações servem apenas para fins de registro e de documentação legal para a família.

“É para que saia correto para a família não ter problemas futuros. Elas tem uma importância muito grande porque é o registro da criança, então é o começo de tudo, então assim, a gente tem que ter muita responsabilidade porque qualquer errinho lá a pessoa leva para a vida toda na verdade. Tanto a data tem que estar corretamente, o horário, então a gente zela muito por isso.... E a de óbito se você não faz o preenchimento aí não tem dado que a pessoa realmente faleceu, que ela morreu, você tem que ter um documento de comprovação". 
Entretanto, a maior parte dos profissionais considera que as informações são importantes para levantamentos epidemiológicos.

\footnotetext{
“Bom, é um controle muito grande aí do Ministério da Saúde, nós vemos, estamos em constantes reuniões com o SINASC porque é uma informação do Brasil todo de nascimentos de controle de certidões de nascidos vivos por regiões, por Estado, por cidade, então é um controle muito grande deles, quais os tipos de mães, por exemplo em tal bairro, porque está tendo mais nascimentos em tal lugar e não no outro, então eles avaliam as malformações também que são informadas nas DNs, então eles avaliam também a parte social também. E os das DOs também é importante pelo controle no Ministério da Saúde também, o total da população também e os diagnósticos acho que para pesquisa da saúde mesmo, quais os motivos de morte, mas da declaração de óbito já não sei muito. Se o SINASC está em todo estado de São Paulo né? E eles pedem assim a maior clareza, não ter erro, informar mesmo, não colocar: não sei, não sabe informar. Informar os dados mais corretos possíveis, corretos, qual a profissão. No treinamento do SINASC eu vi que cada informação é importante, como lá me explicaram que é da declaração de nascido vivo que tiram a quantidade de vacinas por região, nosso então é uma informação assim importante, que é passada adiante. Então todas as informações são assim estudadas. É até impressionante como que eles estudam”.
}

\section{DISCUSSÃO}

Os hospitais podem ser considerados unidades produtoras das informações do SIM e SINASC e, por esta razão, as entrevistas ocorreram nesse lócus. A metodologia DSC pode contribuir para uma melhor compreensão da forma como esses dados são produzidos nos hospitais. O DSC permite captar a visão dos profissionais responsáveis pela coleta dos dados e qual é a sua percepção sobre as informações registradas nos documentos. 
LEFEVRE (2003) considera que o DCS é um produto da coletividade, pois mesmo que composto de um só depoimento, este faz parte de uma coletividade. $\mathrm{O}$ depoimento individual expressa o pensamento coletivo. Por meio da soma e categorização das respostas desses depoimentos torna-se possível atribuir sentido a cada resposta das questões abertas em grupos de categorias (cada categoria se torna a soma das respostas/depoimentos). Esse processo implica na dimensão quantitativa do discurso proveniente da dimensão qualitativa. Cada DSC reúne sob uma mesma categoria conteúdos e agrupamentos que compõem uma opinião compartilhada por um conjunto de pessoas.

A coleta de dados e a operação dos sistemas de informação SIM e SINASC são de responsabilidade das secretarias municipais de saúde. Há uma diferença no fluxo da DO e DN no município de São Paulo. As DOs são levadas pelos familiares ao Serviço Funerário Municipal, que posteriormente encaminha uma cópia ao Cartório de Registro Civil e outra cópia ao Programa de Aprimoramento das Informações de Mortalidade no Município de São Paulo (PROAIM/SMS/SP).

AS DNs são preenchidas e digitadas pelos hospitais onde ocorreu o nascimento e o banco de dados é enviado a SMS/SP. Desse modo, o hospital não preenche apenas o documento básico do SINASC, como também é uma unidade de alimentação do sistema. São essas diferenças que irão refletir nas representações dos diferentes profissionais que atuam nos hospitais e na qualidade da informação.

Vários estudos têm mostrado que a completitude das variáveis das DNs é elevada. ALMEIDA et al. (2006a), mostraram que a ausência de registro de informações no SINASC é inferior a 5\%, para a maioria das variáveis no MSP, COSTA e FRIAS (2009) também encontraram resultados semelhantes em estudo realizado em Pernambuco. Alguns estudos mostram existir problemas quanto à validade de algumas informações registradas nas DNs (ALMEIDA et al., 2006a; ROMERO e CUNHA et al., 2006). Enquanto que vários estudos têm mostrado que completitude das informações registradas nas declarações de óbitos perinatais é bem menor (ALMEIDA et al., 2006b). 
Tanto nos hospitais SUS como não-SUS não se verificou um padrão relativo ao profissional responsável pelo preenchimento das DNs, confirmando os resultados encontrados por MISHIMA et al. (1999). Observou-se que os enfermeiros e o pessoal administrativo dos hospitais preenchem a DN. Em alguns hospitais o profissional administrativo é responsável pelo preenchimento dos dados cadastrais e as enfermeiras pelas demais informações e em outros hospitais são responsáveis pelo preenchimento de toda DN.

Nos hospitais SUS houve a menção de que o preenchimento das DNs era de responsabilidade do SAME, mas essa responsabilidade foi passada às enfermeiras para que o preenchimento ocorresse na sala de parto. Essa transferência de responsabilidade ocorreu, pois normalmente os enfermeiros auxiliam o médico no preenchimento de toda documentação após o parto no hospital.

Com relação à DN os discursos sobre as dificuldades encontradas no seu preenchimento indicam a existência de semelhanças e diferenças entre as categorias profissionais e tipologia de hospitais (SUS e não-SUS). Os profissionais de hospitais SUS mencionaram mais dificuldades do que os profissionais de hospitais não-SUS. É Importante ressaltar que por meio da técnica de pesquisa qualitativa, essas dificuldades expressam particularidades em nível de formação e no tipo de ambiente de trabalho particular a cada sujeito que participou da pesquisa.

Em hospitais SUS foram relatadas dificuldades na obtenção de algumas variáveis como o número de consultas de pré-natal, números de filhos vivos e mortos, pois muitas vezes estas não estavam registradas nos prontuários e indicam a falta de integração entre atenção pré-natal e o parto. Há críticas quanto à qualidade da informação sobre paridade no SINASC (MISHIMA et al., 1999; ZEITLIN et al., 2003). No entanto, ROMERO e CUNHA (2006), mostraram que o nível de parturição das mulheres obtido com os dados do SINASC, era comparável aos resultados obtidos pelo Censo Demográfico de 2000, para o estado de São Paulo e outras unidades da federação. 
Foram relatadas também dificuldades para a obtenção da variável estado civil em hospitais SUS e não-SUS. Os discursos indicam que as mães tem dificuldade de diferenciar união consensual e união legal. Estudo realizado por ALMEIDA et al. (2006a) verificou que as informações do SINASC superestimam a presença de mães sem companheiro, possivelmente porque os registros se referem ao estado civil, às mulheres que possuem companheiro sem união legal provavelmente são registradas como solteiras.

Também foram descritas dificuldades em relação ao endereço da mãe. Em um hospital não-SUS a maior dificuldade era o CEP, mas o profissional conseguia contornar esse problema, pois esses dados sempre constavam e eram bem preenchidos no prontuário. Enquanto que nos hospitais SUS muitas vezes os endereços fornecidos no momento da internação não eram os mesmos quando confirmados pelas mães. Esse fato mostra a importância do registro de qualidade e checagem dos dados no momento do cadastro do paciente, como apontado por ARTS et al. (2002) .

Entre as dificuldades relativas à variável presença de malformações congênitas houve a menção de ausência de registro dos médicos nos prontuários, dificuldades de entendimento do registro quando este está presente e a própria dificuldade de identificar a presença de malformações. GUERRA et al. (2008), indicam que o profissional do setor administrativo responsável por essas informações nem sempre tem familiaridade com os termos médicos registrados no prontuário. GEREMIAS et al. (2009) e GUERRA et al. (2008), indicaram que as DNs subestimam a presença de malformações congênitas, ocorrendo principalmente o registro das malformações aparentes no momento do nascimento.

Apesar de orientações contidas nos treinamentos sobre a DN indicarem que a raça/cor deve ser auto referida pela mãe, verificou-se que ainda persistem duvidas 
sobre esta variável. Com objetivo de aprimorar esta informação a nova versão da DN substituiu esse quesito pela raça/cor da mãe ${ }^{5}$.

Observou-se também que o pessoal do setor administrativo realiza a digitação e checagem de dados em vários hospitais, na medida em que possuem maior facilidade para checagem das informações de identificação dos pacientes. Entretanto, tem maior dificuldade na checagem das informações relativas às características maternas ou dados clínicos, como por exemplo, as malformações congênitas.

Por meio dos discursos do presente estudo, pode ser observado que os treinamentos fornecidos pelo SINASC são fundamentais no dia a dia dos profissionais que preenchem as DNs, tanto para esclarecimento de dúvidas quanto para que conheçam a importância das informações que produzem. Além dos constantes treinamentos, a SMS/SP criou em 2010 o Selo SINASC que fornece um certificado de qualidade baseado em critérios como: cobertura de eventos, pontualidade da digitação dos dados, completitude das informações e controle do uso dos formulários ${ }^{6}$. Além disso, em 2011 foi criado um portal eletrônico para solução de dúvidas quanto ao preenchimento das DNs divulgação de informações do sistema e resultado anuais do selo SINASC ${ }^{7}$. Referidas medidas de incentivo e interação com as instâncias produtoras da informação resultam no aprimoramento do sistema. O envolvimento e comprometimento dos profissionais com o sistema asseguram informações mais fidedignas, conforme afirma ARTS et al. (2002).

Apesar da definição legal de que o médico é o responsável pelas informações da $\mathrm{DO}^{8}$, muitas vezes os profissionais de setores administrativos preenchem as informações de identificação individual, as variáveis sobre características maternas e o histórico da gestação. Como esta responsabilidade não é

\footnotetext{
${ }^{5}$ Brasil. Ministério da Saúde. Secretaria de Vigilância em Saúde. Manual de Instruções para o preenchimento da Declaração de Nascido Vivo. Brasília: MS/SVS: 2009.

${ }^{6}$ Secretaria Municipal da Saúde de São Paulo. Manual Selo SINASC, 2010

${ }^{7}$ Secretaria Municipal da Saúde de São Paulo. (http://www.sinasc.saude.prefeitura.sp.gov.br/)

${ }^{8}$ Conselho Federal de Medicina RESOLUÇÃO no 1.779 , de 11 de novembro de 2005.
} 
oficialmente atribuída a estes profissionais, eles não recebem treinamento específico para esclarecimento de dúvidas e orientações a respeito da DO.

As entrevistas revelaram que os profissionais conhecem e reconhecem a utilidade das informações registradas nas DNs, com base nos treinamentos fornecidos pela equipe do SINASC. Enquanto imaginam que as informações de óbito têm a mesma finalidade, mas não têm certeza e muita clareza da utilização dos dados. Essa constatação indica a importância dos treinamentos e cursos de capacitação e o maior comprometimento do preenchimento da informação quando o profissional conhece a importância dos dados que fornece.

\section{CONCLUSÃO}

A participação efetiva dos hospitais na operação do SINASC na coleta, digitação e verificação das informações, bem como os constantes treinamentos se refletem na percepção e na qualidade dos dados. A responsabilidade dos hospitais no SIM é o preenchimento da DO; outros profissionais que preenchem parte desses documentos não são os responsáveis legais (médicos), o que pode levar à não percepção de se constituir em parte do sistema.

Os profissionais e enfermeiros se reconhecem como parte integrante do processo de produção da informação. Os discursos indicam que a atividade está incorporada na rotina do trabalho; há comprometimento na busca de soluções, quando se deparam com dificuldades de preenchimento; há valorização de se sentirem acompanhados por uma instância superior do sistema e sentem que o treinamento é um espaço de encontro para retorno e compreensão das finalidades e usos das informações que produzem. A participação dos profissionais de enfermagem se mostrou fundamental para boa qualidade dos registros das 
informações. Cabe ainda ressaltar a importância do treinamento para preenchimento das DNs e o treinamento que não recebem para preenchimento das DOs, pois estas são de responsabilidade legal dos médicos e o treinamento é voltado à eles. Essa consciência aumenta o comprometimento e assegura informações mais fidedignas. 


\section{REFERÊNCIAS}

Almeida MF; Alencar GP; França Junior I, Novaes HMD, Siqueira AAF, Schoeps D, Rodrigues LC, Campbell O. Validade das informações das declarações de nascidos vivos com base em estudo de caso-controle. Cadernos de Saúde Pública. 2006;22(3):643-652.

Almeida MF, Alencar GP, Novaes HMD, Ortiz LP. Sistemas de informação e mortalidade perinatal: conceitos e condições de uso em estudos epidemiológicos. Rev. bras. epidemiol.2006;9(1):56-68.

Almeida MF, Alencar GP, Schoeps D, Minuci EG, Silva ZP, Ortiz LP, Novaes $\mathrm{MDH}$, Alencar AP, Raspantini PR, Santos PC. Qualidade das informações registradas nas declarações de óbito fetal em São Paulo, SP. Rev. SaúdePública. 2011;4(5):845-853.

Arts DG, De Keizer NF, SchefferGJ.Defining and improving data quality in medical registries: a literature review, case study, and generic framework. J Am Med Inform Assoc. 2002;9(6):600-11.

Buitendijk S, Zeitlin J, Cuttini M, Langhoff-Roos J, Bottu J. Indicators of fetal infant health outcomes. European Journal of Obstetrics and Gynecology and Reproductive Biology.2003;111:S66-S77.

Costa JMBS, Frias PG. Avaliação da completitude das variáveis da Declaração de Nascido Vivo de residentes em Pernambuco, Brasil, 1996 a 2005. Cad. Saúde Pública. 2009;25(3):613-624.

Geremias AL, Almeida MF, Flores LPO. Avaliação das declarações de nascido vivo como fonte de informação sobre defeitos congênitos. Rev. bras. epidemiol.2009;12(1):60-68.

Guerra FAR, Lerena JC, Gama SGN, Cunha CB, Theme MMF. Confiabilidade das informações das declarações de nascido vivo com registro de defeitos congênitos no Município do Rio de Janeiro,Brasil, 2004. Cad. SaúdePública. 2008; 24(2):438-446.

Jodelet D, organizadora. As representações Sociais. Rio de Janeiro: EdUERJ. 2001. 420p.

Kirby $R S$. The quality of data reported on birth certificates. Am J Public Health. 1997Feb;87(2):a301-301.

Lefevre, F; Lefevre, A.M.C. O discurso do sujeito coletivo: um novo enfoque em pesquisa (desdobramentos). Caxias do Sul: EDUCS; 2003. 
Lefevre F, Lefevre AMC. O sujeito coletivo que fala. São Paulo: Interface; 2006. p. 517-520.

Lima CR de A, Schramm JMA, Coeli CM, Silva MEM.Revisão das dimensões de qualidade dos dados e métodos aplicados na avaliação dos sistemas de informação em saúde. Cad. Saúde Pública. 2009;25(10):2095-2109.

Mishima F C, Scochi, CGS, Ferro MAR, LimaRAG,Costa IAR. Declaração de Nascido Vivo: Análise do seu preenchimento no Município de Ribeirão Preto, São Paulo, Brasil. Cad. Saúde Pública. 1999;15:387-395.

Niobey FML, Cascão AM, Duchiade MP, Sabroza PC. Qualidade do preenchimento de atestados de óbitos de menores de um ano na região metropolitana do Rio de Janeiro. Rev Saúde Pública. 1990;24:311-8.

Romero DE, Cunha CB. Avaliação da qualidade das variáveis socioeconômicas e demográficas dos óbitos de crianças menores de um ano registrados no Sistema de Informações sobre Mortalidade do Brasil (1996/2001). Cad. Saúde Pública. 2006;22:673-684.

Silva ZP, Almeida MF, Flores LPO, Alencar GP, Alencar AP, Schoeps D, Minuci EG, Novaes HM. Morte neonatal precoce segundo complexidade hospitalar e rede SUS e não-SUS na Região Metropolitana de São Paulo, Brasil. Cad. Saúde Pública. 2010;26(1):123-134.

Solomon DJ, Henry RC, Hogan JG, Van Amburg GH, Taylor J. Evaluation and implementation of public health registries. Public Health Rep.1991;106:141-150.

Spink MJP. O conceito de representação social na abordagem psicossocial. Cad.Saúde Pública. 1993;9(3):300-3008.

Zeitlin J, Wildman K, Bréart G, Alexander S. Selecting an indicator set for monitoring and evaluating perinatal health in Europe: criteria, methods and results from the PERISTAT project. Eur J Obstet Gynecol Reprod Biol.2003;111:S5-S14. 
Quadro 1 - Perfil dos profissionais entrevistados de acordo com tipologia do hospital, formação, cargo e setor de trabalho no hospital, Município de São Paulo, 2009

\begin{tabular}{|c|c|c|c|c|}
\hline SUS/não-SUS & Formação & Especialidade & Cargo & Setor \\
\hline \multicolumn{5}{|l|}{ Enfermeiros } \\
\hline Não-SUS & Enfermagem & UTI infantil/Saúde Pública & Enfermeira líder & UTI infantil \\
\hline Não-SUS & Enfermagem & Obstetrícia & Enfermeira obstetra & Maternidade/berçário/CO \\
\hline SUS & Enfermagem & Obstetrícia & Enfermeira obstetra & Obstetrícia \\
\hline SUS & Enfermagem & Obstetrícia & Enfermeira obstetra & Obstetrícia \\
\hline SUS & Enfermagem & Administração hospitalar & Enfermeira & Plantonista pediatria \\
\hline SUS & Enfermagem & Obstetrícia & Encarregada técnica & $\mathrm{CO}$ \\
\hline SUS & Enfermagem & - & Enfermeira & Pediatria \\
\hline SUS & Enfermagem & Auditoria & Enfermeira executiva & Alojamento conjunto/maternidade \\
\hline \multicolumn{5}{|c|}{ Outros profissionais } \\
\hline Não-SUS & Ensino médio & Curso Informática & Técnico em informática & Informática \\
\hline Não-SUS & Recursos Humanos & - & Supervisão atendimento & Atendimento - internação \\
\hline Não-SUS & Ensino médio & Técnico laboratório industrial & Escriturária & Maternidade \\
\hline Não-SUS & Ensino médio & - & Escriturária & Maternidade/berçário \\
\hline Não-SUS & Administração & - & Auxiliar administrativo & Internação \\
\hline SUS & Enfermagem & - & Agente de políticas públicas & Internação \\
\hline SUS & Ciências Contábeis & Literatura & Chefe de registro & SAME/Registro \\
\hline SUS & Ensino médio & - & Oficial administrativo & Registro geral \\
\hline SUS & Ensino médio & - & Agente de políticas públicas & Alojamento conjunto \\
\hline SUS & Ensino médio & - & Auxiliar administrativo & Internação \\
\hline SUS & Ensino médio & - & Auxiliar administrativo & Internação \\
\hline SUS & Matemática & - & Auxiliar administrativo & SAME \\
\hline SUS & Ensino médio & - & Chefe de sessão & Divisão de arquivo médico \\
\hline SUS & Ensino médio & - & Auxiliar administrativo & Maternidade \\
\hline SUS & Ensino médio & Curso Informática & Auxiliar administrativo & Obstetrícia/ginecologia \\
\hline SUS & Ensino médio & Auxiliar necropsia & Auxiliar necropsia & Necrotério \\
\hline
\end{tabular}




\section{TABELAS}

Tabela 1 - Existência de colaboração aos médicos para o preenchimento das DOs, relatada por enfermeiros e profissionais administrativos, Município de São Paulo, 2009

\begin{tabular}{lcc}
\hline Categoria & Enfermeiros & Administrativo \\
\hline Não & 2 & 2 \\
Sim & 5 & 13 \\
Não sabe & 1 & 1 \\
\hline Total & 8 & 16 \\
\hline
\end{tabular}

Tabela 2 - Dificuldades apontadas por enfermeiros e profissionais administrativos no preenchimento de DNs e DOs, Município de São Paulo, 2009

\begin{tabular}{lcccc}
\hline \multirow{2}{*}{ Categorias } & \multicolumn{2}{c}{ Enfermeiros } & \multicolumn{2}{c}{ Administrativo } \\
\cline { 2 - 5 } & SUS & Não-SUS & SUS & Não-SUS \\
\hline Dificuldades em relação ao nome da mãe & - & - & 2 & 1 \\
Definição do nome da criança & - & - & 1 & - \\
Dificuldades em relação ao estado civil & 2 & - & 1 & 1 \\
Dificuldades em relação ao endereço & 1 & 1 & 3 & - \\
Dificuldades em relação a ocupação da mãe & 1 & - & - & - \\
Dificuldades em relação a escolaridade da mãe & - & - & 1 & - \\
Dificuldades em relação ao histórico materno & 2 & - & 1 & - \\
Dificuldades em relação a malformações & 2 & - & 1 & - \\
Dificuldades em relação a raça/cor do RN & 1 & 1 & & 1 \\
\hline Total & 9 & 2 & 10 & 3 \\
\hline
\end{tabular}


Tabela 3 - Aspectos sobre treinamento para preenchimento de DNs e DOs, relatados por enfermeiros e profissionais administrativos, Município de São Paulo, 2009

\begin{tabular}{lcccc}
\hline \multicolumn{1}{c}{ Categorias } & \multicolumn{2}{c}{ Enfermeiros } & \multicolumn{2}{c}{ Administrativo } \\
& SUS & Não-SUS & SUS & Não-SUS \\
\hline $\begin{array}{l}\text { Não recebeu treinamento, aprendeu com a } \\
\text { prática do dia a dia }\end{array}$ & 1 & - & - & - \\
$\begin{array}{l}\text { Recebeu instruções do supervisor ou colegas } \\
\text { de trabalho }\end{array}$ & 4 & 1 & 8 & 5 \\
$\begin{array}{l}\text { Recebeu treinamento da equipe do SINASC } \\
\text { ou órgão oficial }\end{array}$ & 1 & 1 & 5 & 1 \\
\hline Total & 6 & 2 & 13 & 6 \\
\hline
\end{tabular}

Tabela 4-Uso das informações do SIM e SINASC apontadas por enfermeiros e profissionais administrativos, Município de São Paulo, 2009

\begin{tabular}{lcccc}
\hline \multirow{2}{*}{ Categorias } & \multicolumn{2}{c}{ Enfermeiros } & \multicolumn{2}{c}{ Administrativo } \\
\cline { 2 - 5 } & SUS & Não-SUS & SUS & Não-SUS \\
\hline Para registro, uso do cartório & - & - & 4 & 1 \\
$\begin{array}{l}\text { Para uso epidemiológico e estatístico } \\
\text { Para registro, uso do cartório e para uso } \\
\text { epidemiológico e estatístico }\end{array}$ & 3 & 1 & 6 & 3 \\
\hline Total & 3 & 1 & 1 & 1 \\
\hline & 6 & 2 & 11 & 5 \\
\hline
\end{tabular}


ANEXOS 


\section{Anexo I}

I Modelo da Declaração de Óbito.

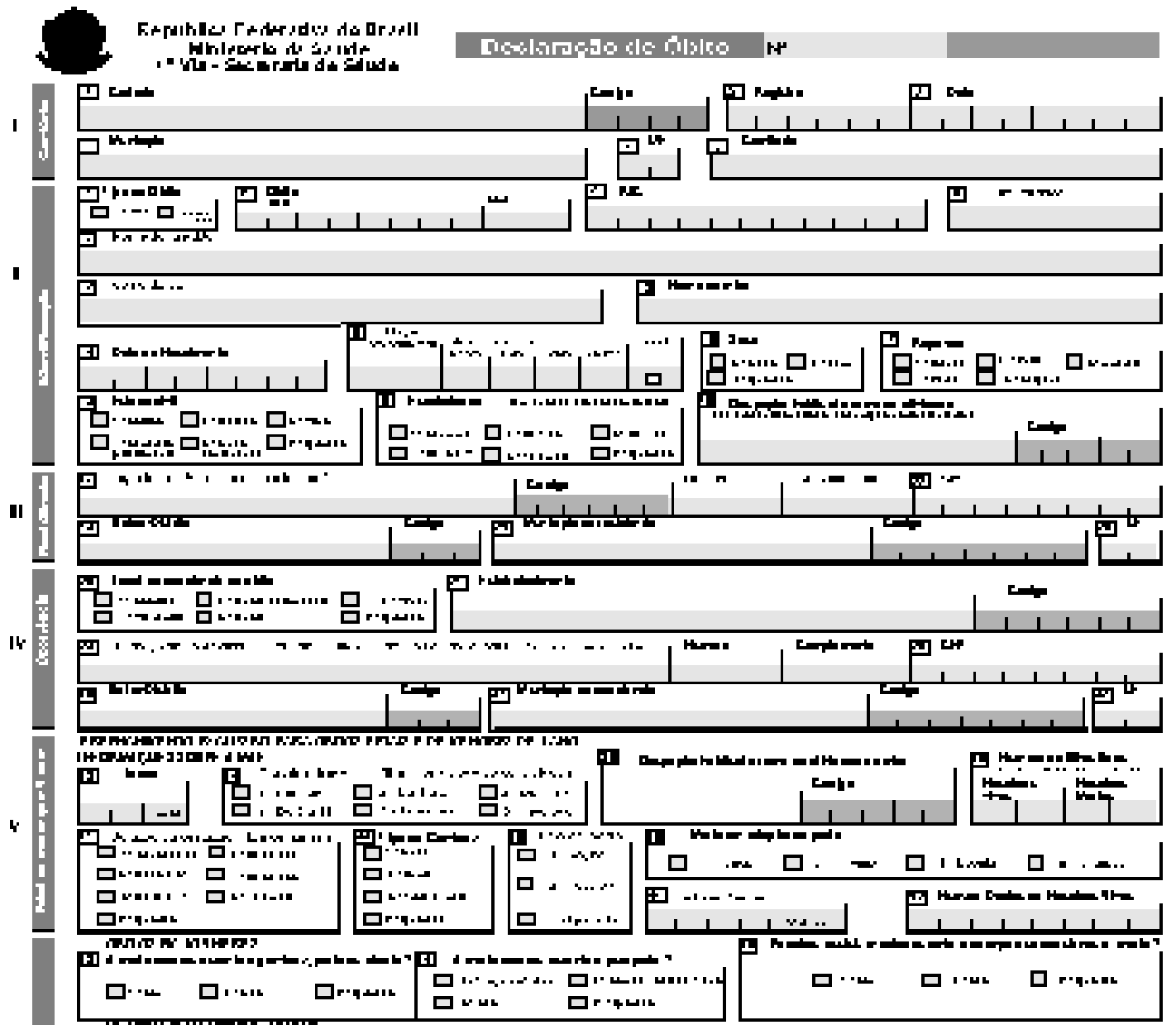

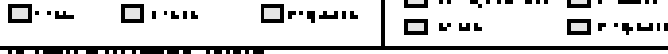

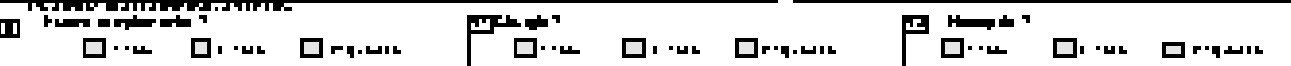

4 1,

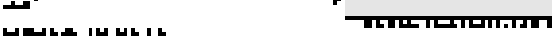

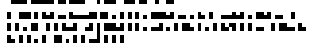

r.min:

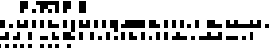

1)

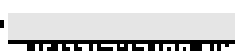

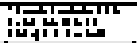

1

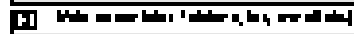

: لـ

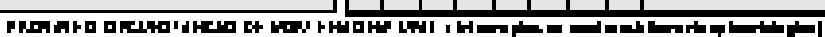

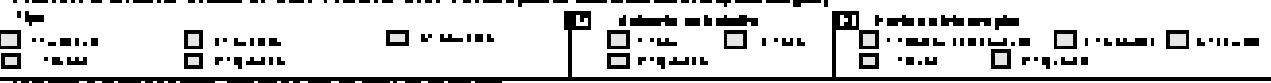
年 


\section{Anexo II}

II Modelo da Declaração de Nascido Vivo

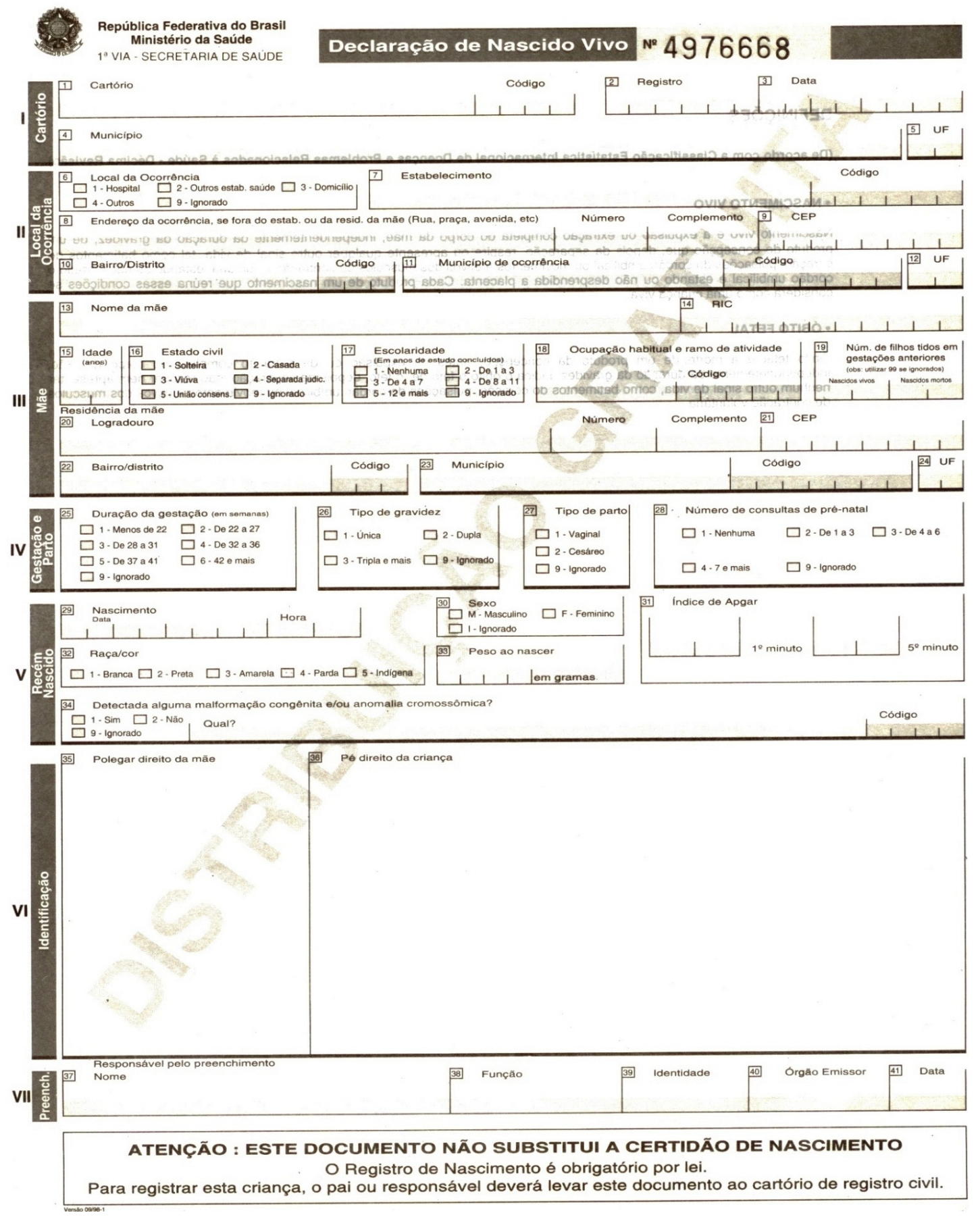




\section{Anexo III}

III Quadros de identificação para as fontes de preenchimento das DOs e DNs

Quadro de entrevista para identificação das fontes utilizadas para preenchimento de DO-perinatais.

\begin{tabular}{|c|c|c|c|c|c|c|c|c|c|c|c|}
\hline \multirow[b]{2}{*}{ Variáveis } & \multicolumn{4}{|c|}{ Quem preenche } & \multicolumn{3}{|c|}{ Local coleta } & \multicolumn{3}{|c|}{ Fonte } & \multirow[b]{2}{*}{ Outro } \\
\hline & $\begin{array}{l}\text { Adminis- } \\
\text { trativo }\end{array}$ & Enfermeira & Médico & $\begin{array}{c}\text { Outro } \\
\text { (especificar) }\end{array}$ & $\begin{array}{l}\text { Cadastro de } \\
\text { admissão }\end{array}$ & $\begin{array}{c}\text { Setor de } \\
\text { perinatologia } \\
\text { (berçario/uti ) }\end{array}$ & $\begin{array}{l}\text { Centro } \\
\text { obstétrico }\end{array}$ & $\begin{array}{l}\text { Outro } \\
\text { (espec) }\end{array}$ & $\begin{array}{l}\text { Prontuário } \\
\text { (papel) }\end{array}$ & $\begin{array}{c}\text { Si hosp } \\
\text { (pronteletretc) }\end{array}$ & \\
\hline \multicolumn{12}{|l|}{ Tipo de óbito } \\
\hline \multicolumn{12}{|l|}{ Data óbito } \\
\hline \multicolumn{12}{|l|}{ Data do nascimento } \\
\hline \multicolumn{12}{|l|}{ Idade } \\
\hline \multicolumn{12}{|l|}{ Sexo } \\
\hline \multicolumn{12}{|l|}{ Raça/cor } \\
\hline \multicolumn{12}{|l|}{ Número da DN } \\
\hline \multicolumn{12}{|c|}{ Informação sobre a mãe } \\
\hline \multicolumn{12}{|c|}{ Idade } \\
\hline \multicolumn{12}{|l|}{ Escolaridade } \\
\hline \multicolumn{12}{|c|}{$\begin{array}{l}\mathrm{N}^{\circ} \text { de filhos em gestações } \\
\text { anteriores }\end{array}$} \\
\hline \multicolumn{12}{|c|}{ Duração da gestação* } \\
\hline \multicolumn{12}{|l|}{ Tipo da gravidez } \\
\hline \multicolumn{12}{|l|}{ Tipo de parto } \\
\hline \multicolumn{12}{|c|}{ Morte em relação ao parto } \\
\hline \multicolumn{12}{|c|}{ Peso ao nascer } \\
\hline Causa da morte & & & & & & & & & & & \\
\hline
\end{tabular}

* Qual a fonte utilizada para informação sobre duração da gestação? ( ) DUM ( ) IG obstétrica ( ) IG pediátrica 
Quadro de entrevista para identificação das fontes utilizadas para preenchimento deDNs

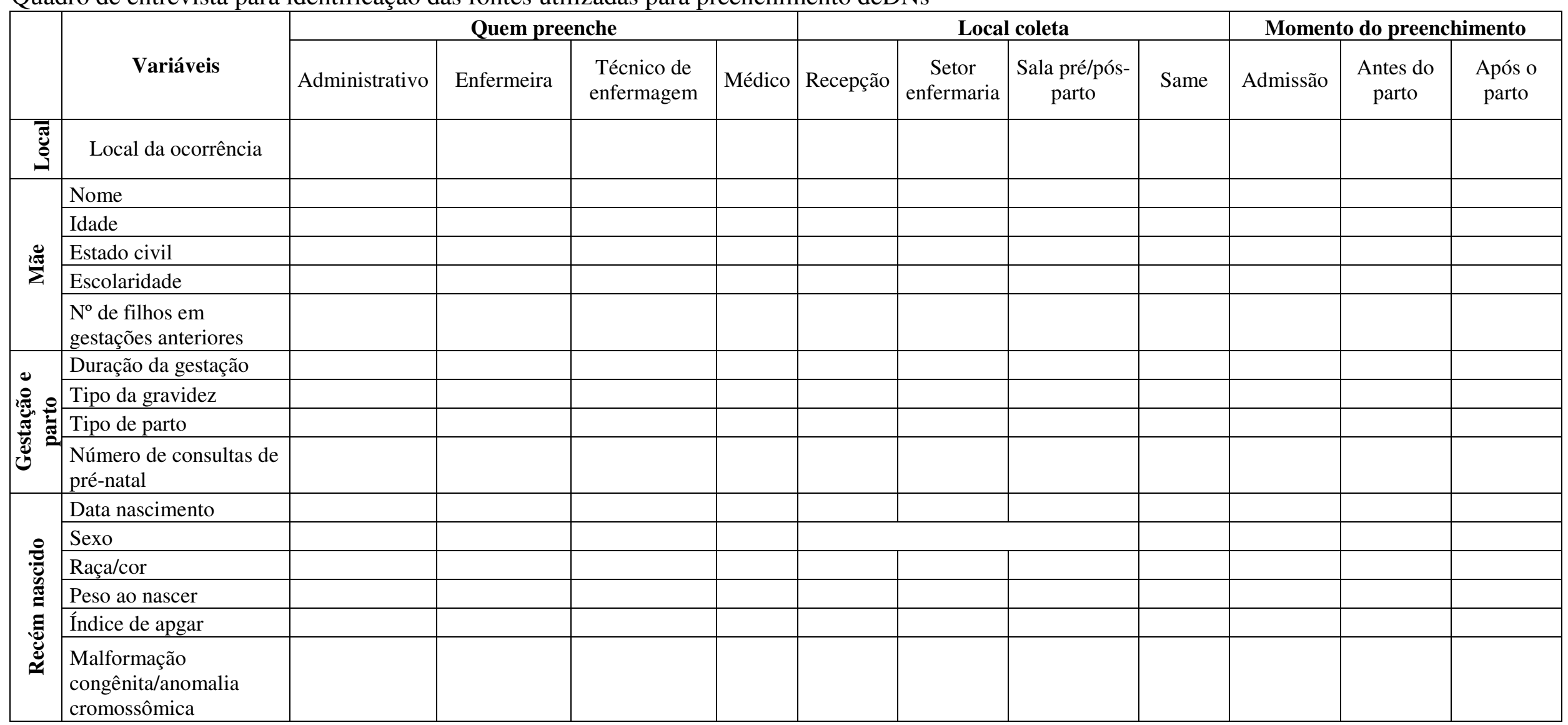

*Qual a fonte utilizada para informação sobre duração da gestação? ( ) DUM ( ) IG obstétrica ( ) IG pediátrica 
DN (continuação)

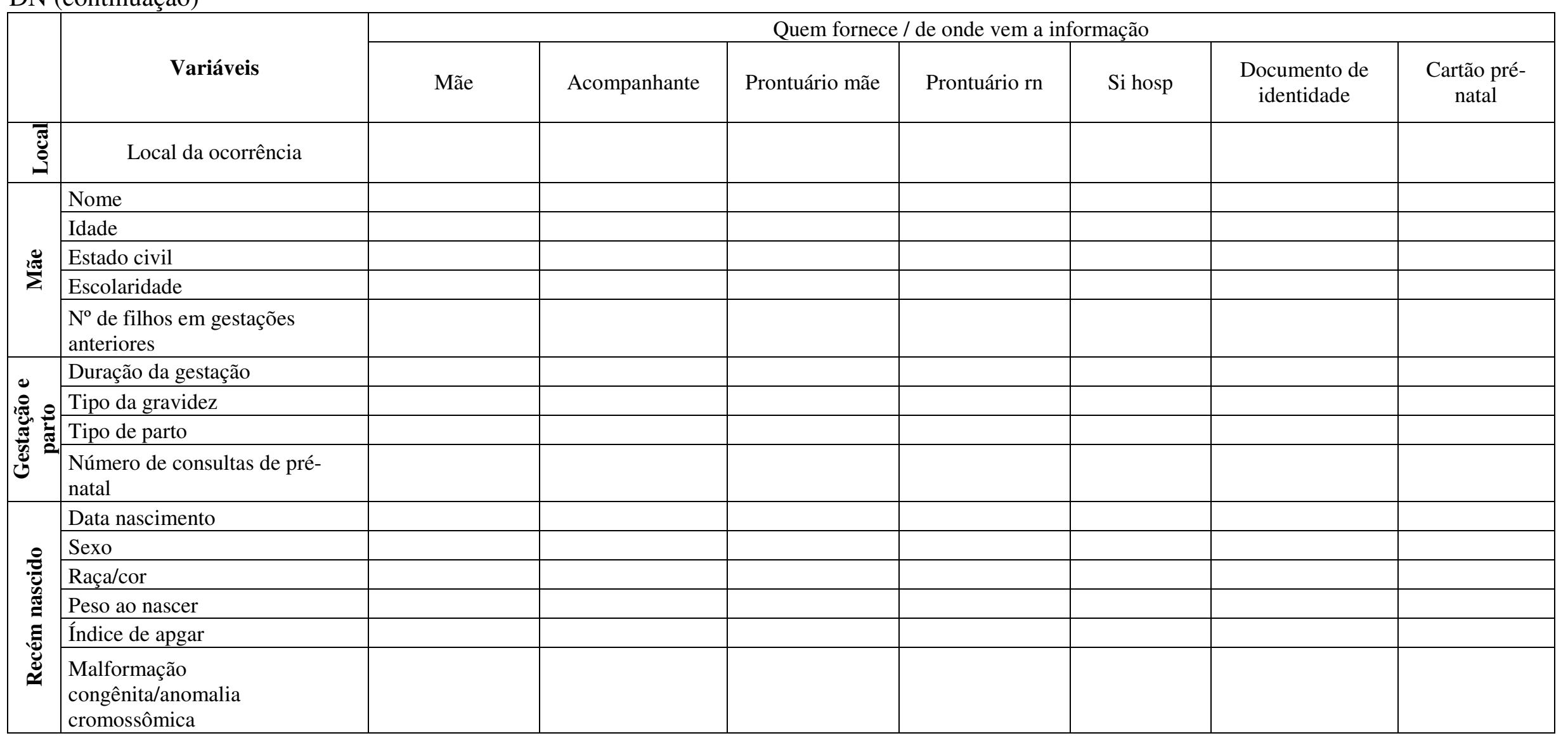




\section{Anexo IV}

IV Roteiro de entrevistas:

Pesquisa: Representação Social dos profissionais de saúde sobre SIM e SINASC

Hospital: Entrevista $n^{\mathrm{o}}$ :

Questões do perfil do profissional em saúde:

Nome:

Data nascimento: Formação acadêmica: Ano:

Especialidade:

Trabalha nesse hospital desde: Setor (atual):

Cargo: Há quanto tempo?

Trabalha em outros hospitais? Quais hospitais?

\section{Questões para serem aplicadas com médicos (as):}

1- Conte um pouco com é sua rotina de trabalho.

2 - O preenchimento das declarações de nascido vivo e de óbito faz parte desta rotina? Fale um pouco sobre isso.

3 - Existe registro eletrônico dos dados? Em caso positivo essas informações são utilizadas para o preenchimento das declarações? De que forma?

4- Você considera que existe dificuldade para preencher alguma informação? Qual (is)?

5- Você recebeu treinamento/capacitação sobre o preenchimento dos documentos (DN e DO)? Se sim, o que achou desse treinamento?

6- Você recebe ajuda para o preenchimento das DOs? Em caso positivo, para quais informações?

7- Em que situações você sente necessidade de encaminhar óbitos para o SVO? Por quê?

8- Para que servem as informações das declarações de nascido vivo e de óbito que você preenche? Como assim? 
Pesquisa: Representação Social dos profissionais de saúde sobre SIM e SINASC

Hospital: Entrevista $n^{\circ}$ :

Questões do perfil do profissional em saúde:

Nome:

Data nascimento: 1

Formação acadêmica: Ano:

Especialidade:

Trabalha nesse hospital desde: Setor (atual):

Cargo: Há quanto tempo?

Trabalha em outros hospitais? Quais hospitais?

\section{Questões para serem aplicadas com os enfermeiros (as):}

1- Conte um pouco com é sua rotina de trabalho.

2 - O preenchimento das declarações de nascido vivo?

3 - E o preenchimento das declarações de óbito (fetal ou neonatal)? Fale um pouco sobre isso.

4 - Existe registro eletrônico dos dados? Em caso positivo essas informações são utilizadas para o preenchimento das declarações? De que forma?

5- Você considera que existe dificuldade para preencher alguma informação? Qual (is)?

6- Você recebeu treinamento/capacitação sobre o preenchimento dos documentos (DN e DO)? Se sim, o que achou desse treinamento?

7- O médico recebe auxílio para o preenchimento da DO? Quem auxilia?

8- Na sua opinião, em que situações os óbitos são encaminhados para o SVO? Por quê?

9- Para que servem as informações das declarações de nascido vivo e de óbito que você preenche? Como assim?

\section{Para enfermeira da obstetrícia}

10 - No caso de óbito fetal, quando é preenchida a declaração de óbito? Porquê?

11- Quem preenche a declaração de óbito quando há morte do recém nascido ainda na sala de parto? 
Pesquisa: Representação Social dos profissionais de saúde sobre SIM e SINASC

Hospital: Entrevista $n^{\circ}$ :

Questões do perfil do profissional em saúde:

Nome:

Data nascimento: Formação acadêmica: Ano:

Especialidade:

Trabalha nesse hospital desde: Setor (atual):

Cargo: Há quanto tempo?

Trabalha em outros hospitais? Quais hospitais?

\section{Questões para serem aplicadas com outros profissionais de saúde:}

1- Conte um pouco com é sua rotina de trabalho.

2 - O preenchimento das declarações de nascido vivo?

3 - E o preenchimento das declarações de óbito (fetal ou neonatal)? Fale um pouco sobre isso.

4 - Existe registro eletrônico dos dados? Em caso positivo essas informações são utilizadas para o preenchimento das declarações? De que forma?

5- Você considera que existe dificuldade para preencher alguma informação? Qual (is)?

6- Você recebeu treinamento/capacitação sobre o preenchimento dos documentos (DN e DO)? Se sim, o que achou desse treinamento?

7- O médico recebe auxílio para o preenchimento da DO? Quem auxilia?

8- Em que situações você é solicitado para preencher a DN? Para preencher quais informações?

9 - E para preencher a DO fetal ou neonatal precoce? Para quais informações?

10- Na sua opinião, em que situações os óbitos são encaminhados para o SVO? Por quê?

11 - Para que servem as informações das declarações de nascido vivo e de óbito que você preenche? Como assim? 


\section{CURRÍCULO LATTES}

\section{ORIENTADOR}

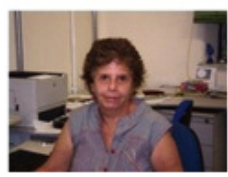

Marcia Furquim de Almeida

Bolsista de Produtividade em Pesquisa do CNPq - Nivel 2

Possui graduaçãa em Farmácia e Bioquímica pela Universidade de São Paulo (1973), mestrado em International Nutrition - Cornell University (1979) e doutorado em Saúde Pública pela Universidade de São Paulo (1995). Atualmente é editora cientifica da Revista Brasileira de Epidemiologia e livre docente da Universidade de São Paulo. Tem experiência na área de Saúde Coletiva, com ênfase em Epidemiologia, atuando principalmente nos seguintes temas: epidemiologia, mortalidade neonatal, fecundidade, peso ao nascer e sistemas de informacao. (Texto informado pelo autor)

Última atualização do currículo em 31/01/2012

Endereço para acessar este CV:

Certificado

http://lattes.cnpq.br/5249772042930769

Dados pessoais

Nome Marcia Furquim de Almeida

Nome em citações ALMEIDA, M. F.;Silva, Zilda Pereira da;Assunção, Paula Lisiane de;Almeida, Marcia Furquim de bibliográficas

Sexo Feminino

Endereço profissional Universidade de São Paulo, Faculdade de Saúde Pública, Departamento de Epidemiologia Av. Dr. Arnaldo, 715

Cerqueira Cesar

01246-904 - Sao Paulo, SP - Brasil

Telefone: (11) 30823886 Fax: (11) 30822920 


\section{CURRÍCULO LATTES}

\section{AUTOR}

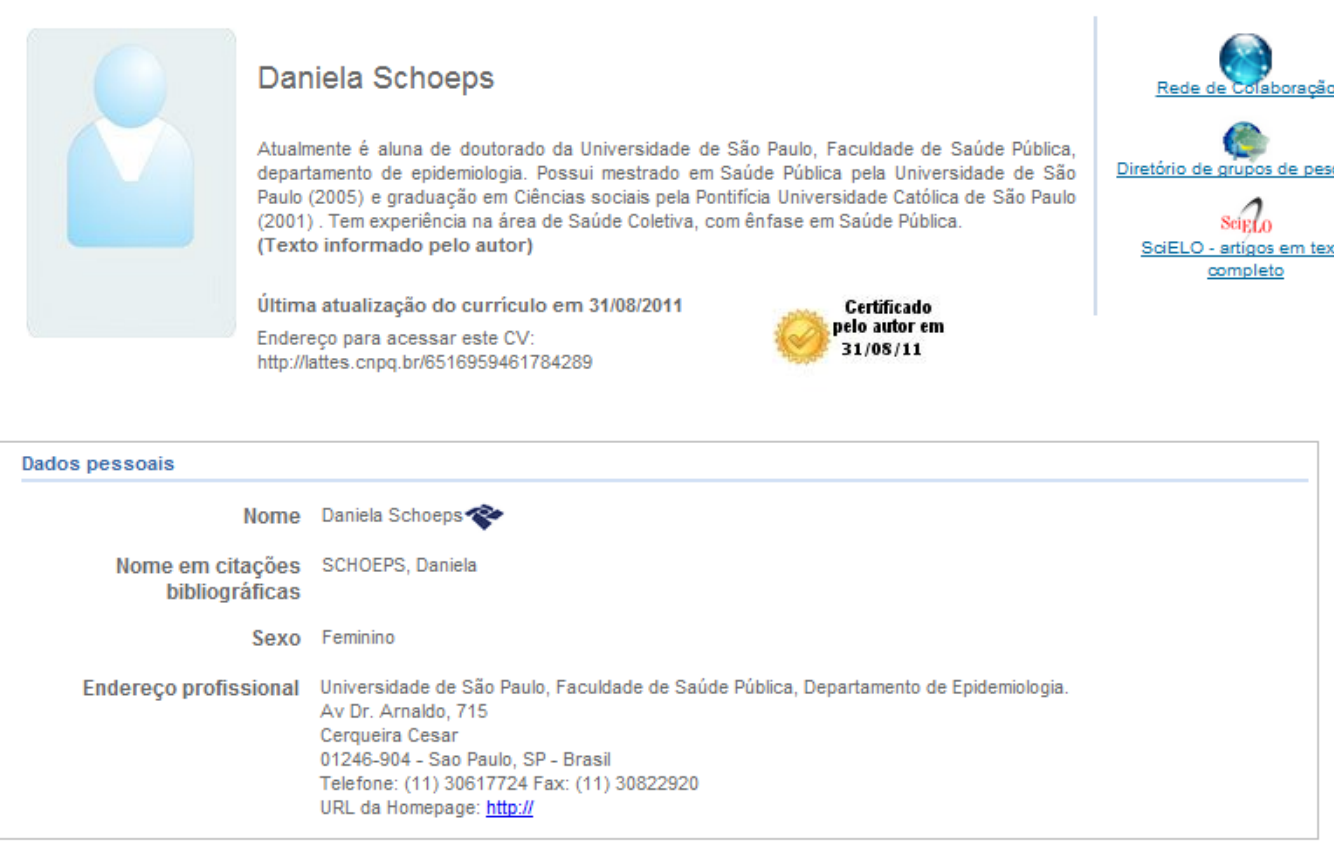

